\title{
Futurismo Now: A Conceptual Menswear Fashion Collection Exploring Masculinity through Futurist Aesthetics \\ An Exhibition of Conceptual Fashion Collection
}

by

Yeonseok Jang,

BFA in fashion design, Columbus College of Art and Design, OH, Aug 2009

\author{
MRP \\ presented to Ryerson University \\ in partial fulfillment of the \\ requirements for the degree of \\ Master in Arts \\ in the Program of \\ Fashion
}

KHS251, April 24, 2014

Toronto, Ontario, Canada, 2014

CYeonseok Jang 2014 


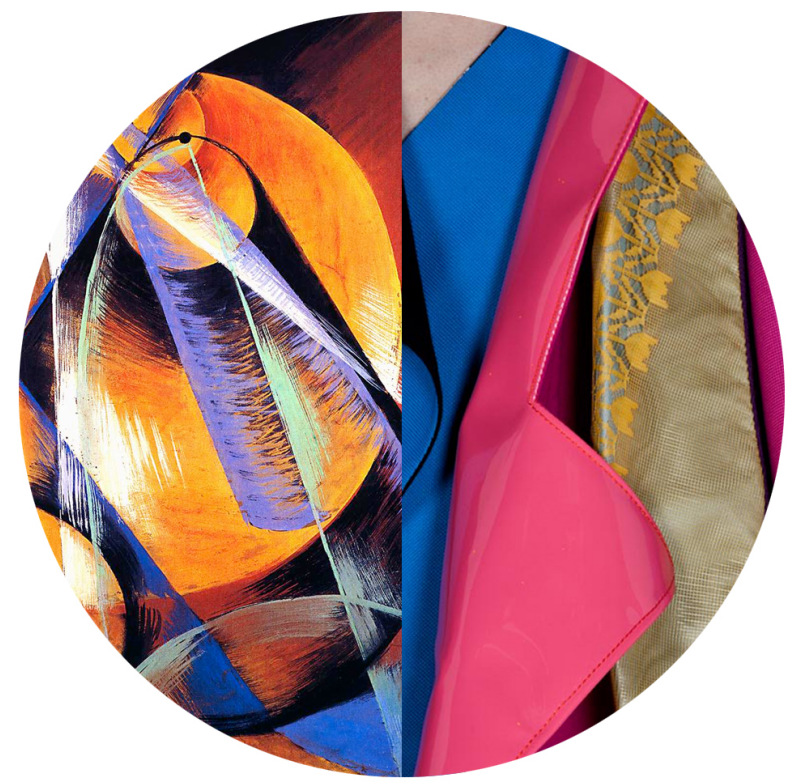

Mercuty Passing in front of the Sun, Giacomo Balla, 1914 (Hulten 98)

Futurism Now, Yeon Jang, 2014

.

\section{Acknowledgements}

I would like to express my gratitude to my supervisor Professor Henry Navarro for his useful comments, remarks and engagement throughout the learning process of this master's thesis. I would like to also thank my second reader, Joseph Medaglia, for his brilliant comments and suggestions for a topic, and for his support along the way. Finally, I want to thank my family, who has supported me throughout this entire process. 


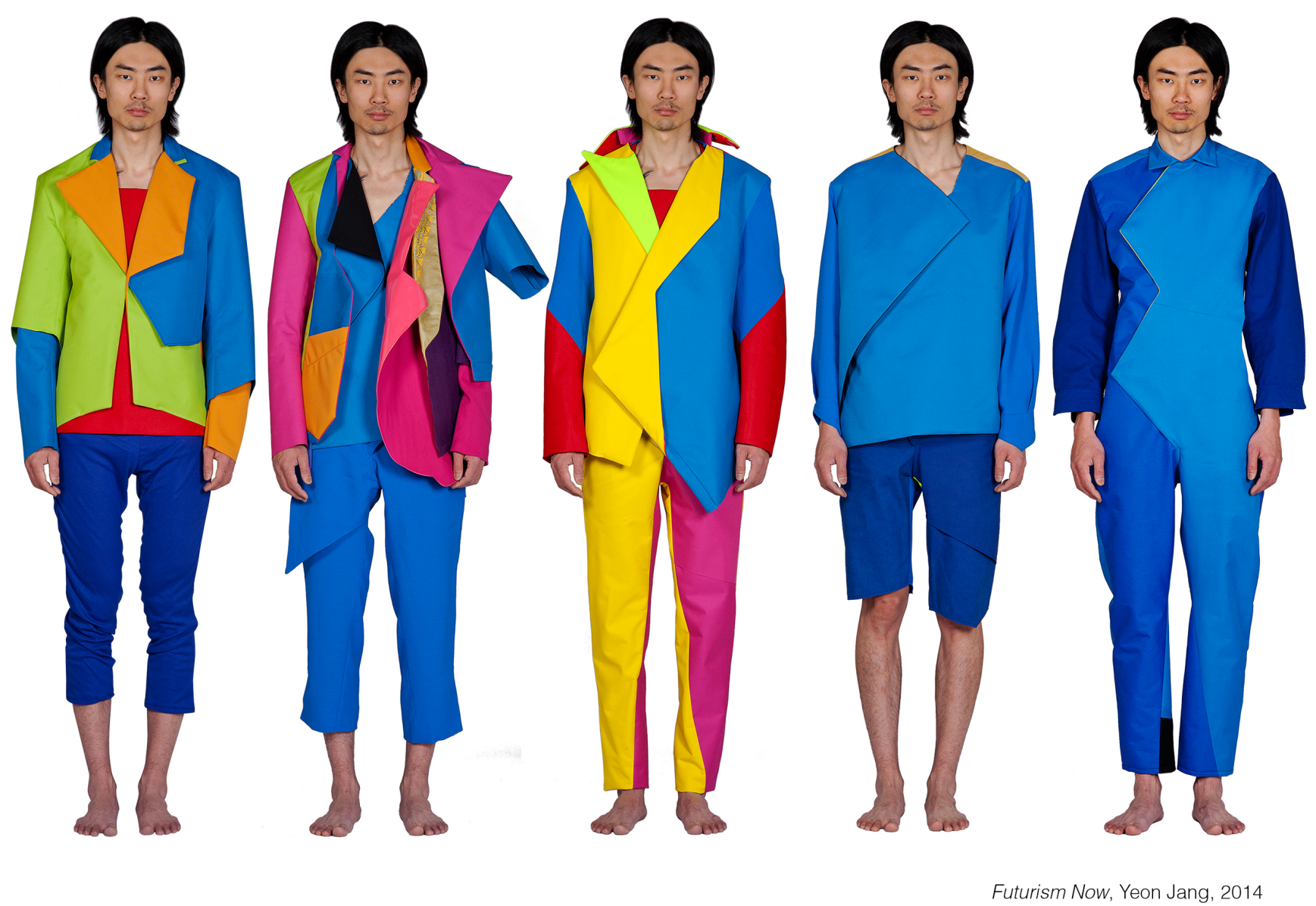


$\begin{array}{ll}\text { Abstract } & 5\end{array}$

$\begin{array}{ll}\text { Introduction } & 6\end{array}$

$\begin{array}{ll}\text { Literature review } & 10\end{array}$

$\begin{array}{lc}\text { Futurist art and artists } & 10\end{array}$

Futurism and Fashion, $\quad 11$

Gender and masculinity 13

$\begin{array}{lr}\text { Hegemonic masculinity } & 14\end{array}$

$\begin{array}{ll}\text { Menswear } & 15\end{array}$

$\begin{array}{ll}\text { Methodology and Framework } & 17\end{array}$

Hegemonic masculinity and Futurism $\quad 20$

Collection Development 22

$\begin{array}{ll}\text { Sketching } & 22\end{array}$

$\begin{array}{ll}\text { Patternmaking } & 26\end{array}$

$\begin{array}{ll}\text { Fabric and Colour Selection } & 29\end{array}$

Research Outcomes

$\begin{array}{ll}\text { Fashions from Futurists } & 37\end{array}$

$\begin{array}{ll}\text { Conclusion } & 39\end{array}$

$\begin{array}{ll}\text { Bibliography } & 41\end{array}$

Table Appendixes $\quad 44$ 


\begin{abstract}
The Futurism Art movement and its manifestoes had a crucial impact on European literature, art, and fashion. This practice-based research project is an exploration of hegemonic masculinity (Connell, Donaldson...) through the lens of the Italian Futurism movement. My goal was to produce a conceptual menswear collection using Giacomo Balla's “The Futurist Manifesto of Men's Clothing” as the main design framework. This research dissects aspects of hegemonic masculinity and compares them with masculine tendencies that characterized the work of the Futurism movement. Through this study I meant to investigate if, by applying design elements and themes promoted by futurist artists, my menswear designs could reflect contemporary masculinities.
\end{abstract}




\section{Introduction}

Futurism was an artistic and social movement initiated in Italy by Filippo Tommaso Marinetti and his Futurist Manifesto in 1909. Futurists were "intoxicated with speed, violence, noise, all the transient impressions and new sensations of life in the modern city; they [...] loathed the cult of the past" (Rye 5). Futurist artists tried to formulate styles of painting, sculpture, music and poetry that would shock and provoke the public. Futurism became a standard of avant-garde art because of five major futurist artists and their iconic paintings in 1910 to 1914 . They were Giacomo Balla's Speeding Car which included between fifteen and twenty paintings in a series (Fig.1), Umberto Boccioni's The City Rises (Fig.2), Luigi Russolo's Revolt (Fig.3), Carlo Carra's Funeral of Anarchist Galli (Fig.4), and Gino Severini's Dynamic Hieroglyphic of the Bal Tabarin (Fig.5). These five different paintings showed the united ambition of futurists and that futurists were organized like other social groups such as a commercial guilds, and political and military services (Hulten 20). Balla's series of speeding cars, was one of the most impressive futurist works, inspired by the cars passing at high speed. He developed the paintings through a complex interrelationship between the spinning of the wheels, the movement of car and the sound of the engine. This series also represents very well how the paintings became abstracted images; the last series of paintings (Fig.1-2) barely represents moving cars even though it still expresses movement as compared with the earliest paintings (Fig.1-1). In turn, Futurism influenced other $20^{\text {th }}$ century art movements including Constructivism, Surrealism and Dadaism (Salvatore). Some influences of Futurism in modern art can be seen in action painting, pop art, minimal art, Bauhaus style 
industrial design and architecture, cartoons, the sexual revolution, the computer revolution and through the use of plastic or synthetic fibers in fashion (Salvatore).

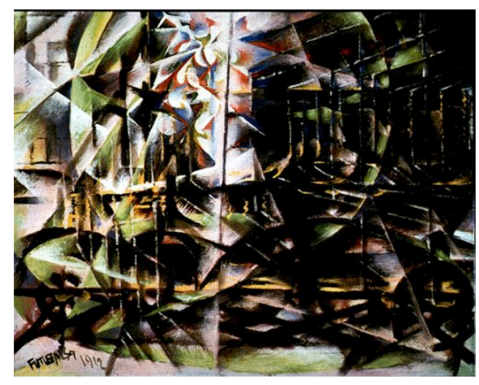

Fig.1 Speeding Car, 1912 (Earilest) (Hulten 75)

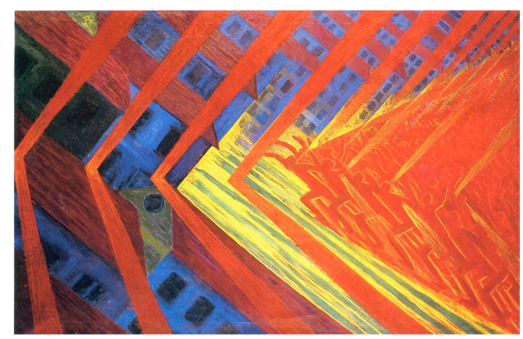

Fig.3 Revolt, Luigi Russolo, 1911 (Hulten 206)

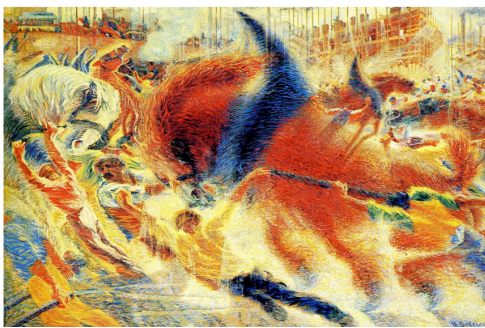

Fig.2 The City Rises, Umberto Boccioni, 1910-11(Hulten 119)

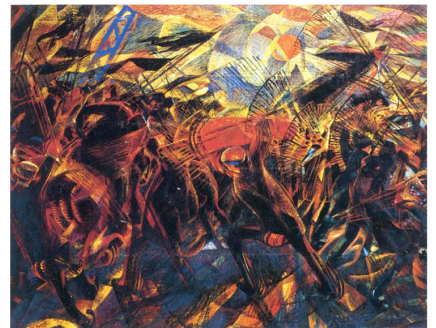

Fig.4 Funeral of the Anarchist Galli, Carlo Carra, 1911(Hulten 153)

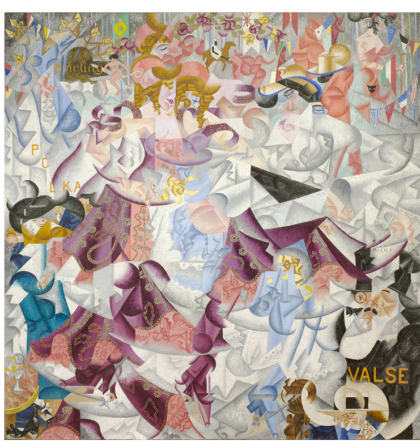

Fig.5 Dynamic Hieroglyphic of the Bal Tabarin, Gino Severini, 1912

The purpose of this research project was to create a conceptual collection of

menswear based on an exploration of masculinity through the lens of the Italian Futurism art movement. Research on the relationship between hegemonic masculinity concepts and the Futurism Manifesto supports the creative design process of this menswear collection. I chose to explore hegemonic masculinity through Futurism because of the strong connections between this concept of masculinity and the aesthetic and conceptual platform of the Futurism art movement. For example, "the signs of faltering confidence in the organic realization of somatic desire" (Poggi 20) are at work in both Futurist imagery and description of the male body. 
The Futurist movement in art processes masculine tendencies deriving from patriarchy. Those tendencies are expressed by the artists' political affiliations to friendly forces of fascism, aspects of glorifying war, the reaction of Futurists to technological development, and the embrace of speed and dynamic movement in futurist artworks (Hulten 17). These instances are widely acknowledged as powerful motifs within the concept of hegemonic masculinity. There are negative aspects associated with the modern Futurism art movement, such as futurists' promotion of fascism, war, and an aggressive chauvinism. However, these values can be better understood by contextualizing the futurist artists' desire for industrialization. Italian futurists believed that Mussolini's reign would help Italy's industrial growth (Jensen). I suggest that these attributes, which have been historically perceived as negative, can be re-evaluated positively by exploring them through a hegemonic masculinity framework. In hegemonic masculinity theory, men are characterized by generally agreed upon attributes such as strength, protectiveness, decisiveness and courage, as well as by more contested qualities such as individualism, competitiveness, rationality and practicality (Donaldson).

Masculinity can be interpreted in numerous ways but I chose to represent it through the creation of a series of garments equally informed by the Futurism Manifesto and the hegemonic masculinity concept. According to Pringle, hegemonic masculinity can be identified in multiple discourses: sexualities, affects, appearances, behaviours, occupations, and domination (Pringle 267). In this project, I explored hegemonic masculinity in fashion design through 'appearances' and 'occupations'. Appearances reflect masculinity in a visual way and I identified these as muscularity, strength, and 
toughness. Hegemonic masculinity can be recognized in traditional occupations such as those related to sports, the military and the construction industry. The way men dress for those occupations also reflects social conceptions of masculinity. The reason why I wanted to explore hegemonic masculinity in this research was because I wanted to examine it as a distinct and innovative concept in the study of masculinities (Cornell 832) which has the potential to be developed into a larger study of mainstream contemporary fashion.

In this research, I intended to apply the guidelines of the Futurism movement to menswear fashion design. I anticipated that the final collection would reflect masculinity in menswear through design elements and themes promoted by the futurists in their artwork and manifestoes. As I mentioned previously, masculinity can be interpreted in many different ways; therefore, characteristics that are often considered to be masculine must be critically examined. For example, the role of a garment is to reflect the wearer's personality, or occupation. Because the type of masculinity this research tries to achieve is not a traditional one, this practice-based research will try to uncover design elements that define masculinity, as seen through the lens of the Futurism movement. This research also provides insight into the ways my own design process and outcomes compare in reference to previous designs that have been based on Futurism. I suggest that my design approach, as demonstrated in my final garment collection, is innovative and has the potential to influence contemporary fashion by providing diversification in menswear and new representations of masculinity by using the principles of Futurism. 


\section{Literature review}

There were four main research areas that I needed to consult in order to create a conceptual fashion collection of menswear based on the exploration of masculinity through Futurism: Futurist art and artists, Futurism and fashion, gender and masculinity, and menswear.

\section{$\underline{\text { Futurist art and artists }}$}

Richard Jensen's "Futurism and Fascism." Jensen outlines the historical background of Futurism and its main principles, here. The book reflects on the Futurism movement, including the political affiliation of Futurist artists, the reasons for their glorification of war, their embrace of technological development as a subject matter, and their interest in the dynamics of speed and movement. Jensen's work also discusses the relationship between the negative aspects of Futurism (e.g. the promotion of fascism, war, and aggressive chauvinism) and early $20^{\text {th }}$ Century Italian culture. This book was useful for providing an outline of the complex relationship between Futurism and its historical context.

Mary Ann Caws's "Manifesto: A Century of Isms." Caws's book contains the manifestoes published by the Futurism movement, which were essential, as I planned to apply the manifestoes to my designs. The text provides a concrete understanding of Futurism from a visual standpoint, which helped me distinguish which artistic or aesthetic elements I could apply to my own creative process and which ones I could not, in order to keep my design work within the futurist style. 
Karl Hulten's “Futurism \& Futurisms. ” Hulten's work outlines the most influential and iconic artworks from the Futurism movement. I used the book to find direction and inspiration from Futurism by analyzing the artwork of major Futurist artists such as Giacomo Balla, Umberto Boccioni, Carlo Carra and Gino Severini. Even though some of its artists promoted fascism and were associated with fascist aesthetics, I felt that Futurism reflected valuable qualities that were visually attractive and accessible. I developed my collection from these core visual aspects of Futurism.

\section{Futurism and Fashion,}

Emily Braun's “Futurism Fashion: Three Manifestoes.” Braun discusses the relationship between Futurism and fashion through manifestoes. The author argues that the futurists' attitudes towards clothes were less about self-expression and more about provocation and performance. These preferences reveal an androcentric way of thinking, which supports the idea that, in general, Futurist artists favoured masculine aspects over feminine ones. I used Braun's analysis to apply androcentric themes and ideas to the conceptualization and design of my own menswear collection.

Eugenia Paulicelli's "Fashion and Futurism: Performing Dress." This text addresses the main concepts of fashion in Futurism. Paulicelli's discusses Futurism as a total reconstruction of the universe and its capacity for the refashioning of masculinity in dress. I found her analysis about symmetry and simplicity in Futurist fashion very useful, especially in designing male fashions. For me, these elements lent weight to my purpose 
of expressing the newness of Futurist fashion. I also utilized her ideas in designing my collection.

Radu Stern's “Against Fashion: Clothing as Art.” Stern's book addresses the Futurists' philosophy about fashion. It states that in dress, the aim of futurists was to break the system of fashion by designing clothing as a work of art, instead of simply changing one fashion style for another. That was the methodology that the Futurists used in order to avoid becoming old-fashioned. I also wanted to "break the system of fashion" with my own project and took inspiration from this idea for my collection.

Judith Clark's essay, “Looking Forward Historical Futurism.” In her analysis of the 'Tuta' garment designed by Futurist artist Thayhat, Clark argues that the main concepts of Futurism, as expressed by this iconic garment, are sustainability, modesty and humility. I used the idea of the Tuta (how it was made, what materials where used, and the garment's purposes) as well as the manifestoes from Thayhat to clarify the character of Futurist apparel design. I was particularly interested in Thayhat's idea to reduce the amount of fabric discarded when a garment is created.

Giacomo Balla's “Futurist Manifesto of Men's Clothing.” Balla's Futurist Manifesto maintains that Futurist principles in dress are important not only to garment appearance but to wearer behaviour. The author implies that Futurist behaviour can be summarized as an aspiration for greater ability and lack of concern for everyday happenings and social relations. Balla suggests that only a specific kind of dress can express Futurist intentions, and that it is impossible to be a Futurist without also assuming Futurist mannerisms. This idea inspired me, as I found it very useful to think 
that, for example, aggressive people might wear aggressive clothing. I sought to apply this Futurist principle connecting clothing and behaviour to the development and presentation of my collection.

\section{Gender and masculinity}

Victor Seidler's "Rediscovering Masculinity: Reason, Language, and Sexuality." Seidler's book explores “men's everyday experiences in a broad framework of patriarchy (Connell 38)". It emphasizes the social construction of masculinity and connects it to the advancement of gender theory in Western intellectual traditions. Seidler was mostly devoted to developing the idea of studying power mechanisms according to disembodied rationalist traditions. I planned to use his text in my discussion of power relations in dress

practice by referencing his attempts to reinsert the body into the historical construction of gender relations in my own analysis of futuristic masculinity.

Raewyn Connell's "Masculinities." Connell argues that 'True Masculinity' is always perceived to proceed from men's bodies. He suggests that true masculinity is inherent in a male body or expresses something about a male body. I borrowed his conception, that the social organization of masculinity is inherently relational, to formulate my own definition of masculinity. I also found his idea that masculinity does not exist except in comparison with femininity, very useful. Connell argues that the masculine gender is represented by "a certain feel to the skin, certain muscular shapes and tensions, certain postures and ways of moving, certain possibilities in sex" (52-53). I 
found Connell's opinion applicable for my own research because these facts of the male body are critical when considering the design of male dress.

Arthur Brittan's "Masculinity and Power." Brittan brings forward the subject of "the internal variation in the gendered reality, and with it an understanding of the crucial distinction between gender differentiation and inequality". I used Brittan's criticism of both misogynistic ideologies that present men as natural conquerors, heroes, and competitors as well as the contrary ideologies that suppose that men and women can live equally in organic harmony. Brittan's text helped me to better outline the masculine role according to the Futurist movement.

\section{Hegemonic masculinity}

\section{Connell's "Hegemonic masculinity: Rethinking The Concept", Donaldson's} "What is Hegemonic masculinity?" and Scott-Samuel's "Patriarchy, Masculinities and Health Inequalities". These articles define the relationship and difference between masculinity and hegemonic masculinity. The term hegemonic masculinity is used primarily here to maintain the central focus in the critique of masculinity (Donaldson 645). These authors also demonstrate how the structural formulation, origin and application of hegemonic masculinity can be understood today. Their clarification of the term helped me gain a greater understanding of hegemonic masculinity as the perception of masculinity that is culturally and politically dominant in a particular time and place. Hegemony refers to the subtle and complex process of "particular beliefs, values and ideologies, which are reinforced by those with political and cultural power" (Scott- 
Samuel 159). This opinion can be effectively cross-referenced with the tendencies of traditional masculinity from the Futurism movement within their cultural and political context. The authors explain how hegemonic masculinity is constructed, reproduced and circulated through cultural spheres. They argue that hegemonic masculinity occurs in a "patriarchal society" and gives rise to gendered socialization as well as power and "social inequalities". In turn, cultural circulation reproduces patriarchy in future societies (ScottSamuel 160).

\section{Menswear}

Maria Constantino's “Men's Fashion in the Twentieth Century: From Frock Coats to Intelligent Fibres". Constantino's book examines the standards of dress for the welldressed man in the twentieth century. Her work is particularly informative about the beginnings of mandatory dress codes for gentlemen attending social events in the early twentieth century. I found this useful for developing my argument that fashion within the Futurism Movement could be interpreted as a backlash against early 1900's trends in formalwear for Western men.

Paul Jobling's "Man Appeal: Advertising, Modernism and Men's Wear." In this book Jobling covers the development of menswear advertising during the Modernist Period and includes the contributions of market research, Modernist influences in commercial art, tailors as specialized types of advertisers, and the impact of WWII on men's dress. Jobling is concerned, here, about documenting how changes in clothes and the clothing industry shaped new forms and styles of publicity, and how the material 
aspects of clothing were depicted in posters and magazine advertisements. I planned to use portions of the text which relate how menswear advertising overlaps with market research, to create new ways of classifying the reader's preferences in my own research. Michael Londrigan's "Menswear: Business to Style." This book explores the historical beginnings of menswear to set the stage for today's industry and reviews how menswear has transformed to adopt new positions in the fashion industry as it continues to develop. This author discusses design and manufacturing of menswear through four aspects: tailored clothing, home furnishings, formal wear and sportswear. Because it covers mostly contemporary menswear, this text was useful as a reference for making my collection accessible and relevant to a contemporary audience. 


\section{Methodology and Framework}

My methodology for this project reflects practice-based qualitative research. I undertook the research using a deconstructive fashion design exploration to break down the traditional structures and notions of menswear. This whole process happens within the hegemonic masculinity theory but is seen through the aesthetic lens of the Futurism Art Movement. My intention was that the research results might provide concept and design guidelines for the development of a new menswear collection.

I planned to conduct practice-based work within the framework provided by one of the manifestoes of Futurism, "Futurist Manifesto of Men's Clothing" which was written by Giacomo Balla in 1913 (Appx.1). Because this manifesto is very specific in what it claims to invent and to avoid regarding futurist menswear, I felt it would be an effective guideline for developing the creative component of the project — the actual menswear collection. The research plan also included an analysis of the relationship between the masculine characteristics of the Futurism movement and contemporary hegemonic masculinities, to consider the ways they might be integrated in today's menswear.

The objective of my experimental menswear collection was not to create a series of garments based on futurist philosophy, but to integrate the precepts that defined the Futurism movement, into contemporary design. To achieve that goal, I first dissected the aspects characterizing hegemonic masculinity and compared them with masculine tendencies present in the work and documents from the Futurism Movement. Then, I identified how those combined elements could be used to emphasize or express 
masculinity for a contemporary audience. Throughout this process, Futurist practices in fashion and art informed my designs.

After completing the preliminary data gathering and analysis, I began the process of garment design. From the beginning, I developed the designs using key concepts of Futurism. For example, each of the conceptual design pieces had to include an element that expressed futurist themes and emphasized masculine tendencies (e.g aggressive, shocking, violent...). Once I had clarified the design concept, I was ready to undertake the detailed process of design and organization, which included selecting fabrics, color scheme, shapes or form of dress, and designing accessories. To select materials, I used Balla’s “Futurist Manifesto of Men's Clothing” (1913) (Appx.1) and "The Antineutral Suit; Futurist Manifesto" (1914) (Appx.2) as guides. Both manifestoes discuss ways to create futurist clothing and, most importantly, detail what to avoid. Balla makes suggestions for futurist design methods, attire selection, and other stylistic and visual cues. Whenever possible, I tried to apply Balla's rules for creating futurist garments, while reflecting a contemporary masculine sensibility.

In each of the design stages, I focused on expressing aspects of masculinity (strength, violence, assertiveness, and subordination of women) that related to Futurist philosophy. For example, each garment piece was designed to reflect both the aspects of Futurism and masculinity in symbolic, metaphoric, or direct ways. I designed and produced five different garment sets that were either composed of a maximum of three pieces (top, bottom and piece of outerwear), or a minimum of two pieces (under-garment and outer-garment). By mixing and matching the five different garment sets, one could 
create approximately 10 to 20 different outfits, which fulfilled the principles of Futurism symbolically, metaphorically or directly. In choosing which garments would be used to create an outfit, I followed the rules that are suggested for contemporary menswear. 


\section{Hegemonic masculinity and Futurism}

Since I decided to reflect the characteristics of hegemonic masculinity in my garment collection through utilizing the framework of the Futurism manifesto, I had found that the theory of hegemonic masculinity and the Futurist manifesto of men's clothing contain similar characteristics. According to Connell (2005), Donalson (1993), and Pringle (2005), hegemonic masculinity is described through characteristics such as violence (force), strength, dominance, 'risk-taking practices' (Connell 851), and 'defending prestige and showing off' (Donaldson 647). Especially Pringle suggested that hegemonic masculinity was defined by those characteristics (Pringle 267). Those aspects characterizing hegemonic masculinity were reflected in the behaviours, appearances, thoughts, and the occupations of men.

According to the Futurist manifesto of men's clothing (Appx.1), the characteristics which futurists wanted to emphasize: dynamism, aggression, shock, energy, and violence, were similar to the aspects characterizing hegemonic masculinity. The behaviour and thoughts of the futurists that reflected the characteristic of hegemonic masculinity are found in the way they published their manifesto (supremacy) to elevate their new artistic movement (leadership and prestige). What futurists were praised for during the actual historical period of Futurism - agitation, embrace of industrialization, glorification of war, technology development, dynamism, and speed - are linked to the characteristics of hegemonic masculinity such as risk-taking, aggression, violence, and dominance. Comparing the aspects characterizing both hegemonic masculinity and the 
masculine tendencies presented in the works and documents from the futurists seems like convincing evidence that there is a connection between them. 


\section{Collection Development}

I undertook four main garment design and making processes in order to create a conceptual design collection of menswear based on masculinity as dictated by the Futurist aesthetic. This development process included the following stages: sketching, patternmaking, fabric and color selection, and construction. Each stage is explained in detail on the following pages.

\section{Sketching}

Futurism was one of the first avant-garde art movements in Italy, and reflected a new wave of artists obsessed with the now, not the past. Through their artistic expression and attitudes, the Futurists wanted to destroy the past. The sketching process was characterized by two major stages: the first focused on creating wearable contemporary garments based on the suggestions from the Futurist manifesto of men's clothing, and the second stage fully adhered to the Futurist framework. From these two different stages, I intended to find out which one better reflected the Futurist principles.

I created fifteen sketches for the first stage, detailing designs for five jackets, three trousers, two jumpsuits, a vest, a shirt, a coat, and two basic bodice designs. I focused on the use of details that might represent men's garments and masculinity in appearance. The design details were taken from traditional menswear garment styles, such as athleticwear, military uniforms, and work wear. I based the jackets on the outline of a contemporary blazer with attachable pockets that were inspired by military and workwear uniforms such as the M-65 and sports blazers (Figures 6-10). The sketches for 
three pairs of trousers (Fig. 11) and two jumpsuits (Fig.12 and 13) had similar aspects to the jacket designs, as they were also inspired by workwear pant patterns and design details. Because I was too focused on making the garments wearable and bounded by the forms of contemporary garments, this first stage of the sketching process was not successful.
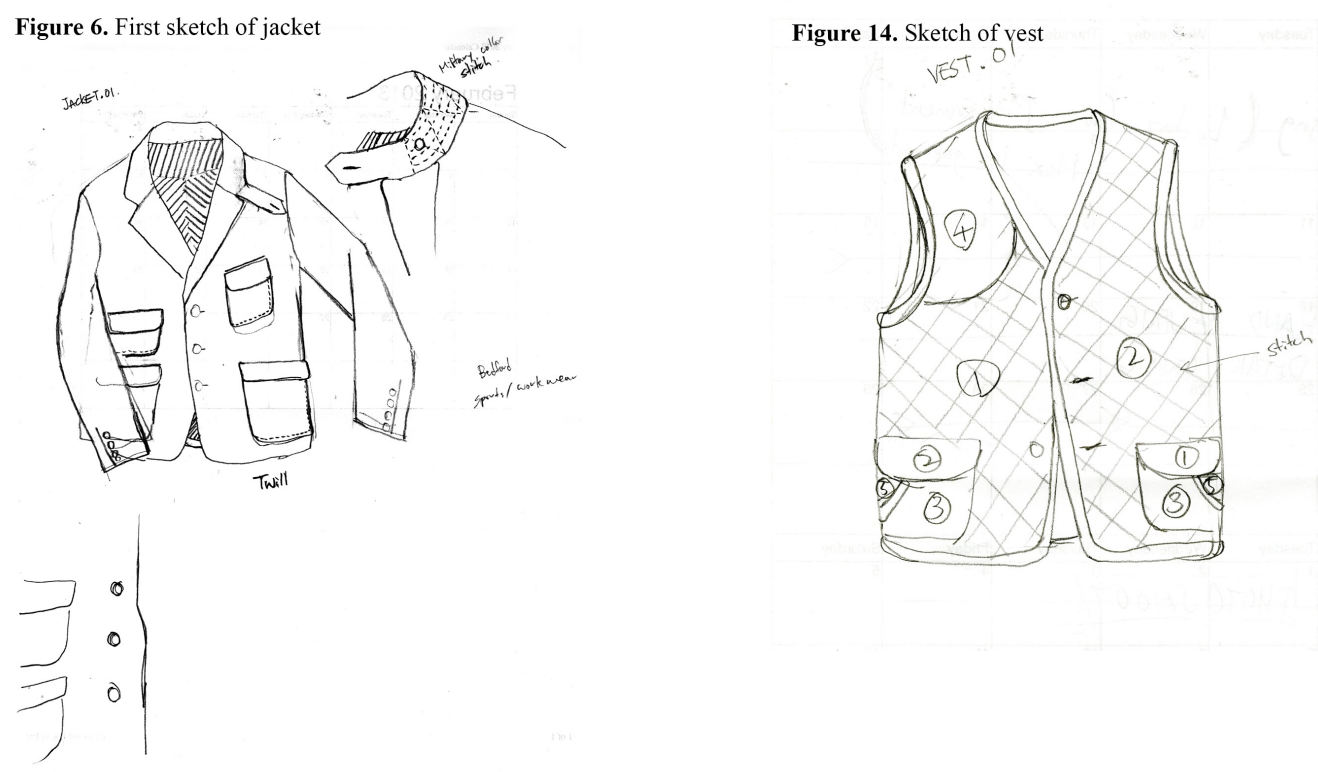

The greatest issue with the first group of sketches was that I did not follow the suggestions from the "Futurist Manifesto of Men's Clothing" for abolishing the past. In retrospect, these sketches (Figures 6-17) reflected designs that the Futurists very much wanted to destroy. The Futurist Manifesto of Men's Clothing suggested the elimination of static lines and uniformity in cut and designs. However, my sketches from the first stage were constantly composed of static lines and they all had unnecessary attachable pockets, which represent uniformity. Overall, while the sketches from the first stage reflected masculinity in menswear, they did not represent the type of menswear that the Futurists wanted to achieve. 
After the failure of this first sketching process, I focused more on expressing the core concepts of Futurism, such as dynamism and aggression, by creating designs with mostly diagonal lines and asymmetric silhouettes. The guidelines in "The Futurist Manifesto of Men's Clothing" dictated that garments must be simple and comfortable for the wearer. The manifesto also outlined what not to do in creating Futurist men's clothing. For example, it suggested avoiding "tight fitting, colorless, funereal, decadent, boring and unhygienic garments" and abolishing static lines and uniformity. In Balla's vision, Futurist clothing must be comfortable, practical, dynamic, aggressive, shocking, energetic, violent, flight, peppy, joyful, and might integrate such details as illuminating devices, phosphorescent effects, and might be lit by electric lamps. In each of the sketches from the second stage, I included at least one of these elements.

By the end of stage two, I had created thirty different designs from which I felt twenty-four were satisfactory. I discarded six sketches (Fig.18 and 23) because they included circular and round shapes. Because "The Futurist Manifesto of Men's Clothing" recommended the use of ellipses and circular shapes to create dynamic designs, I incorporated these shapes during the sketching. However, my creations too closely reflected a feminine sensibility because they were reminiscent of the female body, which is typically narrower at the waist and shaped by smooth, curved lines. The final sketches for this second round included blazer jackets, hoodies, pants, capes, jumpsuits and more. For all of them, I used abstracted geometric shapes that resembled tilted stairs and formed diagonal hemlines. 

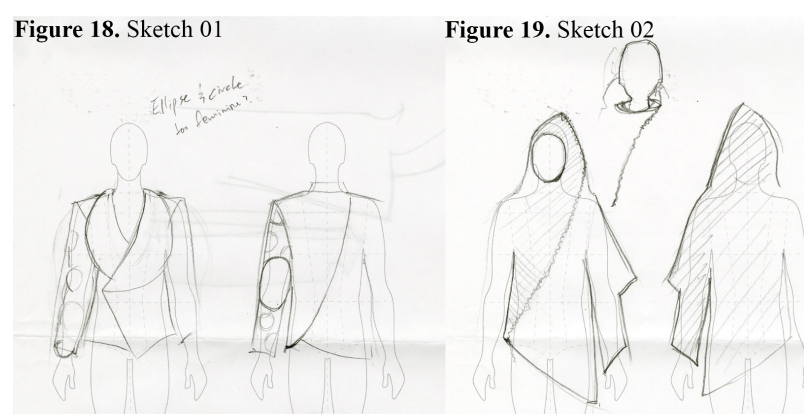

Figure 20. Sketch 03

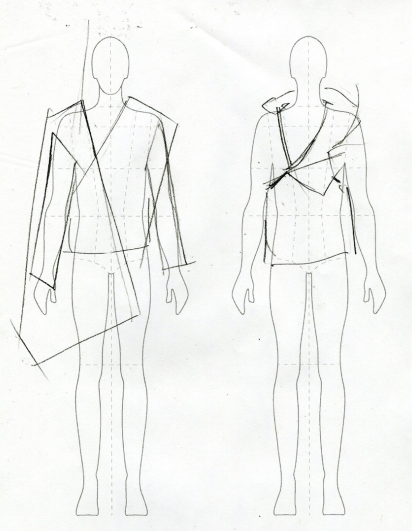

Eventually, I ended up with twenty-five sketches that could be made into

garments. They were designed to fulfill the guidelines of "The Futurist Manifesto of Men's Clothing" while at the same time demonstrated hegemonic masculine characteristics such as the representation of strength and power. Notably, several designs had multiple layered sleeves and bodices, upstanding shaped lapels, irregular cuts, and placements that, overall, stressed asymmetry (Figures 24 to 47). In this second group of sketches, there were several designs that had nothing in common with each other (figures 41 to 47 ), so I discarded these as well. The final 25 sketches satisfied the requirements of "The Futurist Manifesto of Men's Clothing" and fulfilled at least one of the aforementioned futuristic attributes (practical, dynamic, aggressive, shocking, etc). I used the final sketches for the next stage to develop actual designs that could be worn on a male body. 


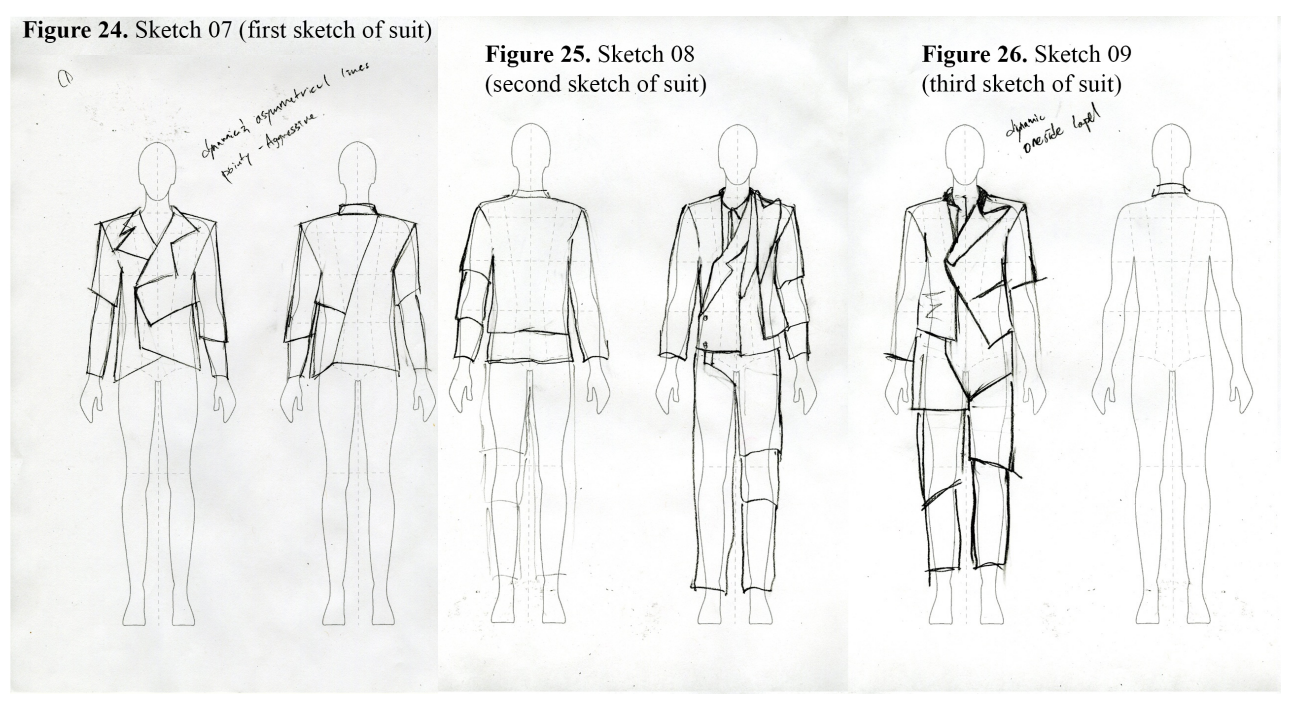

\section{Patternmaking}

In the patternmaking process, one develops flat versions of sketched silhouettes that can conform to the three dimensional human body. The reason why I chose the patternmaking method to develop designs for the wearable garments was that this method is more commonly used in menswear, as it involves drafting a pattern directly onto pattern paper using a variety of lines and edges. I began with what I had built to be the basic patterns of a jacket, a shirt, and a pair of trousers; these were all based on the sizing for a medium male subject in North America.

I used standard measurements for sizes 38 and 40 for the jacket form, medium size standard measurements for the shirt, and a size 30 standard waist measurement for the trousers. Figure 48 illustrates the basic pattern of the jacket including front and back. Figure 49 reflects the basic pattern for a sleeve and was used for the jackets, the shirts, and all the other upper garments. Figure 50 forms the basic pattern of a shirt and is composed of front and back, and Figure 51 includes the pattern for the front and back of a 
pair of trousers. Both "Patternmaking A Comprehensive Reference for Fashion Design" by Sylvia Rosen and “The Blue Book of Men's Tailoring” by Frederick T. Croonborg informed my patternmaking for these basic pieces.

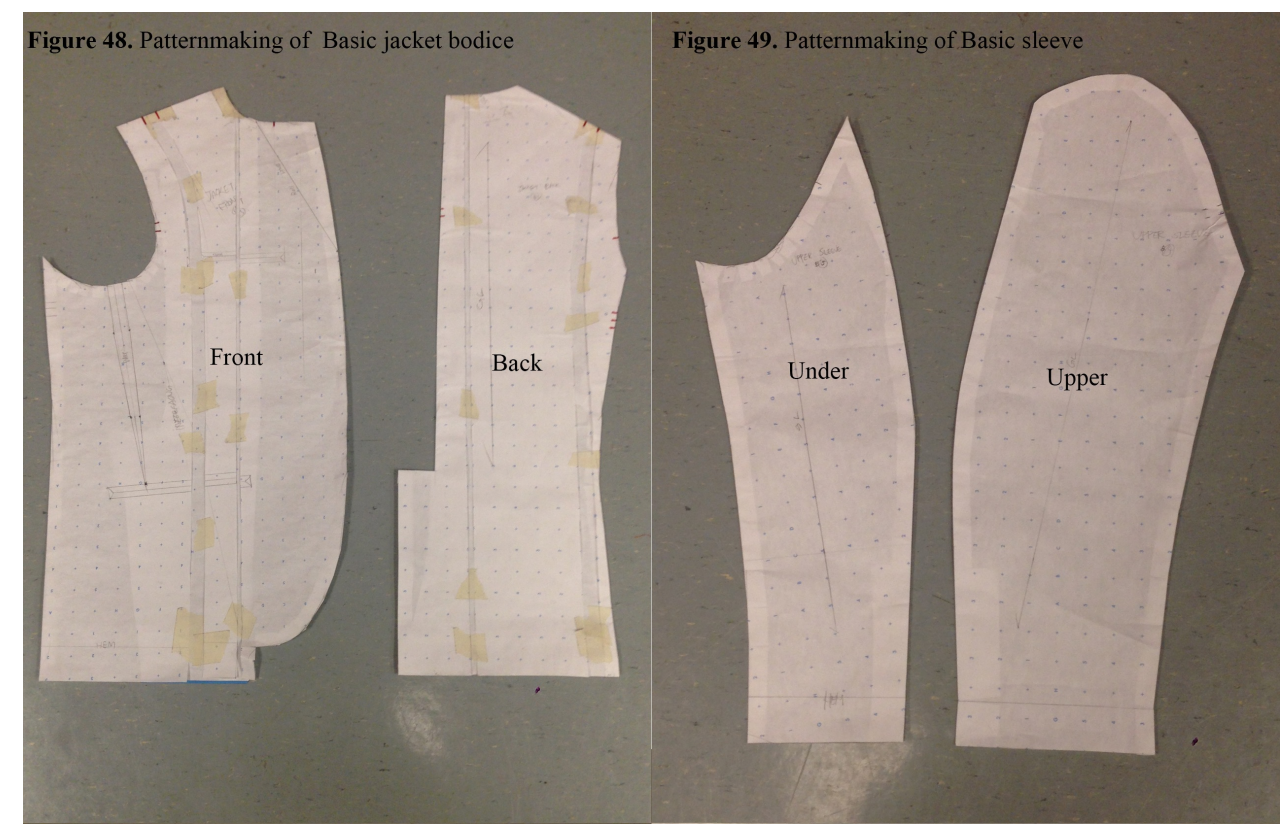

The reason that I employed this methodology (of using basic pattern pieces to create each of the sketched designs) was because I wanted my garments to be composed of simple pattern pieces and to be easy to construct. This goal reflected one of the key principles of an innovative Futurist garment known as the Tuta. The Tuta was created by the Futurist artist Ernesto Thayhat in 1919. This garment was a kind of one-piece made out of synthetic fabric, though it was not related to the workwear jumpsuit. The Tuta is a significant garment because it fulfills the Futurist ideals of dress and also reflects the elements of "The Futurist Manifesto of Men's Clothing".

The Tuta garment was designed for simplicity and practicality. It was plaincolored without decorative elements, and could be modified by the wearer without any assistance (Stern 40). I adopted the principles of simplicity and practicality from the Tuta 
design, and tried not to split my garment into too many pieces when formulating essential parts such as the bodice or sleeves. I focused on creating garments that were composed of simply patterned pieces, and on getting rid of unnecessary elements that would disturb the expression of dynamism.

I used the sketches in Figure 24, 25, 27, 28 to design the jackets, and those in Figure 33 and 34 for the upper garments. The jumpsuits were based on sketches in Figure 36(front) and 37(back) and the trousers were built from designs in Figures 25 and 28. Based on the basic pattern pieces for each body form, I applied each of my designs from the sketches to the basic patterns. First, I traced the basic drafted pattern form of whichever body part I wanted to re-create, and added the distinctive parts for the design by referring to the sketches. For example, the first jacket's patternmaking design (Figure 52) corresponds with the jacket sketch of Figure 24 . It had three differently shaped bodices, one for the right side and two for the left side. For the right side bodice, I added a triangular shape on the lapel area and cut a diagonal line on the hemline from the basic jacket pattern. The two left side bodices had the same added shapes on the lapel area, so I cut the upper bodice on the hemline shorter than the under bodice, and cut both of the left side bodice hems on a diagonal line. For the back side, I combined the left and right sides of the back piece from the basic pattern and cut it in a vertical diagonal line on the center back. I trimmed the hem in a diagonal line, as well. The under sleeve of Figure 52 was cut to be slimmer than the basic sleeve pattern and the upper sleeve was edited from the basic sleeve pattern as well, to be formed into what it showed on Figure 52. All of the other pattern pieces (Figures 52-59) for the rest of the selected designs were constructed 
using the methods applied to the first jacket. At this point, all of the patterns did not include seam allowances.

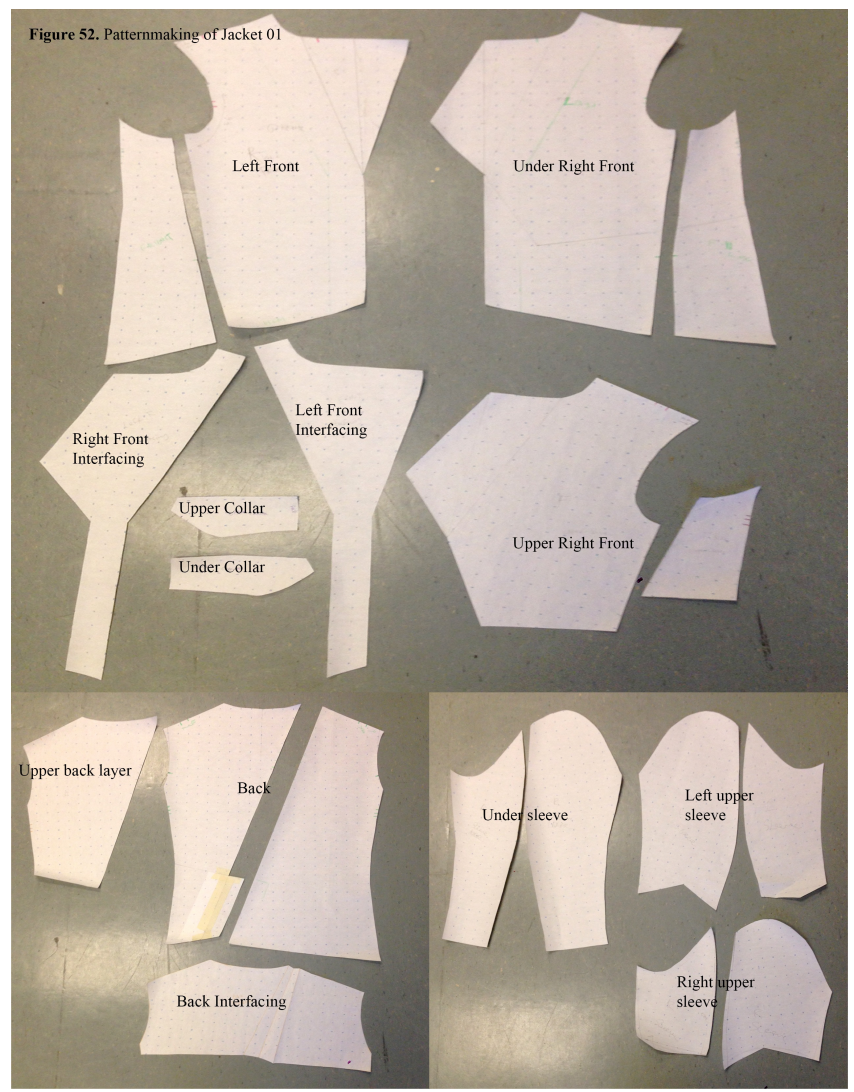

\section{$\underline{\text { Fabric and Colour Selection }}$}

For the garment fabrics I wanted to use innovative textiles such as Microfiber.

However, I could not find any Microfiber with strong density, less stretch, more weight/ thickness and in bright colours. Every fabric sample that I found in local markets lacked at least one of the features that I needed for constructing the garments from a Futurist perspective. Therefore, I re-adjusted my plan for fabric selection and based it on colour instead. 
Figure 60. Fabric Swatches of Main Matertial: Cotton Canvas with rubber coated on the back

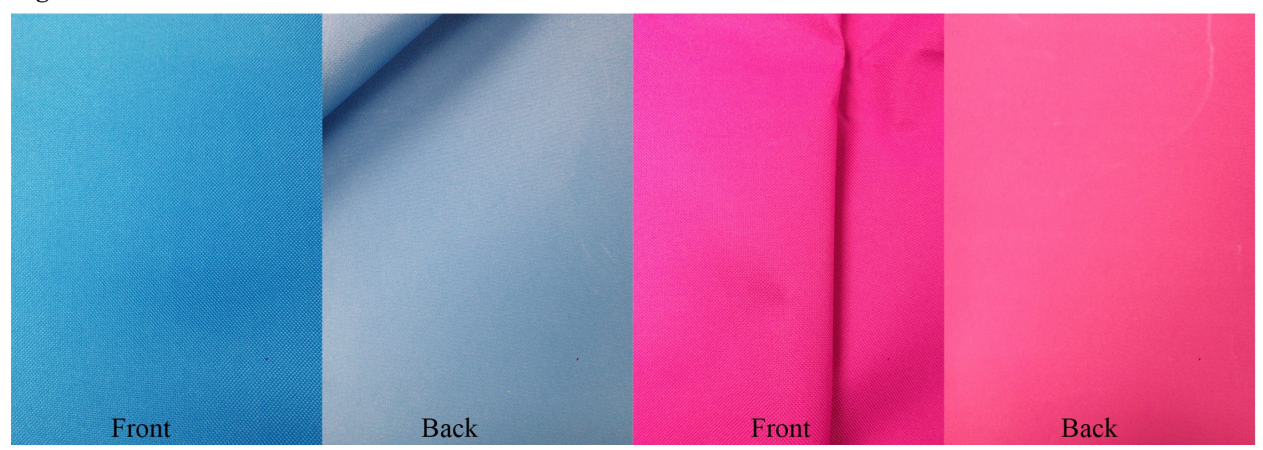

“The Futurist Manifesto of Men's Clothing” decrees that Futurist colour themes ought to be brilliant. According to the manifesto, colours must be forceful and reflect the reddest reds, the deepest purples, the greenest greens, and intense yellows, oranges, and vermilion. In my interpretation, these hues were achieved with solid-coloured fabrics. The fabric I eventually chose was a cotton canvas coated with a rubber backing. The salient feature of this fabric was that it was stiff and thick, and thus it could best capture the shape of the Futurist garments I had designed. Because it didn't fray, I could also leave all of the edges of the garments unfinished, and a raw edge would, most importantly, fulfill the Futurist principle of simplicity.

For the entire collection, I used that rubber-coated cotton canvas in a variety of solid colours such as blue, red, green, yellow, pink, and vermillion as the main material (Figure 60). I also added some sections of glossy plastic and vinyl, as well as floral lace, neon-coated synthetic fabric and solid coloured wools as accent materials (Figure 61), because their textures and sheens were dazzling. When combined, I expected them to “sparkle like the glorious prism of a jeweler’s gigantic glass front" (Balla).

The title of my menswear collection is "Futurismo Now". The word "Futurismo" is derived from the concept of Futurism translated in Italian. I wanted to use the word to 
connote both the meaning of Futurism, and the place where Futurism originally developed. The reason I added the word "Now" was to emphasize the Futurist's obsession with immediacy and rejection of the past. Because "Futurismo Now" is a very short and simple phrase, I felt it would be easily remembered and referenced. 


\section{Research Outcomes}

Overall, each of outfits in the final collection successfully fulfilled the elements of Futurist design as outlined by the "Futurist Manifesto of Men's Clothing". I developed five outfits through the processes of sketching, patternmaking and fabric and colour selection. The overall composition of outfits in the collection (Figure 65) is sorted in three different looks. They are the compounding of a jacket, upper garment, and a pair of trousers, the compounding of an upper garment and a pair of trousers, and a jumpsuit. In terms of its visual unity, the collection is composed of various pieces of bright and bold colours, which are featured in each of the outfits. Additionally, the boundary lines of colour segmentation are clear and certainly emphasize the dynamic theme in the entire collection. The compounding of various colour segments and dynamical cuts creates an atmosphere of vibrancy displaying a man with a general sense of confidence.
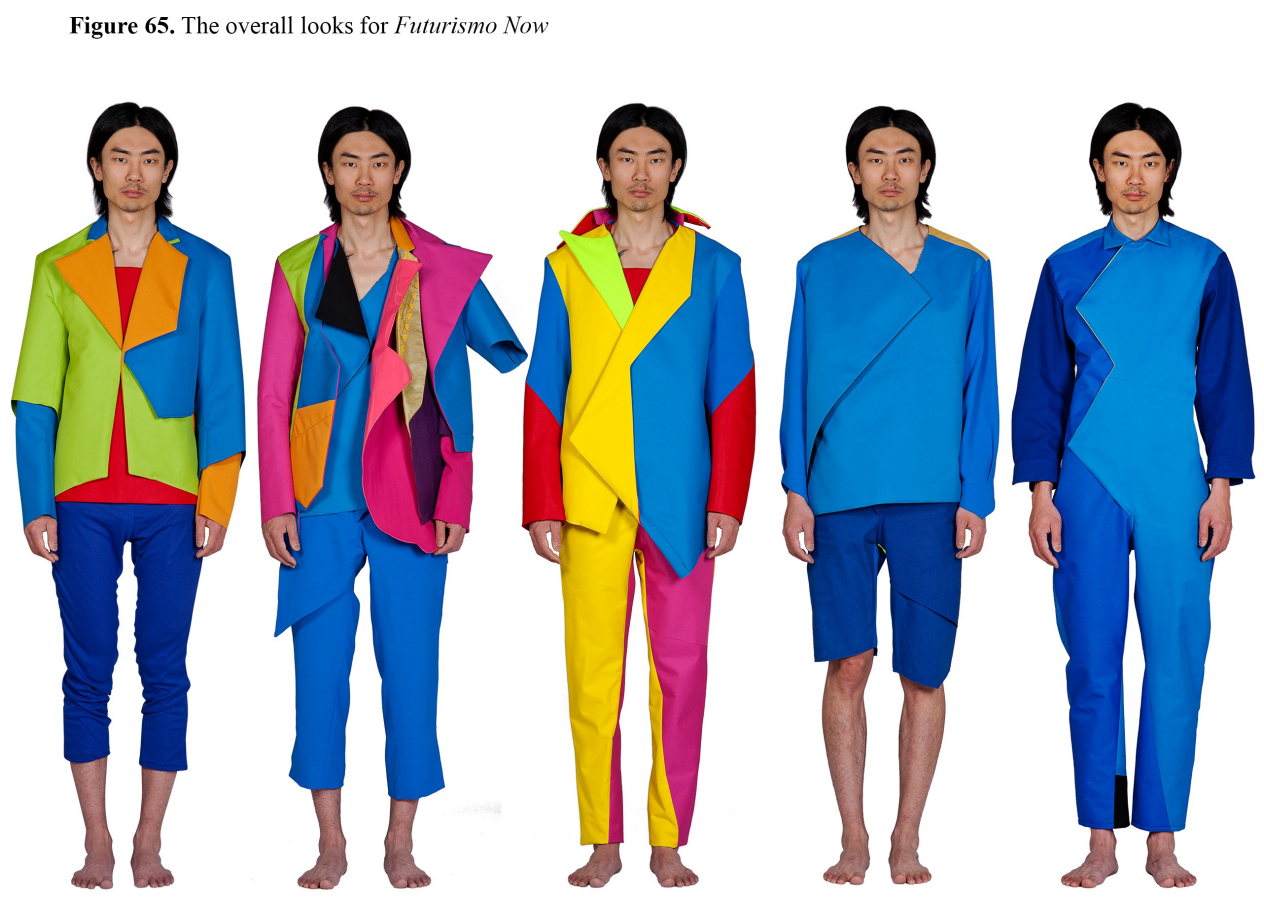

Futurism Now, Yeon Jang, 2014 
Overall, each outfit seems hardly suited for the mainstream menswear fashion market, especially now. Still, the general current trend of menswear applies bright and bold colours within 2 or 3 solid pieces in the overall look (head to toe). The most recent trend forecast for menswear suggests the 'layering', 'color blocking', and 'trying with tailoring' (Gill). Those suggestions of menswear trends are included in my collection as well. All of the outfits in my collection are composed of multiple solid colours which revolve around a limited palette of bright and bold shades placed within defined areas (colour blocking). All of the jackets are built based on men's tailoring (trying with tailoring) and composed of multiple layers (layering). However there is a different perspective between this collection and contemporary menswear. Mainstream trends use the previously mentioned characteristics in a restrained way but my collection uses them as a tool to express a dynamic theme. However, if all the outfits of my collection were modified to place less emphasis on the areas of colours and cut usages, they might have a chance to provide a wearable approach to the forecasted trends.

Then there are the pieces themselves. The first jacket (Figure 66), which corresponds to the sketch in Figure 24 and the patternmaking demonstrated by Figure 52 reflects the central mandate of the collection: it is comprised of dynamic lines, which are achieved through asymmetrical and diagonal cuts. My use of dynamic lines and colours are very limited here in comparison with other jackets in the collection. I used three different colours for this particular jacket: solid blue, green and orange. It had different shaped lapels on each side: One forms a triangle, and the other a trapezoid. The left side of the jacket was double-layered as it was not built for a functional purpose but conceived 
to express a feeling of dynamism. The upper layer was not attached to the under layer, leaving room between the upper and under layers from the bodice to the sleeve on the left side. The upper layer was only attached at the lapel and the neckline.

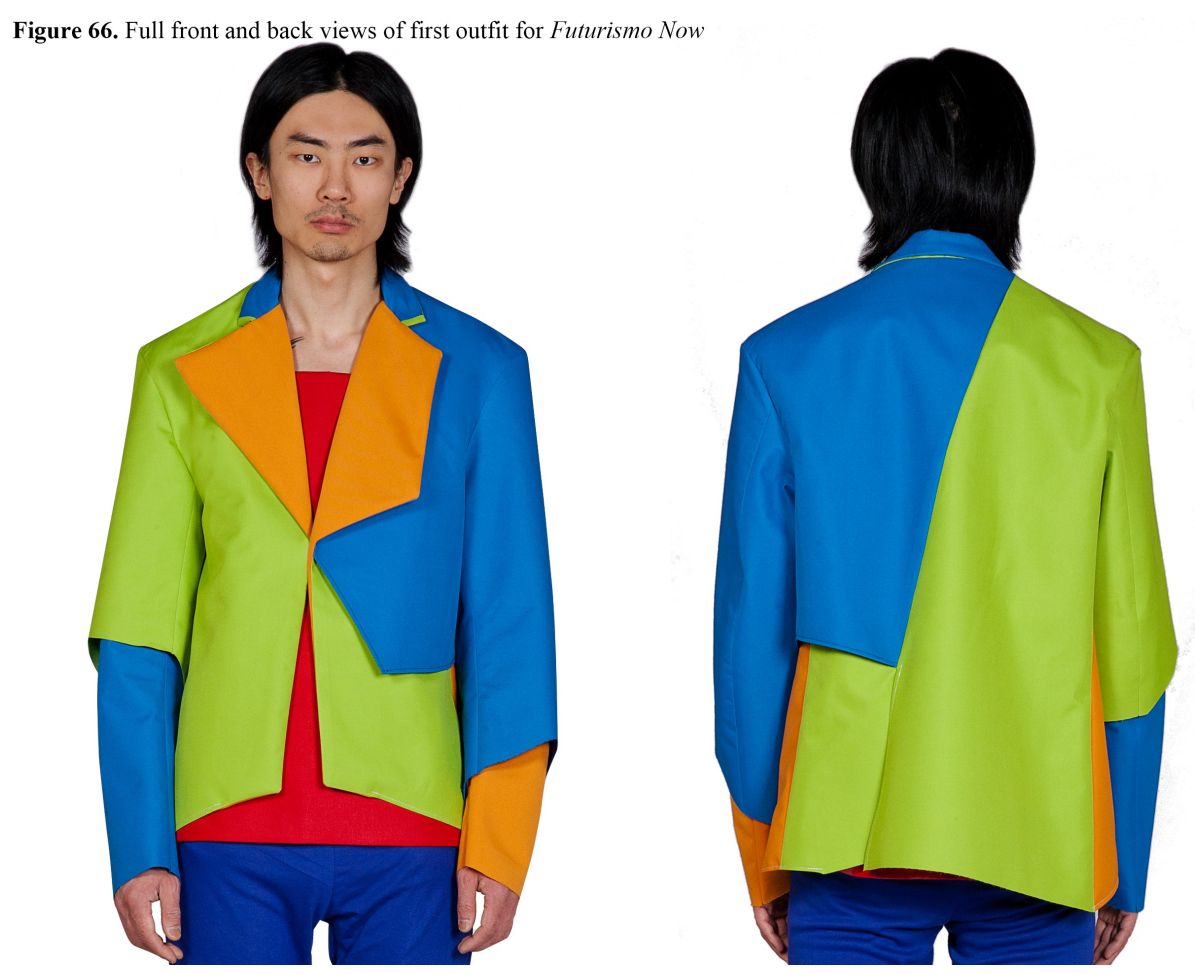

Interestingly, this jacket creates an optical illusion, due to the use of a limited colour combination and diagonal line cuts. For example, from the front viewpoint, each of the parts in the same colour seems to be connected to each other. The blue upper layer bodice on the left side appears to be connected with the blue under layer sleeve on the right side. This illusion is recreated in other parts of the garment, which are composed of the same colour. However, in the actual garment, corresponding colour pieces do not actually connect. This resulting optical illusion further fulfills the goals of what futurists want futurist clothes to be, artworks unto themselves. 


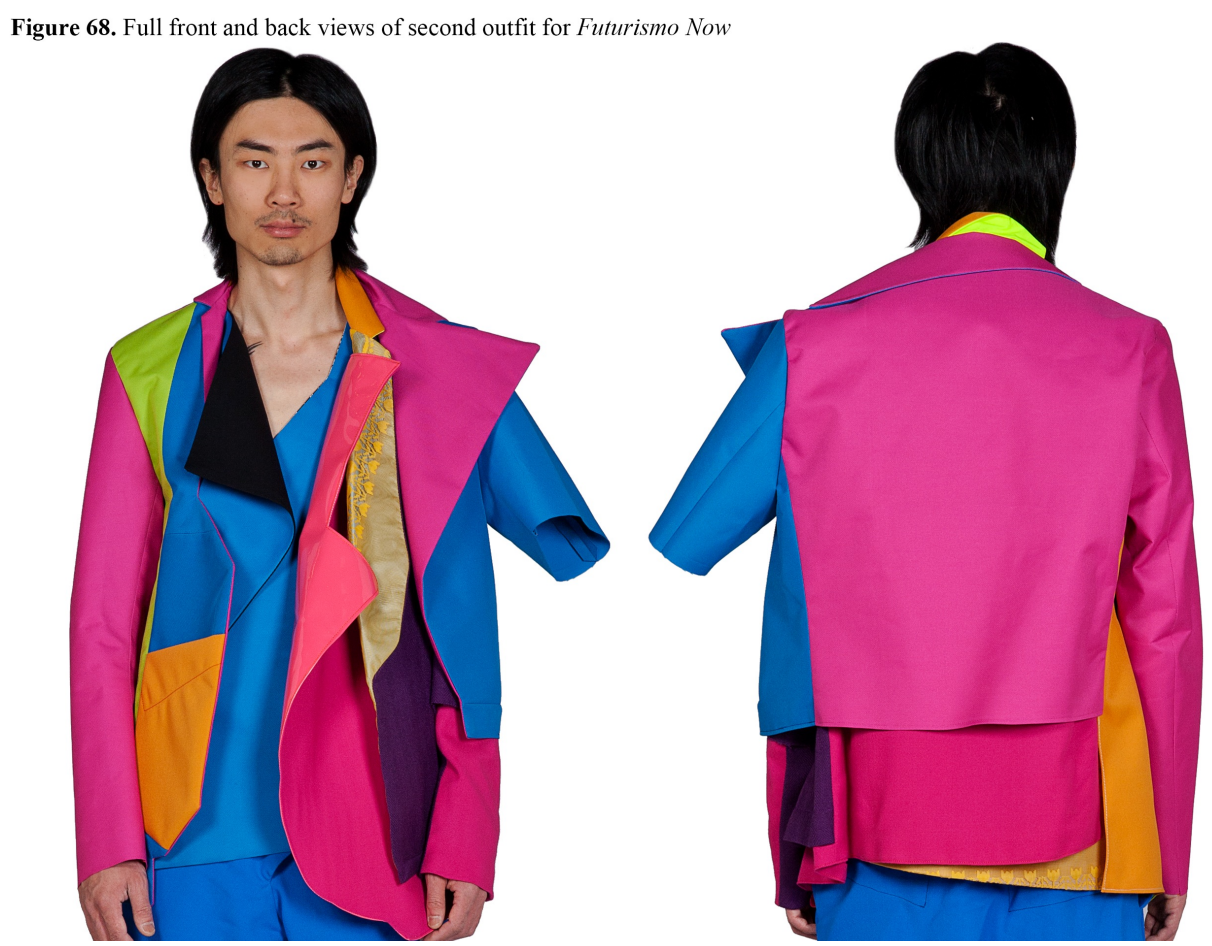

The second jacket (Figure 68) is the busiest design in the entire collection, as it is constructed with ten different colours and materials. The idea for this jacket was to express the ways that simplicity and complexity might co-exist in a single garment. Originally, the idea was to use three layers on one side, to demonstrate dynamism. In actuality, the multiple layers made the garment too complex, which violated a key ideal from “The Futurist Manifesto of Men's Clothing”. Therefore, I adjusted the design to reflect a simplified version of the complicated look the multiple layering had created on the other side of the bodice by fragmenting it with colours and shapes. The result was that I achieved a dynamic aesthetic in the garment without causing complexity in its construction through the use of a flat patchwork of diagonal cuts and colour combinations. 
deconstructive method on a small portion of the design. The effect is achieved, therefore,

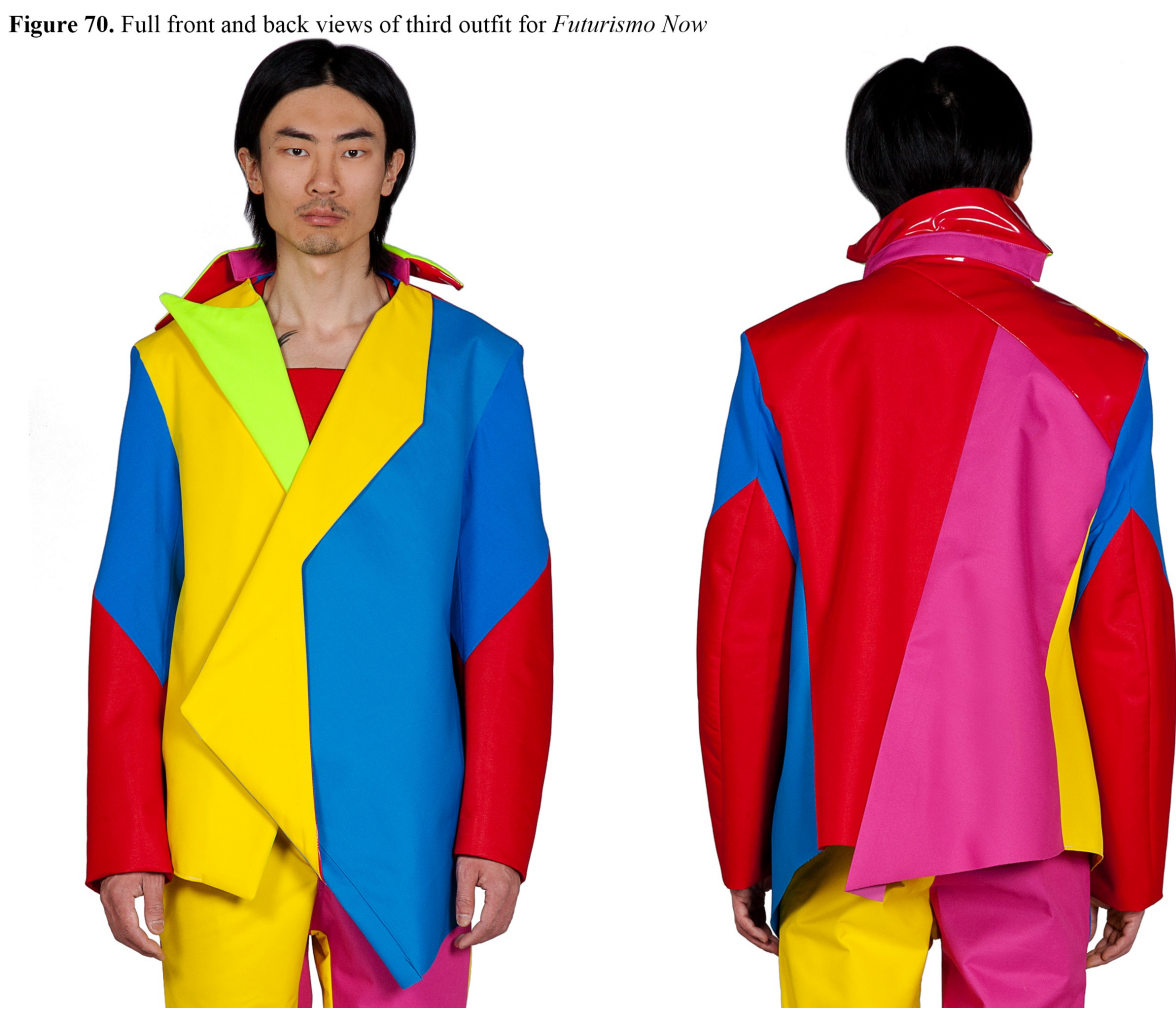

through trickery, and the jacket retains a very simple design with limited dynamic cuts.

Overall, the fabric selection for the entire collection was successful, as each constructed outfit fit closely on the body and retained its original design, meaning its intended shape and form was not changed from the original design when translated into an actual garment. Even though each of the sides from each outfit had different shapes and colour combinations, they did not appear unbalanced or demonstrate poor construction. The features of the chosen textile caused this outcome to be realized.

The colour choices of bright and solid-coloured textiles for the garments were also effective and demonstrated the power of colour use in Futurism. The pop-up colours were dynamic and dazzling and reflected many of the characteristics promoted by "The 
Futurist Manifesto of Men's Clothing" and hegemonic masculinities (Donaldson), such as: power, strength, courage, toughness, adventure, energy, shock, joy and dynamism.

\section{$\underline{\text { Fashions from Futurists }}$}

If one compared this menswear collection with the futurist suit made by Giacomo Balla in 1918, one would find similarities. Balla was the most representative futurist who also happened to work in the field of fashion, whereas the majority of Futurist artists were painters, sculptors, and poets. To many Futurists, dress was only one more practical area to work rhetorically; they were not interested to learn how to make the clothing or understand its construction methods (Clark). For Balla dress was critical, and within five years of publishing his manifesto (1913) he created the first Futurist suit. The Futurist suit is the best example of what Futurist men's clothing should look like, as dictated by Balla's manifesto. The suit (Figure 62) has geometric shapes in abstract motifs and reflects a "powerfully dynamic use of colours and playfully destructive energy" (Battista). This play on the design of a basic shape of a man's suit has a distinctive accent of a red, yellow, orange, and dark brown triangle shape on the left side lapel.

Another important example of a Futurist garment is Depero's waistcoat, created in 1924 (Figure 63). Depero was a representational Futurist, like Balla, and the artistic development of the Futurism movement in the 1930s and 40s can mostly be attributed to both Balla and Depero. Depero mostly produced toys, tapestries and furniture in the Futurist style; however, he conceived a Futurist men's vest of wool cloth for his private 
collection in Milan. Marinetti, the founder of Futurism, wore this vest in 1924 (Figure

64). These garments are representative of how the aesthetic and ideological goals of

Futurism could be represented by clothing.
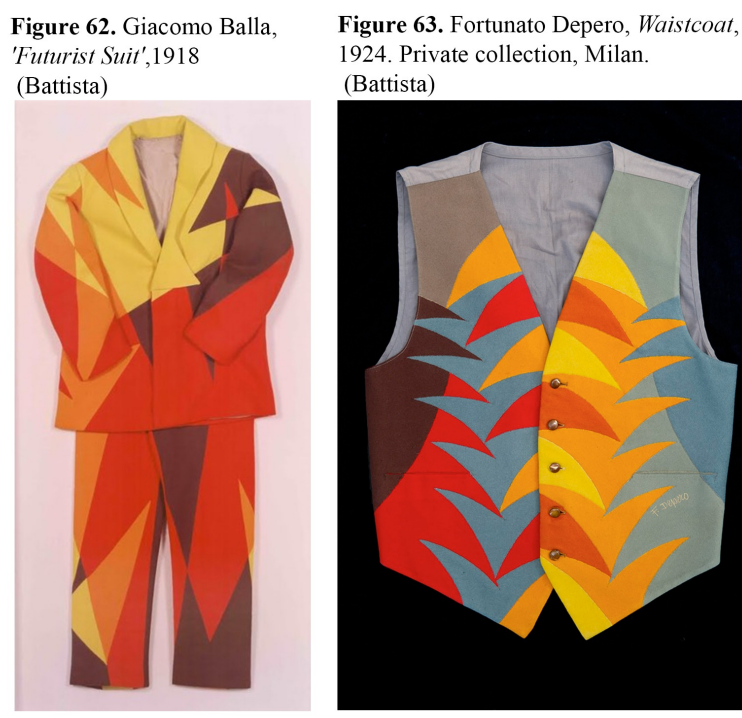

Figure 63. Fortunato Depero, Waistcoat,

1924. Private collection, Milan.

(Battista)

Figure 64. Fortunato Depero and F.T

Marinetti wearing Futurist vests

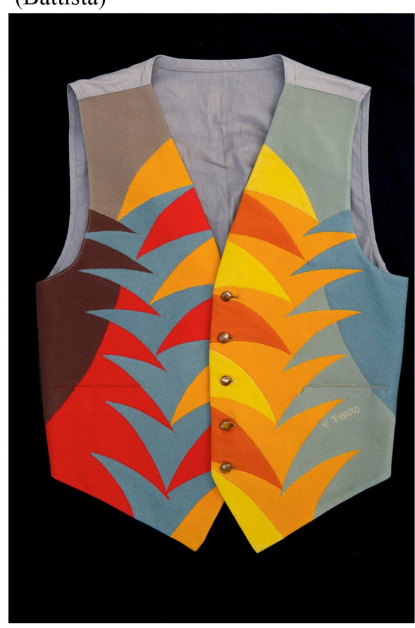

designed by Depero. 1924 (Braun 34)

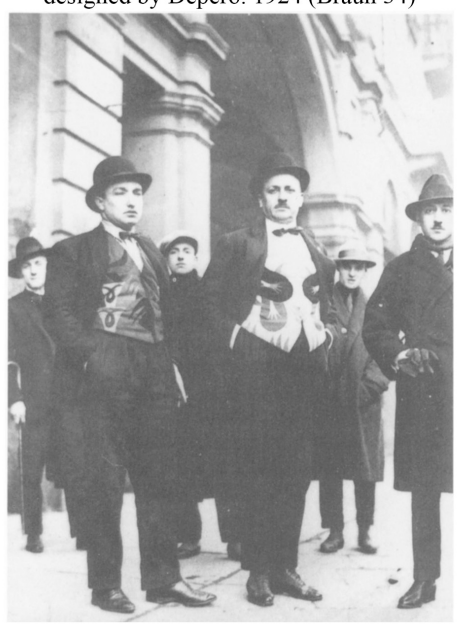

There are important visual similarities between these examples of Futurist

garments and my menswear collection. First, Balla, Depero and my designs utilize the same lines and colours to stress dynamism in the garments. Because they are built using the same framework (The Futurist Manifesto of Men's Clothing), what they wanted to express through their designed garments and what I did in my collection, are aimed in the same stylistic direction. The comprehensive messages of both of their designs, like my own pieces, also represent the tedium of the past and the aspiration of change for the new. 


\section{Conclusion}

This project of designing and developing a Futurist garment collection yielded positive results that fulfilled my original objective to design clothing based on the principles outlined in Balla's “Futurist Manifesto of Men's Clothing”.

In the beginning, I hoped to explore both representations of masculinity in contemporary menswear and Futurist practices within the framework of "The Futurist Manifesto of Men's Clothing". At the same time, I became aware of creating a totally different fashion style or suggesting avant-garde design in a futuristic way. My research developed from the idea that the Futurism movement reflected similar attributes to those characteristics of hegemonic masculinity (strength, aggression, dynamism, violence, energy, and practical concerns). Also, through this project I wanted to learn more about the Futurist manifestoes. This idea of putting out manuscripts containing the rules and methods of what they wanted to invent and abolish, based on their own ideology, could be seen as supremacy or progressivism at this point. Therefore I assumed that the futurist's supremacist tendencies would be reflected as hegemonic masculinity on their manifesto of men's clothing.

By exploring hegemonic masculinity through the development of a conceptual menswear collection, I utilized the framework of the futurist manifesto of men's clothing to explore the tendencies of hegemonic masculinity in the futurist's behaviour. With such tendencies towards violence and aggression, from the aspects of glorifying war and promoting fascism, those behaviours represent hegemonic masculinity. The behaviour of publishing the various manifestoes which contain the futurist's ideals, can, though, be 
interpreted as incendiary behaviour. In its time Futurism was a very progressive movement and the manifestoes represented their sense of leadership, which in turn symbolized authority and prestige.

Can hegemonic masculinity be interpreted through this garment collection, even though these principles are evident in “The Futurist Manifesto of Men's Clothing?” First of all, I believe that this conceptual menswear collection reflects characteristics of hegemonic masculinity such as strength, aggression, dynamism, violence, and energy, and practical concerns that were promoted by the Futurists in Balla's manifesto. For the interpretation using by the role of dress within masculine representation as the occupation in the hegemonic masculinity, each of the outfits from the collection are close to formulate with the dress of the industries that are of great importance to men such as the business suit and jumpsuit. As well, the use of bright colours and dynamic lines in the entire collection presents the viewers with a new yet masculine appearance of strength and confidence. 


\section{Bibliography}

Balla, Giacomo. “Futurist Manifesto of Men's Clothing.” In Futurist Manifestoes. Edited by Umberto Apollonio. London: Thames and Hudson, Inc., 1986

Battista, Anna. "Salvatore Ferragamo: Inspiration and Vision - Zoot Magazine."

Salvatore Ferragamo: Inspiration and Vision-Zoot Magazine. 30 June 2011. Web. 14

Apr. $2014<$ http://www.zootmagazine.com/2011/06/30/salvatore-ferragamo-inspiration-

and-vision/>

Braun, Emily. "Futurist Fashion: Three Manifestoes." Art Journal 54 (1995): 34-41.

Brittan, Arthur. Masculinity and power. Oxford, UK: Basil Blackwell, 1989. Print.

Caws, Mary Ann. Manifesto: a century of isms. Lincoln: University of Nebraska Press, 2001. Print.

Clark, Judith. "Looking Forward Historical Futurism.” Judith Clark Costume. N.p., n.d.

Web. 14 Dec. 2012.<http://www.judithclarkcostume.com/publications/essays_02.php>.

Connell, Raewyn. Masculinities. Berkeley: University of California Press, 1995. Print.

Connell, R. W. "Hegemonic Masculinity: Rethinking The Concept." Gender \& Society

19.6 (2005): 829-859. Print.

Costantino, Maria. Men's fashion in the twentieth century: from frock coats to intelligent fibres. New York: Costume \& Fashion Press, 1997. Print.

Donaldson, Mike. "What Is Hegemonic Masculinity?" Theory and Society 22.5 (1993):

643-657. Print. 
Gill, Chris. “Men’s SS14 Fashion Trend: Colour Segmentation.” FashionBeans. 20

March 2014. Web. 14 Apr. 2014. < $\underline{\text { http://fashionbeans.com/2014/mens-ss14-fashion- }}$ trend-colour-segmentation/>.

Hultén, Karl Gunnar Pontus. Futurism \& futurisms. New York: Abbeville Press, 1986.

Print.

Jensen, Richard. "Futurism and Fascism.” History Today 45.11 (1995): 35-.

Jobling, Paul. Man appeal: advertising, modernism and men's wear. Oxford: Berg, 2005.

Print.

Londrigan, Michael. Menswear: business to style. New York: Fairchild ;, 2008. Print.

Paulicelli, Eugenia. "Fashion and Futurism: performing dress.” Annali d'Italianistica 27 (2009): $187+$.

Poggi, Christine. "Metallized Flesh: Futurism and the Masculine Body.” Modernism/ Modernity 4.3 (1997): 19-43.

Pringle, Richard. "Masculinities, Sport, And Power: A Critical Comparison Of Gramscian And Foucauldian Inspired Theoretical Tools." Journal of Sport and Social Issues 29.3 (2005):256-278 .

Rye, Jane. Futurism. London:Studio Vista;, 1972.

Salvatore, Fillippo. “A century of Futurism Its legacy and shortcomings (1909-2009).”

Panoram Italia. 23 July 2013. Web. 22 Oct. 2013. < $\underline{\text { http://www.panoramitalia.com/en/ }}$ arts-culture/history/century-futurism-legacy-shortcomings-1909-2009/1911/>.

Scott-Samuel, Alex. "Patriarchy, Masculinities And Health Inequalities." Gaceta Sanitaria 23.2 (2009): 159-160. Print. 
Seidler, Victor J. Rediscovering masculinity: reason, language, and sexuality. London:

Routledge, 1989. Print.

Stern, Radu. Against fashion: clothing as art, 1850-1930. Cambridge, Mass.: MIT Press,

2004. Print. 


\section{Table Appendixes}

Appendix 1 Futurist manifesto of men's clothing 47-48

Appendix 2 The antineutral dress a Futurist Manifesto $\quad 49-50$

Figure 1 Six examples from Series of Speeding Car 51

Figure 2 The city rises, Umberto Boccioni, 1910-11 52

Figure 3 Revolt, Luigi Lussolo, 1911

Figure 4 Funeral of the Anarchist Galli, Carlo Carra, 1911

Figure 5 Dynamic Hieroglyphic of the Bal Tabarin, Gino Severini, 1912

Figure 6 First sketch of jacket 53

Figure 7 Second sketch of jacket 53

Figure 8 Third sketch of jacket

Figure 9 Forth sketch of jacket 53

Figure 10 Fifth sketch of jacket

Figure 11 Sketches of three pair of trousers

Figure 12 First sketch of jumpsuit

Figure 13 Second sketch of jumpsuit $\quad 54$

Figure 14 Sketch of vest

Figure 15 Sketch of coat

Figure 16 Sketch of two examples of bodices

Figure 17 Sketch of shirt

Figure 18 Sketch 01

Figure 19 Sketch $02 \quad 56$

Figure 20 Sketch $03 \quad 56$

Figure 21 Sketch 04

Figure 22 Sketch $05 \quad 56$

Figure 23 Sketch 06

Figure 24 Sketch 07(first sketch of suit)

Figure 25 Sketch 08(second sketch of suit) $\quad 58$

Figure 26 Sketch 09 (third sketch of suit) 
Figure 27 Sketch 10(forth sketch of suit) 58

Figure 28 Sketch 11 (fifth sketch of suit)

Figure 29 Sketch 12(sixth sketch of suit) 58

Figure 30 Sketch 13(seventh sketch of suit) $\quad 58$

Figure 31 Sketch $14 \quad 59$

Figure 32 Sketch $15 \quad 59$

Figure 33 Sketch $16 \quad 59$

Figure 34 Sketch 17

Figure 35 Sketch $18 \quad 59$

Figure 36 Sketch 19

Figure 37 Sketch $20 \quad 60$

Figure 38 Sketch 21

Figure 39 Sketch 22

Figure 40 Sketch 23

Figure 41 Sketch 24

Figure 42 Sketch $25 \quad 61$

Figure 43 Sketch $26 \quad 61$

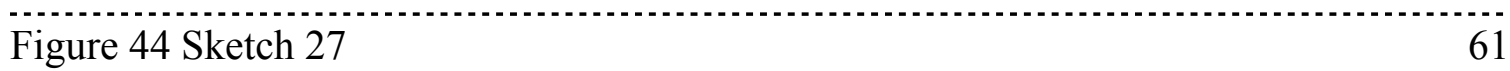

Figure 45 Sketch $28 \quad 61$

Figure 46 Sketch 29

Figure 47 Sketch $30 \quad 61$

Figure 48 Patternmaking of Basic jacket bodice $\quad 62$

Figure 49 Patternmaking of Basic sleeve

Figure 50 Patternmaking of Basic shirt bodice $\quad 62$

Figure 51 Patternmaking of Basic trousers

Figure 52 Patternmaking of Jacket 01

Figure 53 Patternmaking of Jacket 02

Figure 54 Patternmaking of Jacket 03

Figure 55 Patternmaking of Jacket $04 \quad 66$ 
Figure 56 Patternmaking of jumpsuit 01-1 67

Figure 57 Patternmaking of jumpsuit 01-2 68

Figure 58 Patternmaking of Upper garments $01 \& 02$

Figure 59 Patternmaking of Trousers 70

Figure 60 Colour swatches of main material: Cotton canvas with rubber coated on the back $\quad 71$

Figure 61 Colour swatches of substitutional materials 71

Figure 62 Giocomo Balla, 'Futurist Suit', 1918

Figure 63 Fortunato Depero, Waistcoat, 1924. Private collection, Milan 72

Figure 64 Fortunato Depero and F.T. Marinetti wearing Futurist vests designed by

Depero. 1924

Figure 65 The overall looks for Futurismo Now 73

Figure 66 Full front and back views of first outfit for Futurismo Now

Figure 67 Two Detail views of first outfit for Futurismo Now

Figure 68 Full front and back views of second outfit for Futurismo Now 76

Figure 69 Two Detail views of second outfit for Futurismo Now 77

Figure 70 Full front and back views of third outfit for Futurismo Now 78

Figure 71 Two Detail views of third outfit for Futurismo Now 79

Figure 72 Full front and back views of Forth outfit for Futurismo Now 80

Figure 73 Two Detail views of Forth outfit for Futurismo Now 81

Figure 74 Full front and back views of fifth outfit for Futurismo Now 82

Figure 75 Two Detail views of fifth outfit for Futurismo Now 83 


\section{Appendix 1}

\section{Futurist Manifesto of Men's Clothing, 1913}

We Futurists, in those brief gaps between out great struggles for renewal, have spent the time discussing, as is our wont, very many subjects. For quite some time now we have been convinced that today's clothes, while they may be somewhat simplified to suit certain modern requirements, are still atrociously passéist.

WE MUST DESTROY ALL PASSÉIST CLOTHES, and everything about them which is tight-fitting, colourless, funereal, decadent, boring and unhygienic. As far as materials are concerned, we must abolish: wishywashy, pretty-pretty, gloomy, and neutral colours, along with patterns composed of lines, checks and spots. In cut and design: the abolition of static lines, all uniformities such as ridiculous turn-ups, vents, etc. Let us finish with the humiliating and hypocritical custom of wearing mourning. Our crowded streets, our theatres and cafés are all imbued with a depressingly funereal tonality, because clothes are made only to reflect the gloomy and dismal moods of today's passéists.

WE MUST INVENT FUTURIST CLOTHES, hap-hap-hap-hap-happy clothes, daring clothes with brilliant colours and dynamic lines. They must be simple, and above all they must be made to last for a short time only in order to encourage industrial activity and to provide constant and novel enjoyment for our bodies. USE materials with forceful MUSCULAR colours - the reddest of reds, the most purple of purples, the greenest of greens, intense yellows, orange, vermilion - and SKELETON tones of white, grey and black. And we must invent dynamic designs to go with them and express them in equally dynamic shapes: triangles, cones, spirals, ellipses, circles, etc. The cut must incorporate dynamic and asymmetrical lines, with the left-hand sleeve and left side of a jacket in circles and the right in squares. And the same for waistcoats, stockings, topcoats, etc. The consequent merry dazzle produced by our clothes in the noisy streets, which we shall have transformed with our FUTURIST architecture, will mean that everything will begin to sparkle like the glorious prism of a jeweller's gigantic glass-front, and all around us we shall find acrobatic blocks of colours set out like the following wordshapes:

Coffeecornhou Rosegreebastocap transpomotocar legcutshop blueblackwhitehouses aerocigarend skyroofliftyellight anomoviesphot barbebbenpurp.

Human beings, until now, have dressed (more or less) in black mourning.

We are fighting against:

(a) the timidity and symmetry of colours, colours which are arranged in wishy-washy patterns of idiotic spots and stripes;

(b) all forms of lifeless attire which make man feel tired, depressed, miserable and sad, and which restrict movement producing a triste wanness; 
(c) so-called 'good taste' and harmony, which weaken the soul and take the spring out of the step.

We want Futurist clothes to be comfortable and practical

Dynamic

Aggressive

Shocking

Energetic

Violent

Flying (i.e. giving the idea of flying, rising and running)

Peppy

Joyful

Illuminating (in order to have light even in the rain)

Phosphorescent

Lit by electric lamps.

Pattern changes should be available by pneumatic dispatch; in this way anyone may change his clothes according to the needs of mood.

Available modifications will include:

Loving

Arrogant

Persuasive

Diplomatic

Unitonal

Multitonal

Shaded

Polychrome

Perfumed.

As a result we shall have the necessary variety of clothes, even if the people of a given city lack the imagination themselves.

The happiness of our Futurist clothes will help to spread the kind of good humour aimed at by my great friend Palazzeschi in his manifesto against sadness.

Giacomo Bella

Translation: Robert Brain 


\section{Appendix 2}

Giacomo Balla The Antineutral Dress A Futurist Manifesto (Milan: Direzione del Movimento Futurista, 11 September 1914)

We will glorify war, the world's only hygiene.

Marinetti (First Futurist Manifesto, 20 Feb 20 1909)

Long live Asinari di Bernezzo!

Marinetti (First Futurist Evening, Teatro Lirico, Feb 1910)

Humanity always dressed itself with calm, fear, caution, and indecision, wearing forever the mourning dress, the mantle, or the cape. The man's body was always diminished by neutral hues and shades, debased by wearing black, stifled by belts, imprisoned by draperies.

Until now, men wore clothes of static color and forms - that is, solemnly draped, heavy, uncomfortable, and sacerdotal. They were expressions of timidity, melancholy, and slavery, the negation of the muscular life, which suffocated in an antihygienic passeisme of weighty fabrics and boring, effeminate, or decadent halftones. Moods and rhythms of depressing, distressing, and funereal peace.

Today, we want to abolish:

1.All of the neutral, "soft," shaded, fancy, gray, and humiliating colors.

2.All pedantic, professorial, and Teutonic hues and forms. Stripes, checks, and diplomatic little dots.

3.The mourning clothes, which are not adapted even for the pallbearers. The heroic dead should not be wept over but celebrated by wearing red clothes.

4.The mediocrity of equilibrium, the so-called good taste and the so-called harmony of hues and forms that check our enthusiasm and slow us down.

5.The symmetrical cut and the static lines that tire, depress, grieve, and chain the muscles, the uniformity of lapels. The useless buttons. The starched collars and cuffs.

We futurists want to liberate our race from any neutrality from fearful and quietist indecision, from nihilist pessimism, and from nostalgic, softening Romantic inertia.

We want to color Italy with Futurist audacity and risks, and finally give Italians joyful and bellicose clothing.

Futurist clothing will therefore be:

1.Aggressive, able to increase the courage of the strong and to disrupt the sensitivity of cowards.

2.Nible; that is, able to increase the flexibility of the body and to favor its surge to fight, to race or to charge.

3.Dynamic, with the dynamic colors and patterns of fabrics triangle, cones, spirals, ellipses, circles able to inspire the love of danger, of speed and assault, the hatred of peace and of immobility.

4.Simple and comfortable; that is, easy to put on and off, adapted for rifle shooting, for crossing rivers, and for swimming.

5.Hygienic; that is, cut in such a way that every pore of the skin can easily breathe during long marches and steep climbs. 
6.Joyful. Fabrics with enthusiastic colors and iridescence. Use muscular colors, very vivid violets, the bloodred, the intense turquoise, the greenest of green, vivid yellows, very colored oranges, and vermilions.

7.Illuminating. Phosphorescent fabrics that can ignite temerity in a timorous crowd, spread light when it rains, and lift the melancholic dullness of twilight in the streets and in the hearts.

8.Strong-willed. Violent, imperative, and impetuous colors and design like the ranks on a battlefield.

9.Asymmetrical. For example, the tips of sleeves and fronts of jackets will be round on the left side and square on the right side. The same for waistcoats, trousers, and cardigans.

10.Short-lived, so that we may incessantly renew the pleasure and liveliness of our body and patronize the fabric industry.

11.Variable, by means of modifiers (applique pieces of cloth of differing size, thickness, and color) that can be attached at will to any part of the dress with pneumatic buttons. Thus, anyone can invent a new dress at any instant. The modifier could be arrogant, shocking, explosive, decisive, warlike, etc.

The futurist hat will be asymmetrical and of joyful, aggressive colors. Futurist shoes will be dynamic, distinctive from one another in form and color, and cheerfully able to kick all neutalists.

The juxtaposition of black and yellow will be totally prohibited.

One thinks and acts as one dresses. Since neutrality is the synthesis of all passeismes today, we Futurists dress in these antineutral outfits as flags - that is, joyfully bellicose clothing.

Only the gouty ones will disapprove.

All the Italian youth will recognize in us, who wear them, the Futurist banners for our great, URGENT, necessary war.

If the government does not take off its passeist dress of fear and indecision, we will double, we WILL MUTIPLY BY TEN AND BY A HUNDRED the red of the tricolor flag, in which we dress.

Milan, 11 September 1914

Approved enthusiastically by the Directorate of the Futurist Movement and by all of the Italian Futurist groups. 
Figure1. Six examples from Series of Speeding Car, Giacomo Balla, 1912-14 (Hulten)

Figure 1-1. Speeding Car, 1912 (Earilest)(75)

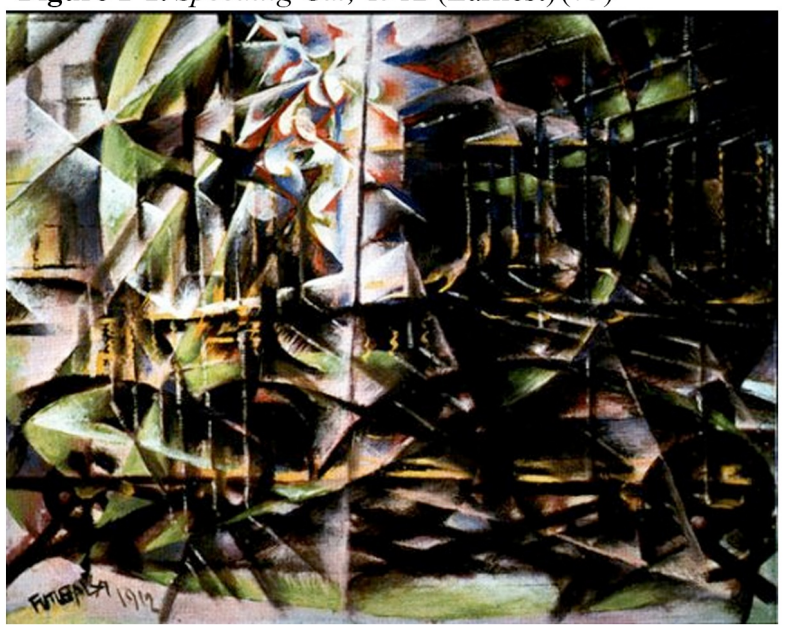

(77)

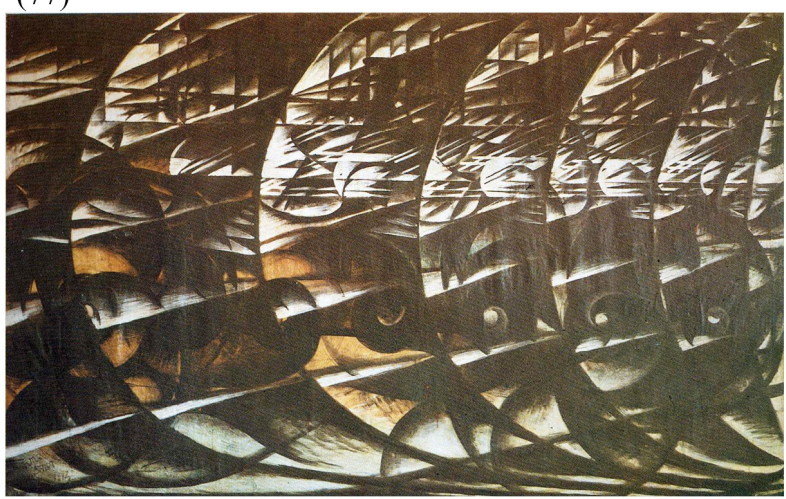

(83)

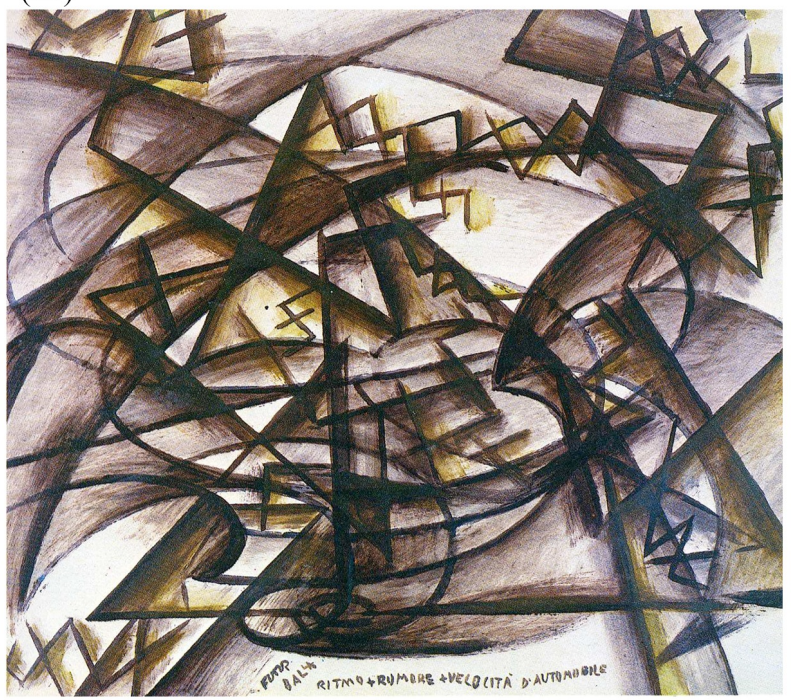

(82)

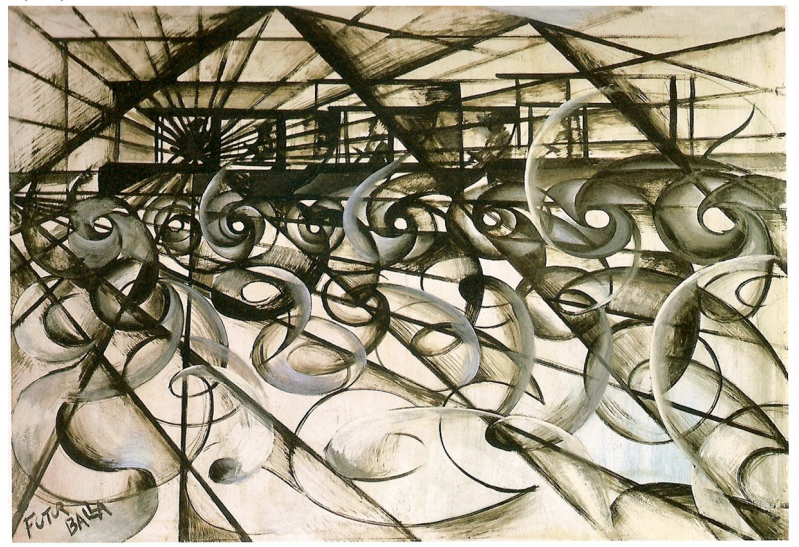

(78)

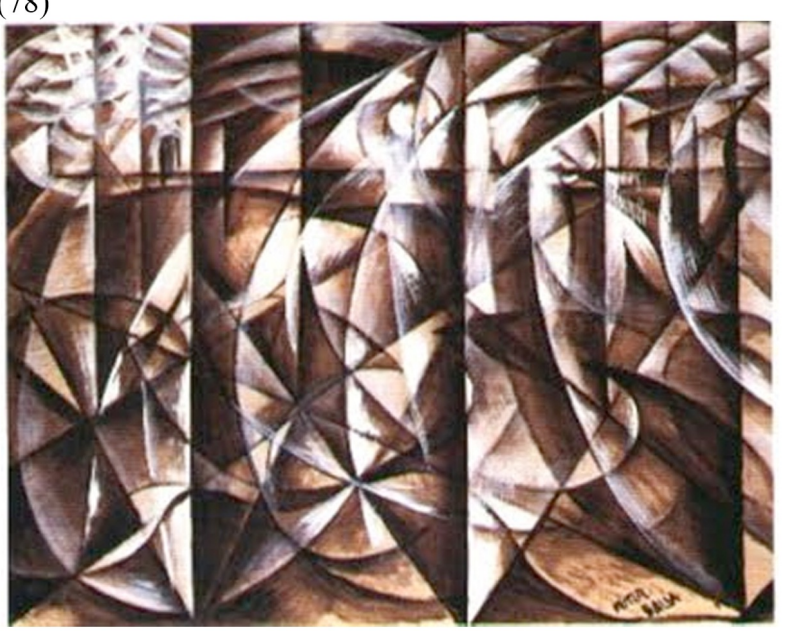

Figure1-2. Speeding Car, 1914 (Latest) (84)

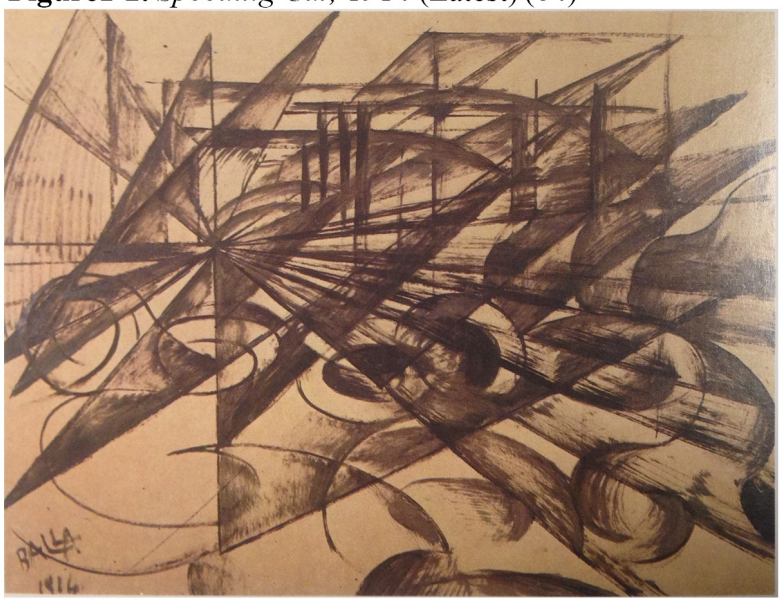




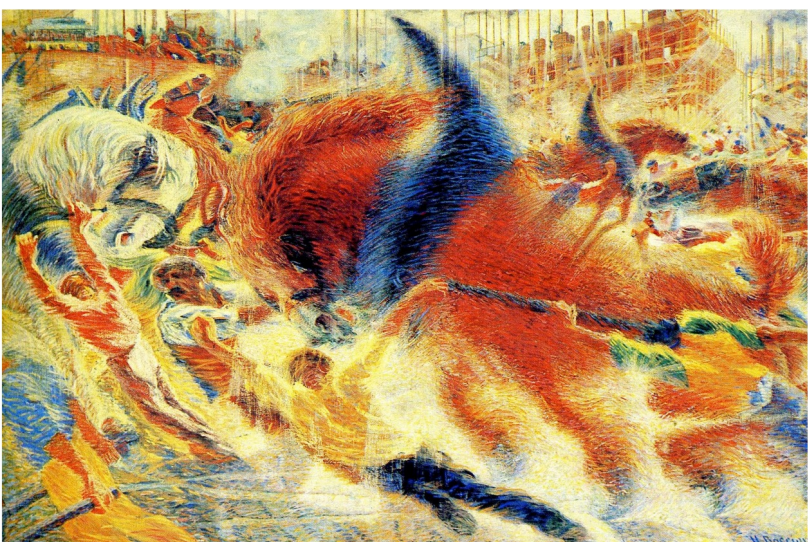

Figure 2. The City Rises, Umberto Boccioni, 1910-11 (Hulten 119)

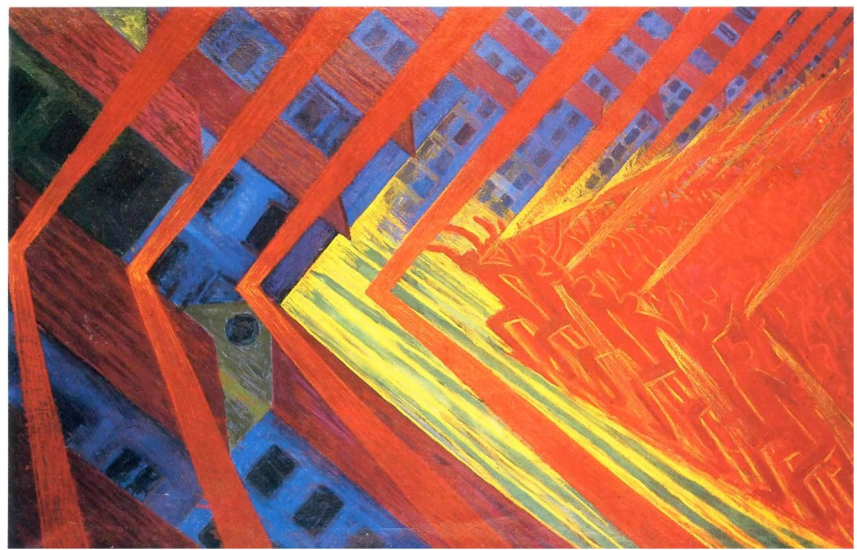

Figure 3. Revolt, Luigi Russolo, 1911 (Hulten 206)

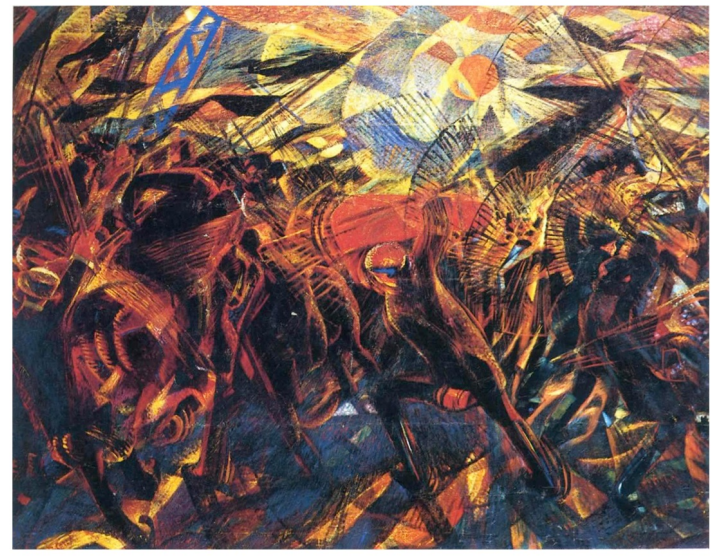

Figure 4. Funeral of the Anarchist Galli, Carlo Carra, 1911 (Hulten 153)

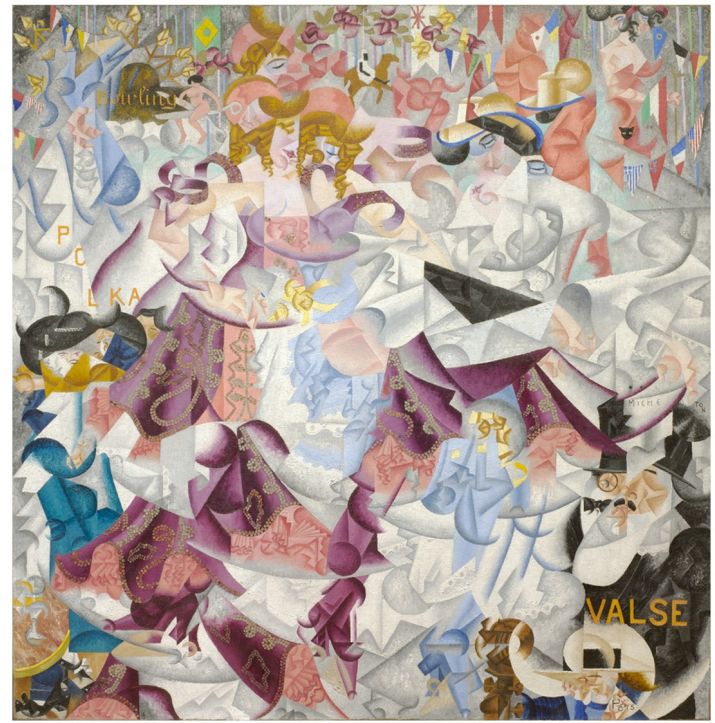

Figure 5. Dynamic Hieroglyphic of the Bal Tabarin, Gino Severini, 1912 
Figure 6. First sketch of jacket
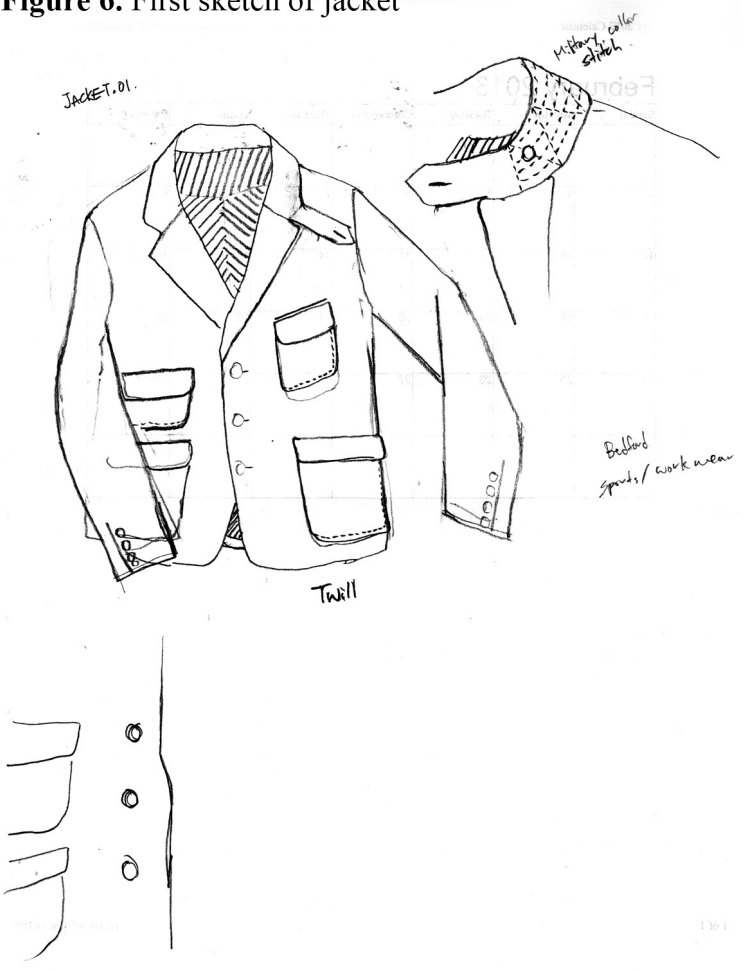

Figure 7. Second sketch of jacket

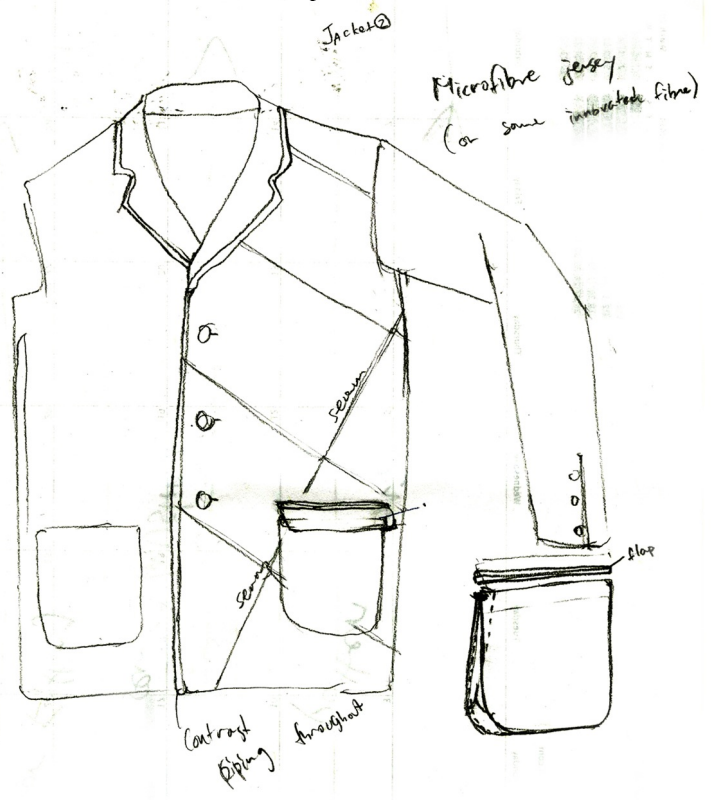

Figure 8. Third sketch of jacket

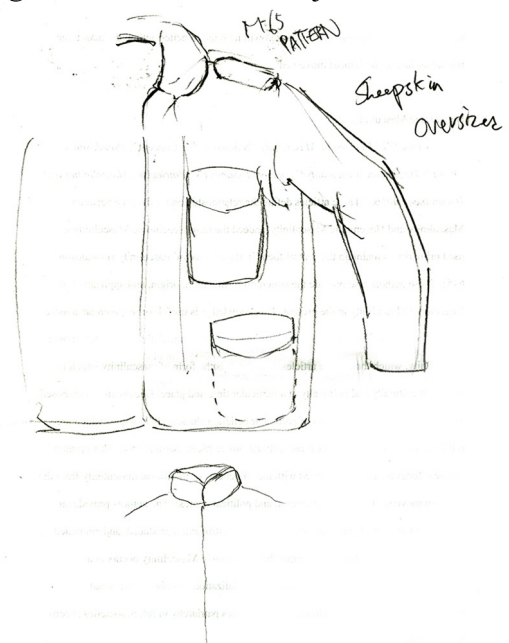

Figure 9. Forth sketch of jacket
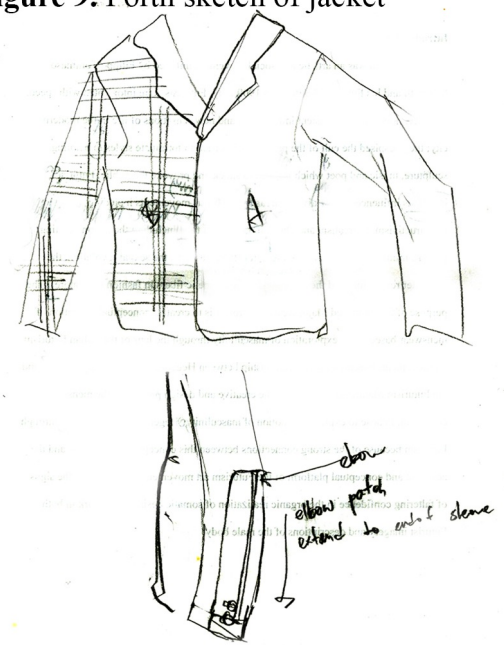

Figure 10. Fifth sketch of jacket
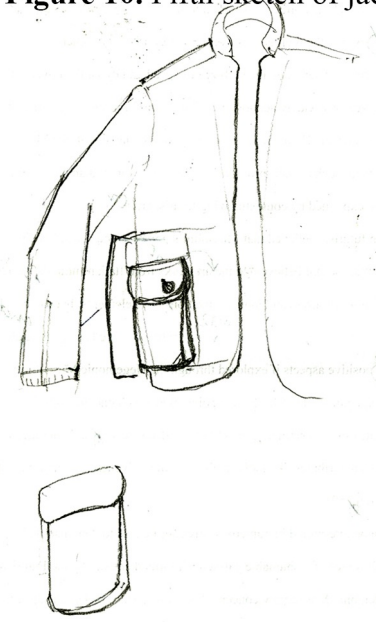
Figure 11. Sketches of three pair of trousers

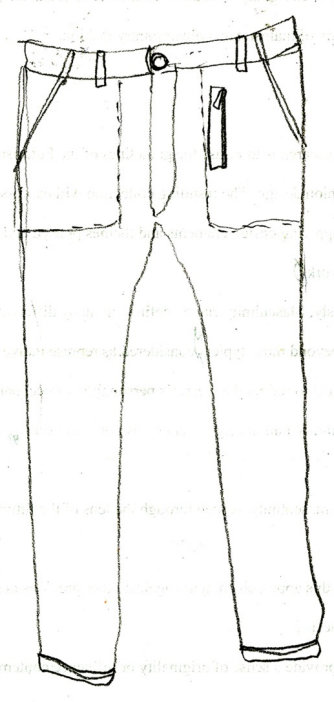

Figure 12. First sketch of jumpsuit

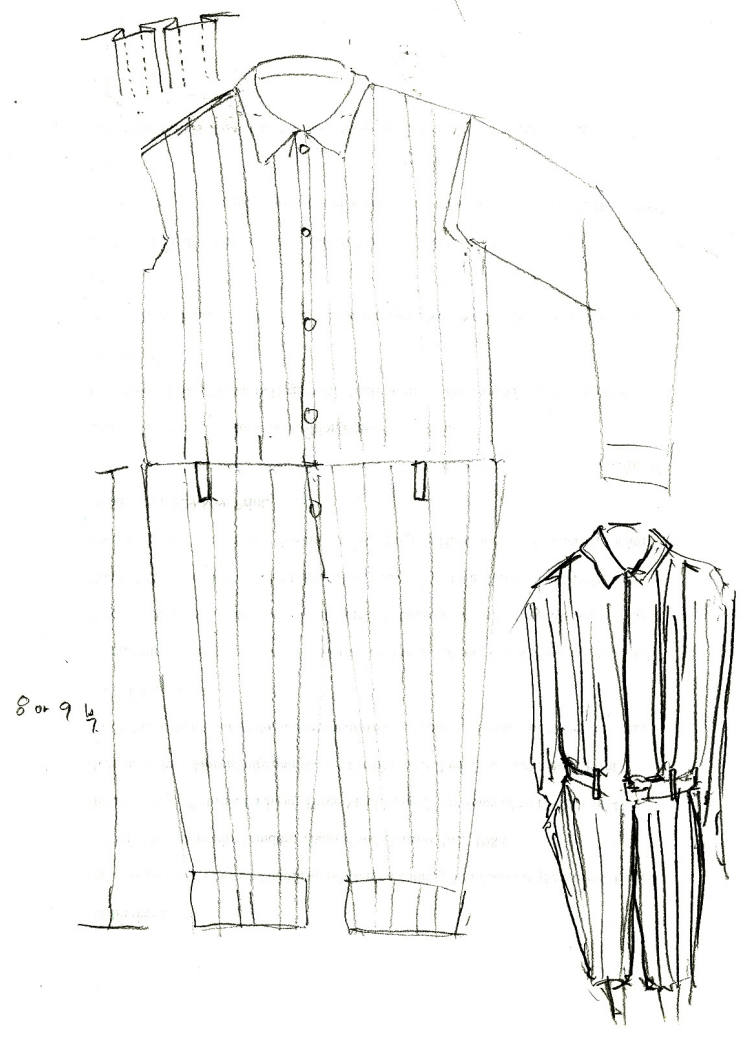

Figure 13. Second sketch of jumpsuit

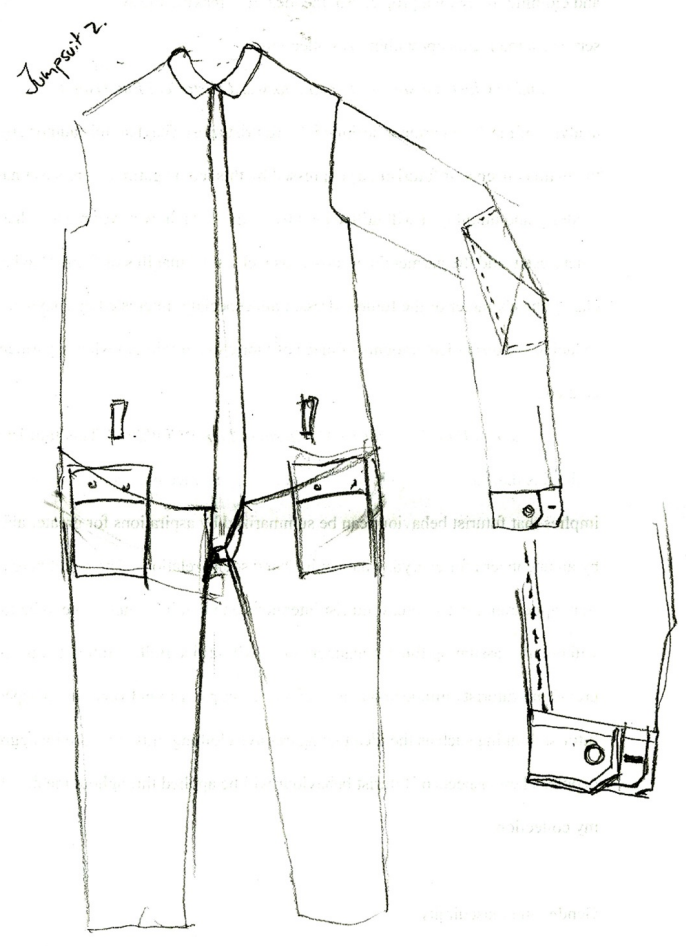


Figure 14. Sketch of yest
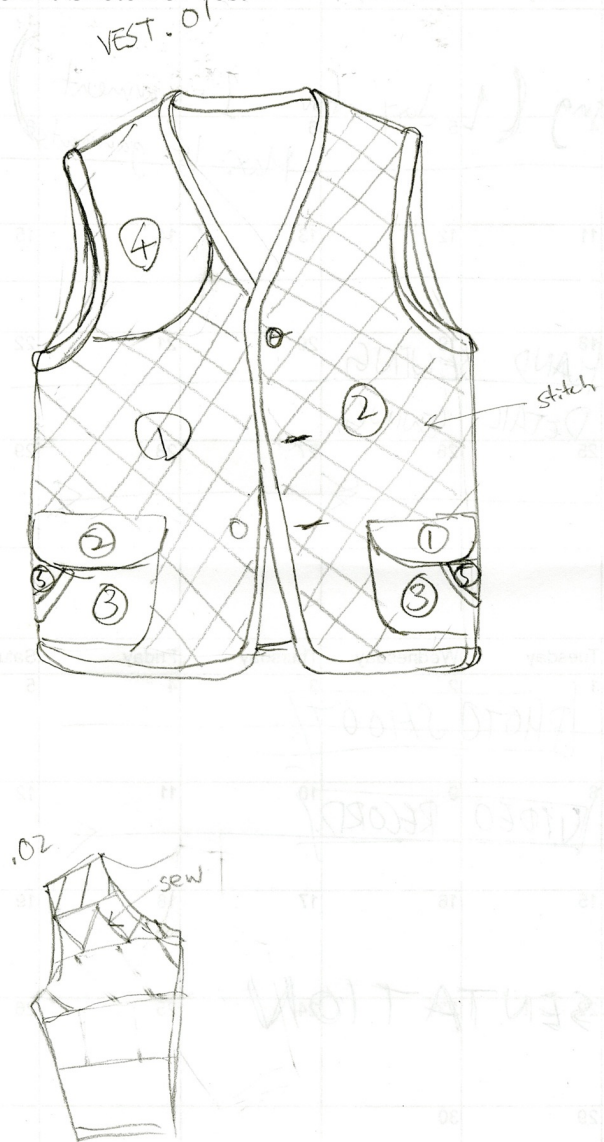

Figure 16. Sketch of two example of bodices

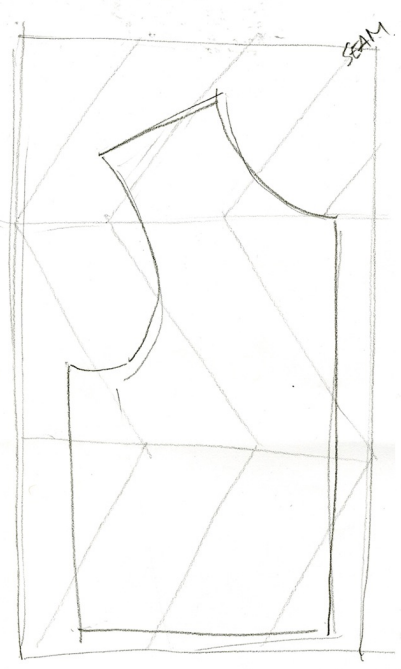

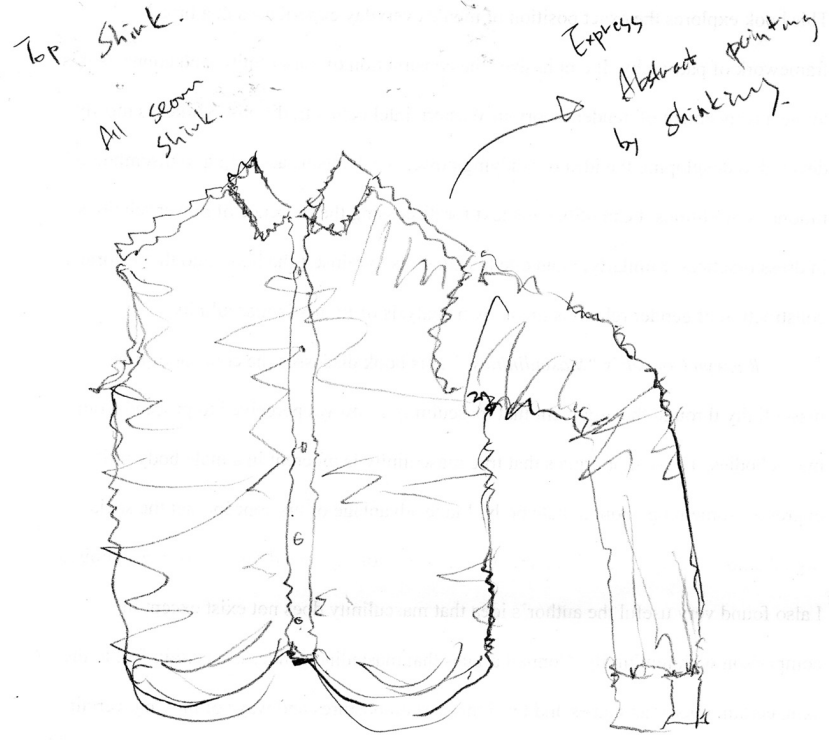

Figure 17. Sketch of shirt

Figure 15. Sketch of coat

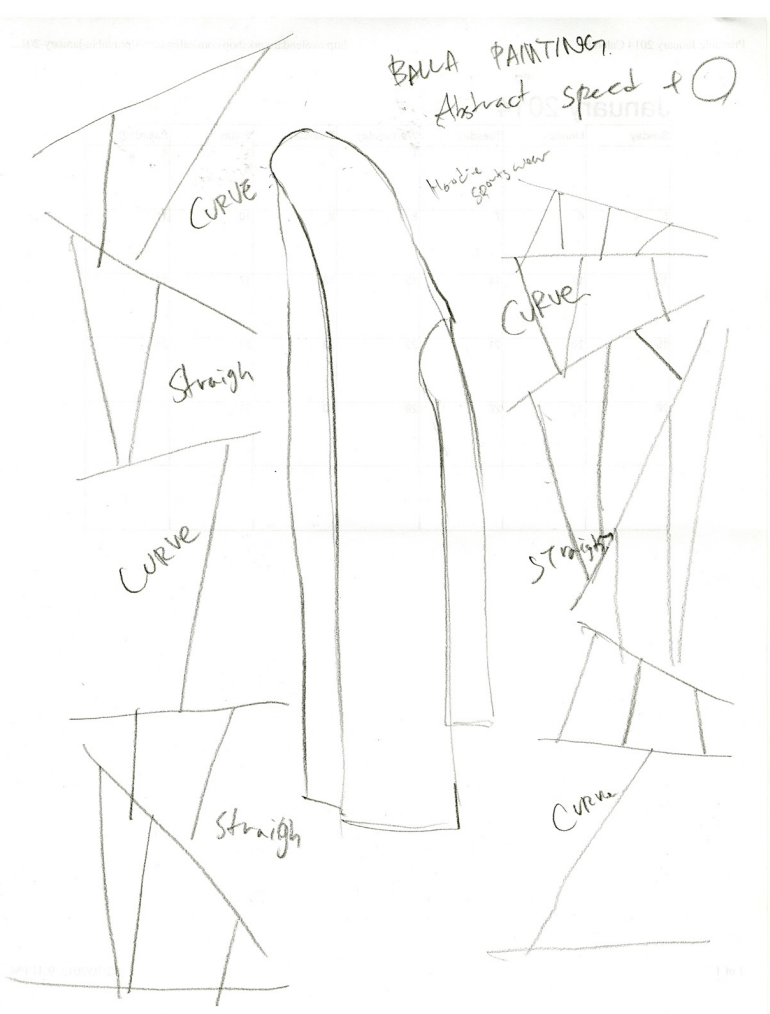




\section{GROUP OF DISCARED SIX SKETCHES}

Figure 18. Sketch 01

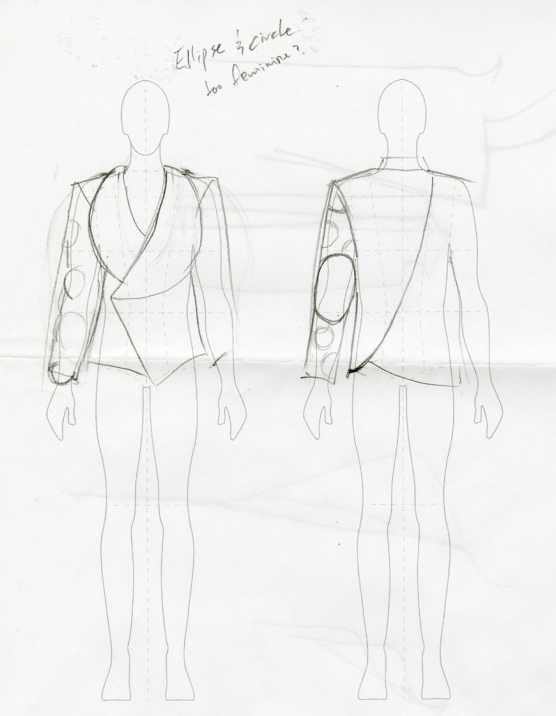

Figure 21. Sketch 04

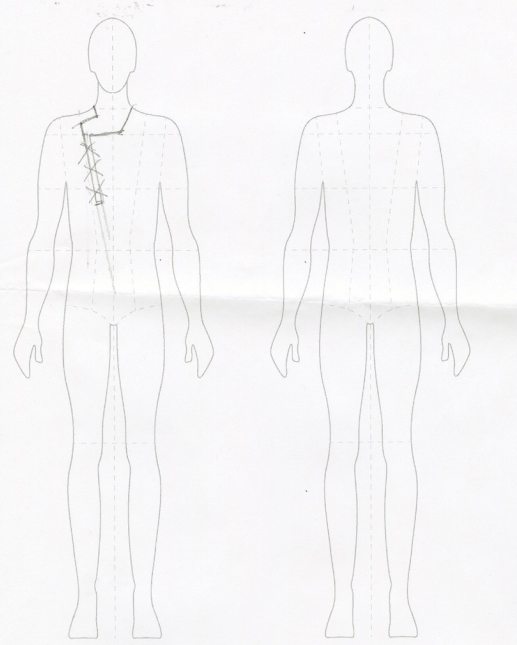

Figure 19. Sketch 02

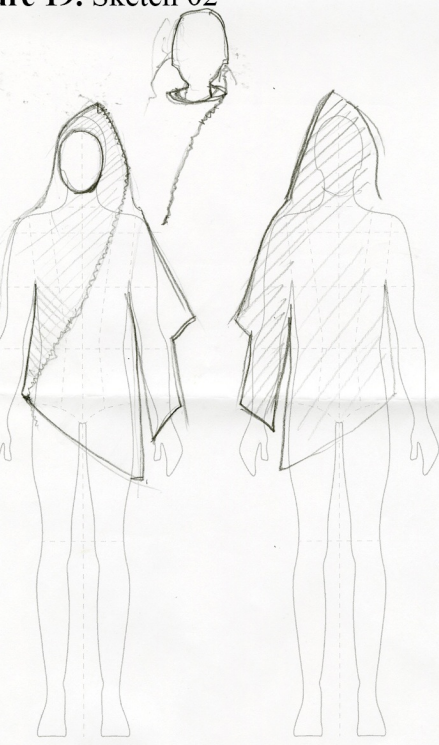

Figure 22. Sketch 05
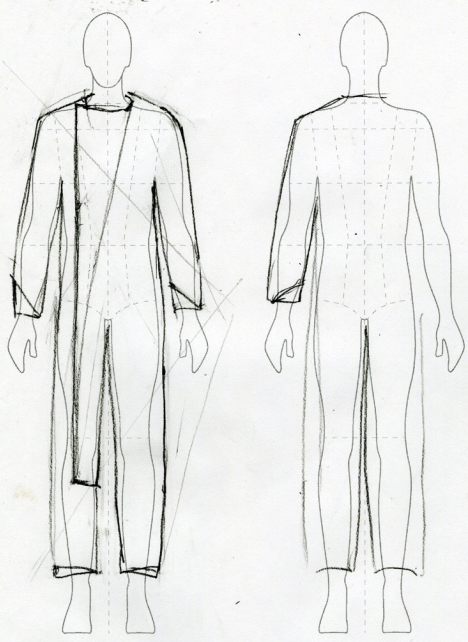

Figure 20. Sketch 03

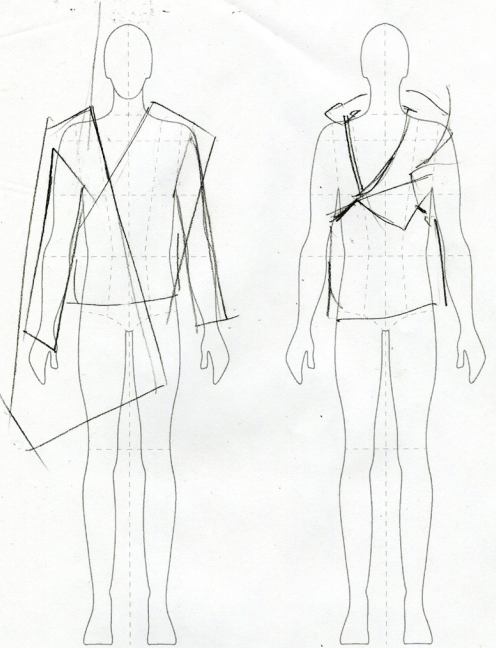

Figure 23. Sketch 06
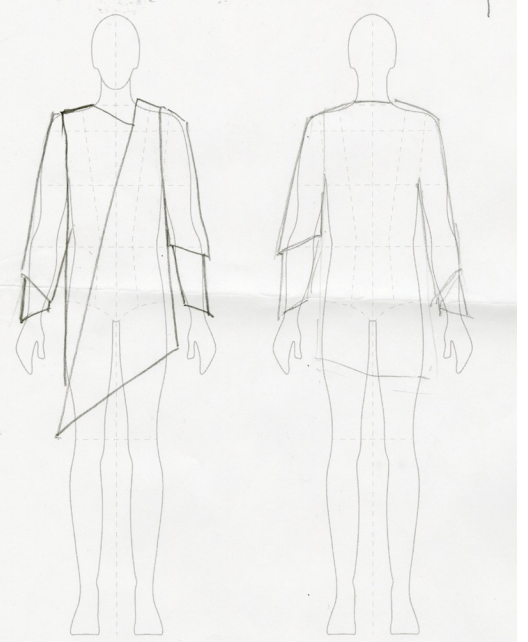
Figure 24. Sketch 07 (first sketch of suit)

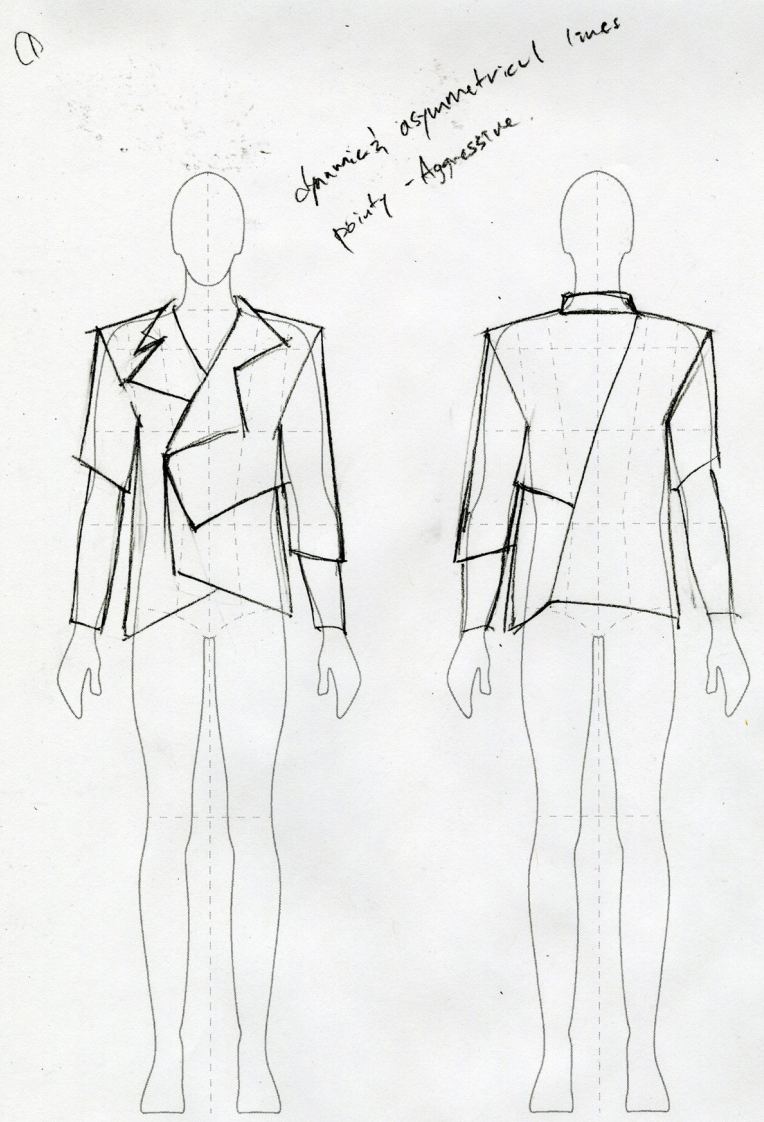


Figure 25. Sketch 08

(second sketch of suit)
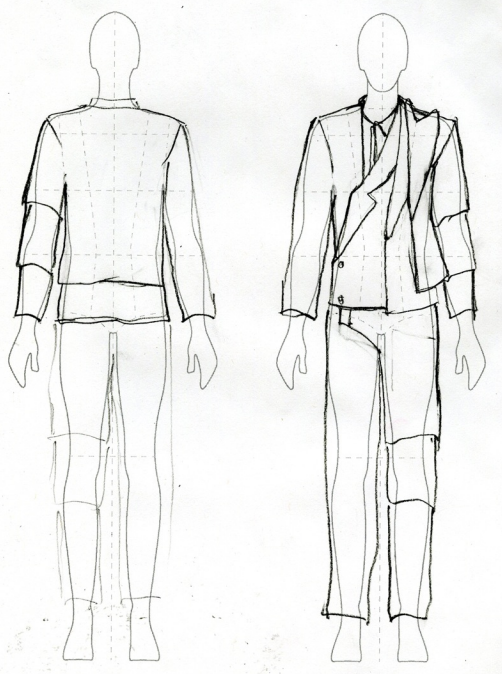

Figure 26. Sketch 09

(third sketch of suit)

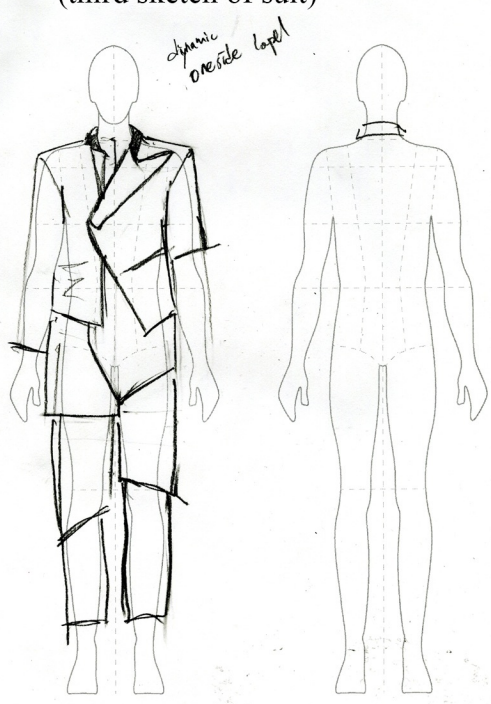

Figure 27. Sketch 10

(forth sketch of suit)
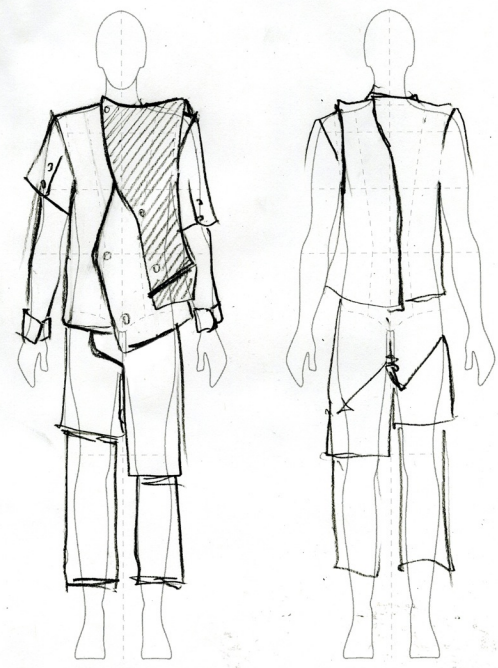

Figure 28. Sketch 11

(fifth sketch of suit)

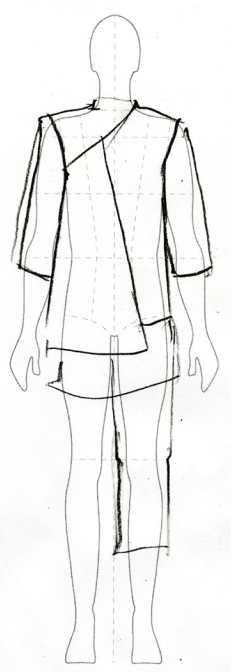

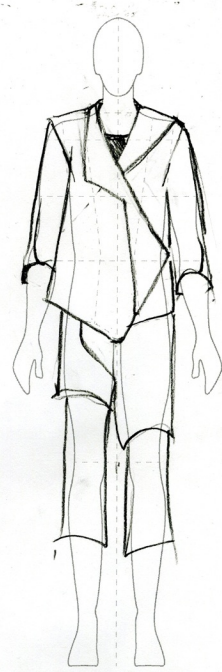

Figure 29. Sketch 12

(sixth sketch of suit)

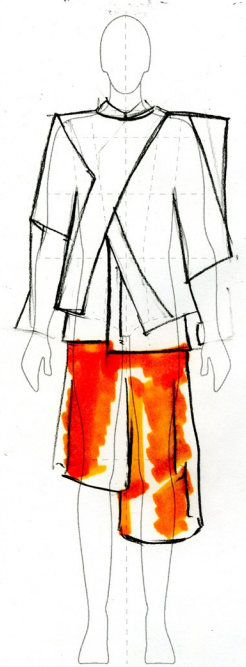

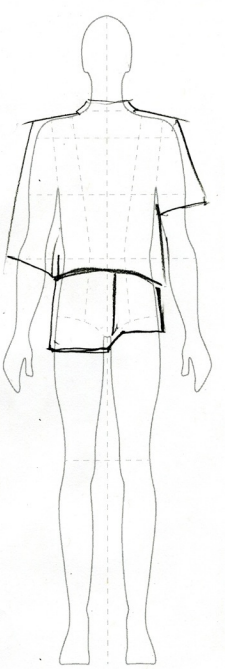

Figure 30. Sketch 13 (seventh sketch of suit)

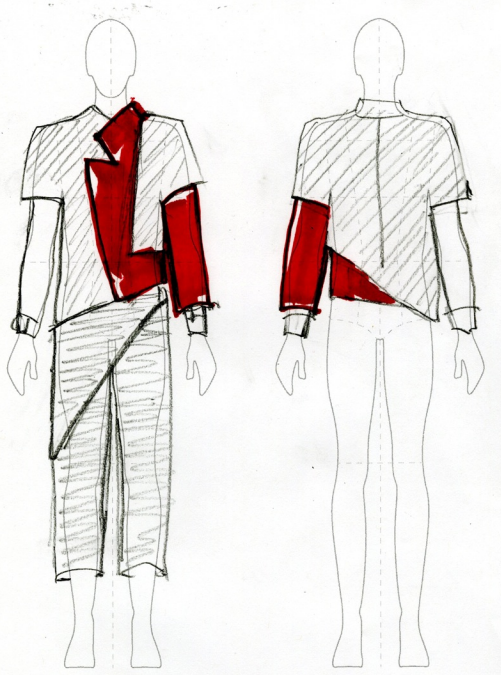


Figure 31. Sketch 14

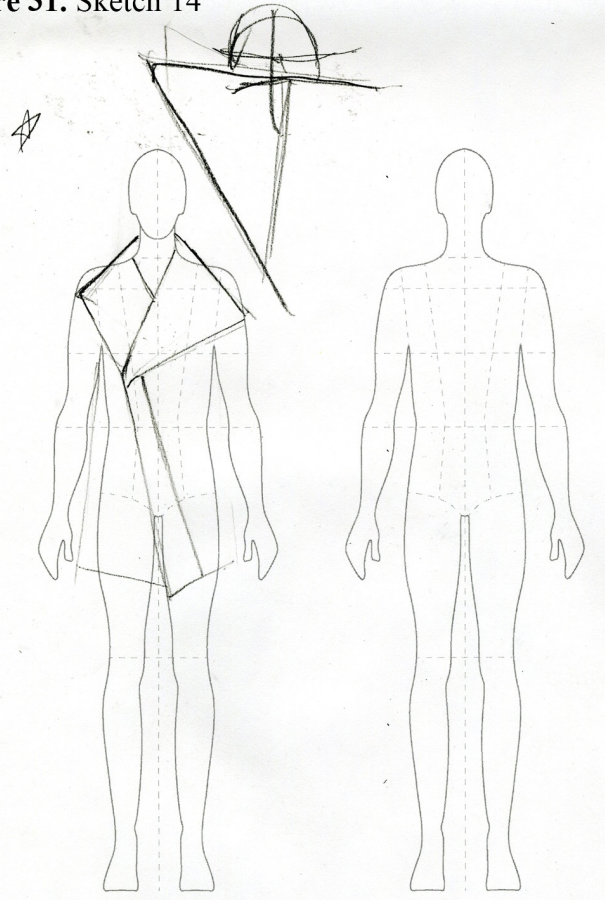

Figure 32. Sketch 15

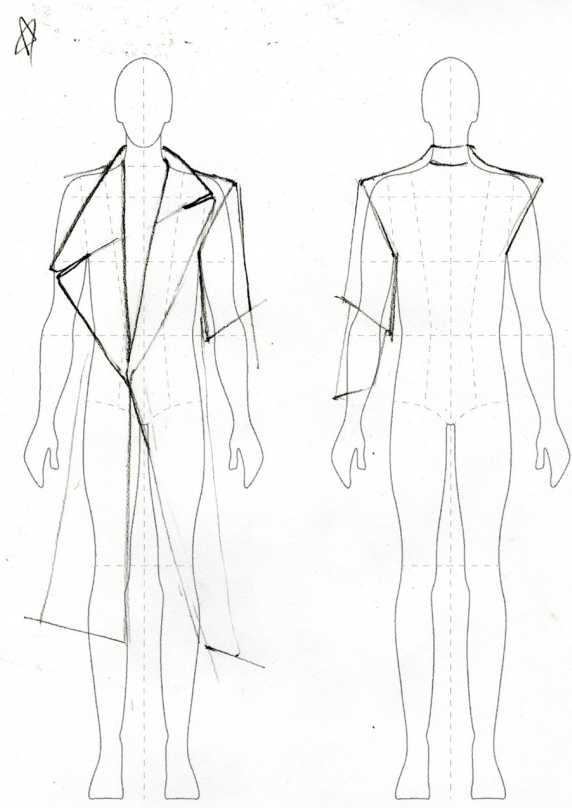

Figure 33. Sketch 16

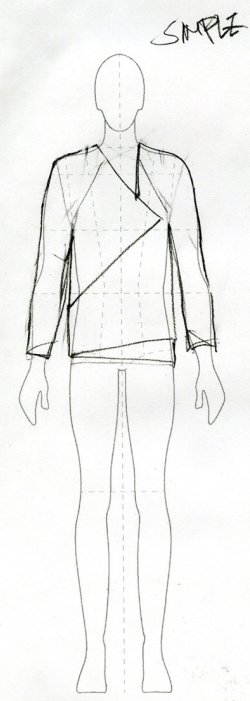

Figure 34. Sketch 17

Simple

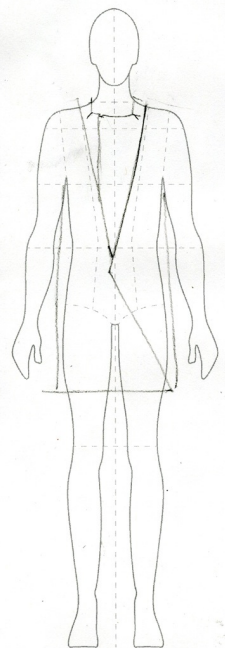

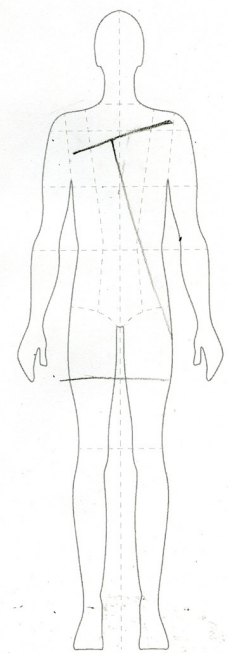

Figure 35. Sketch 18

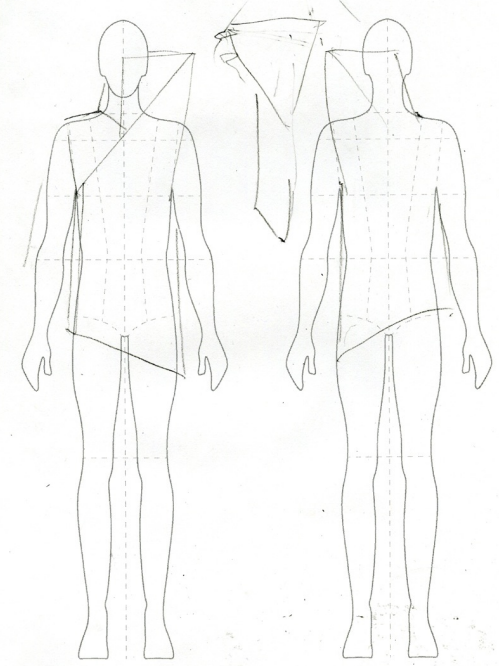


Figure 36. Sketch 19

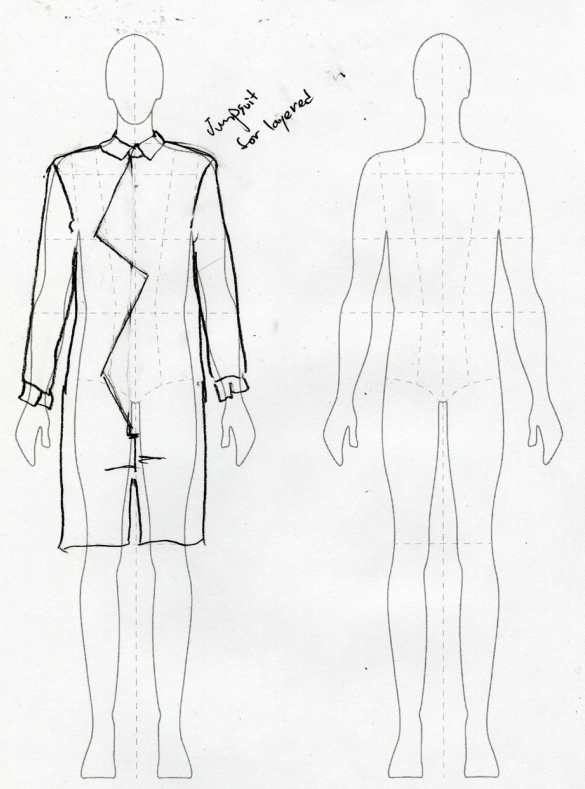

Figure 37. Sketch 20

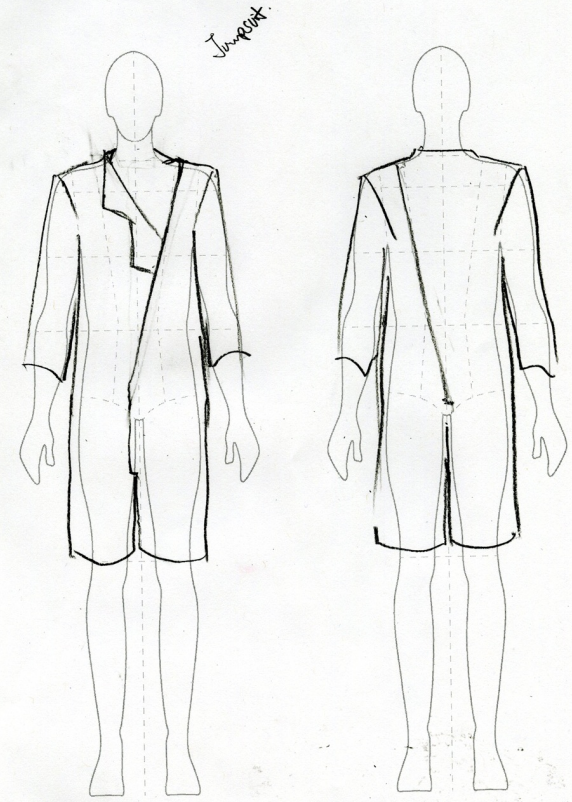

Figure 38. Sketch 21

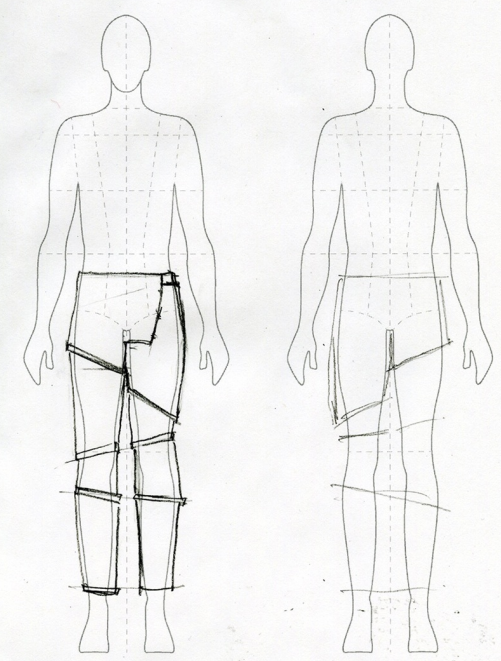

Figure 39. Sketch 22

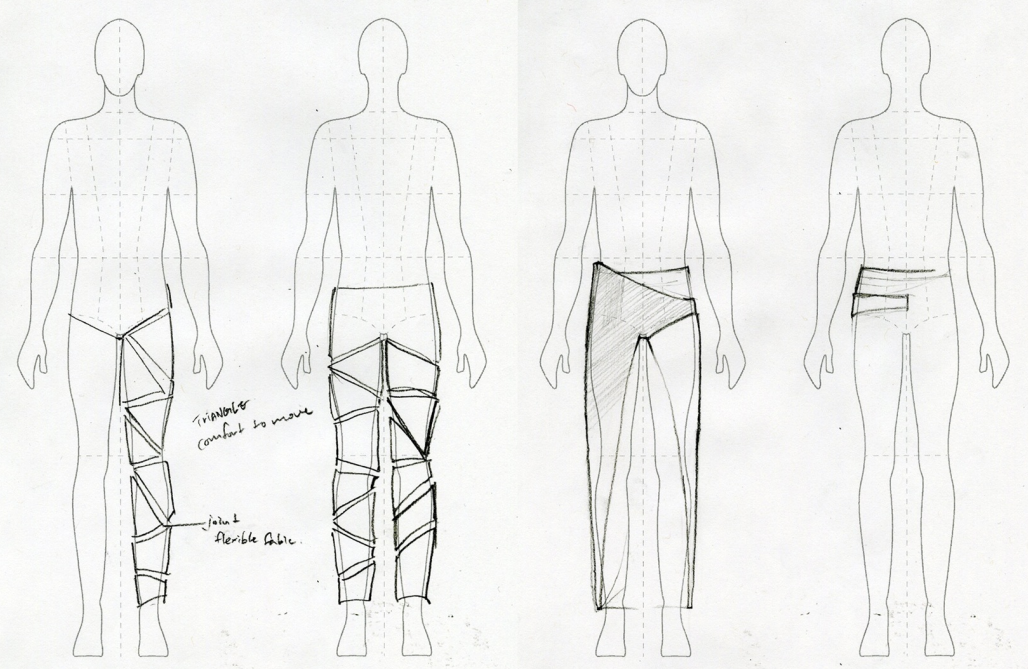

Figure 40. Sketch 23 
Figure 41. Sketch 24

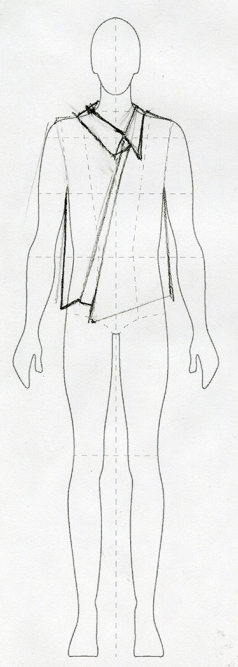

Figure 44. Sketch 27
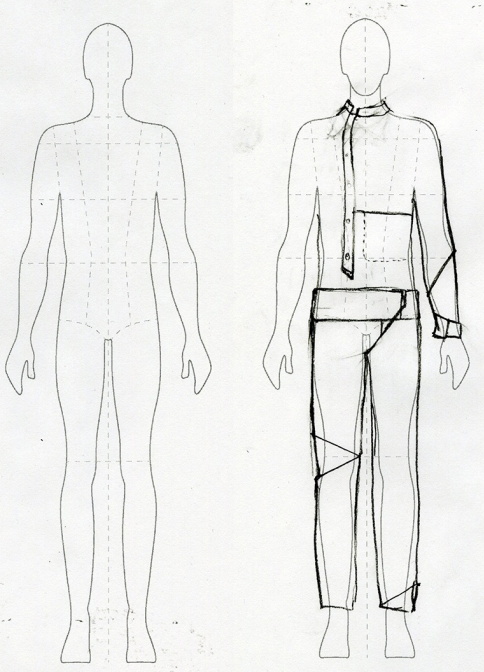

Figure 43. Sketch 26

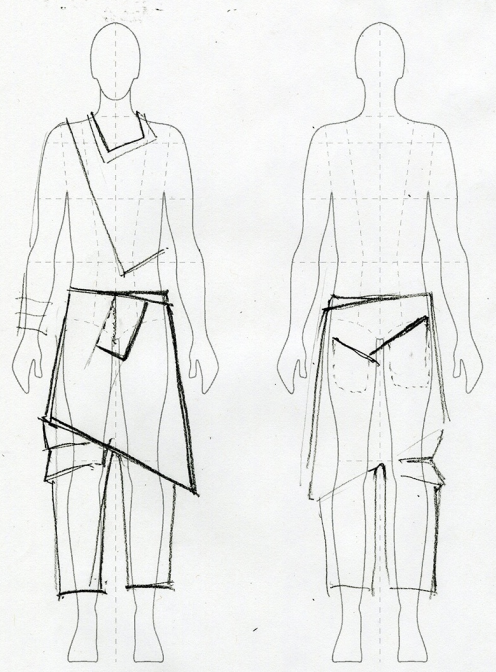

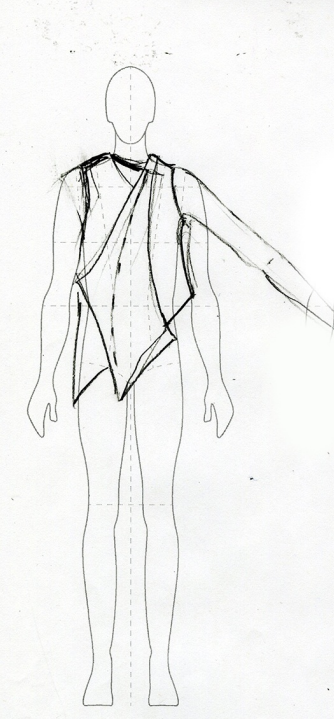

Figure 45. Sketch 28

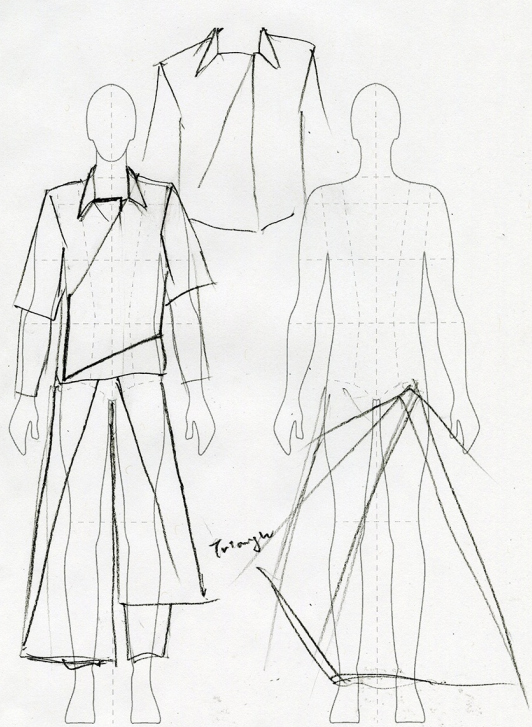

Figure 46 Sketch 29

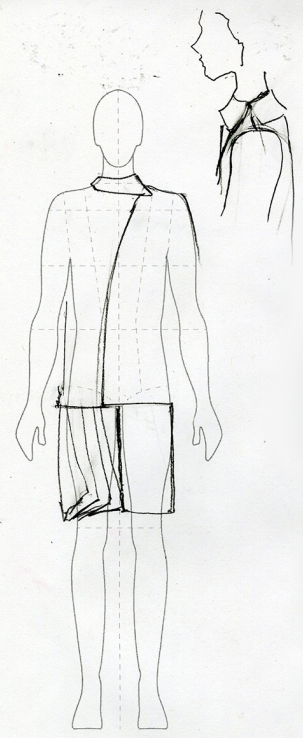

Figure 47. Sketch 30

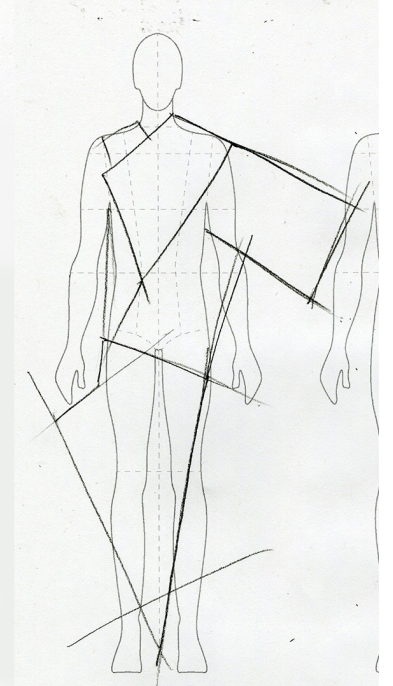

(8) 


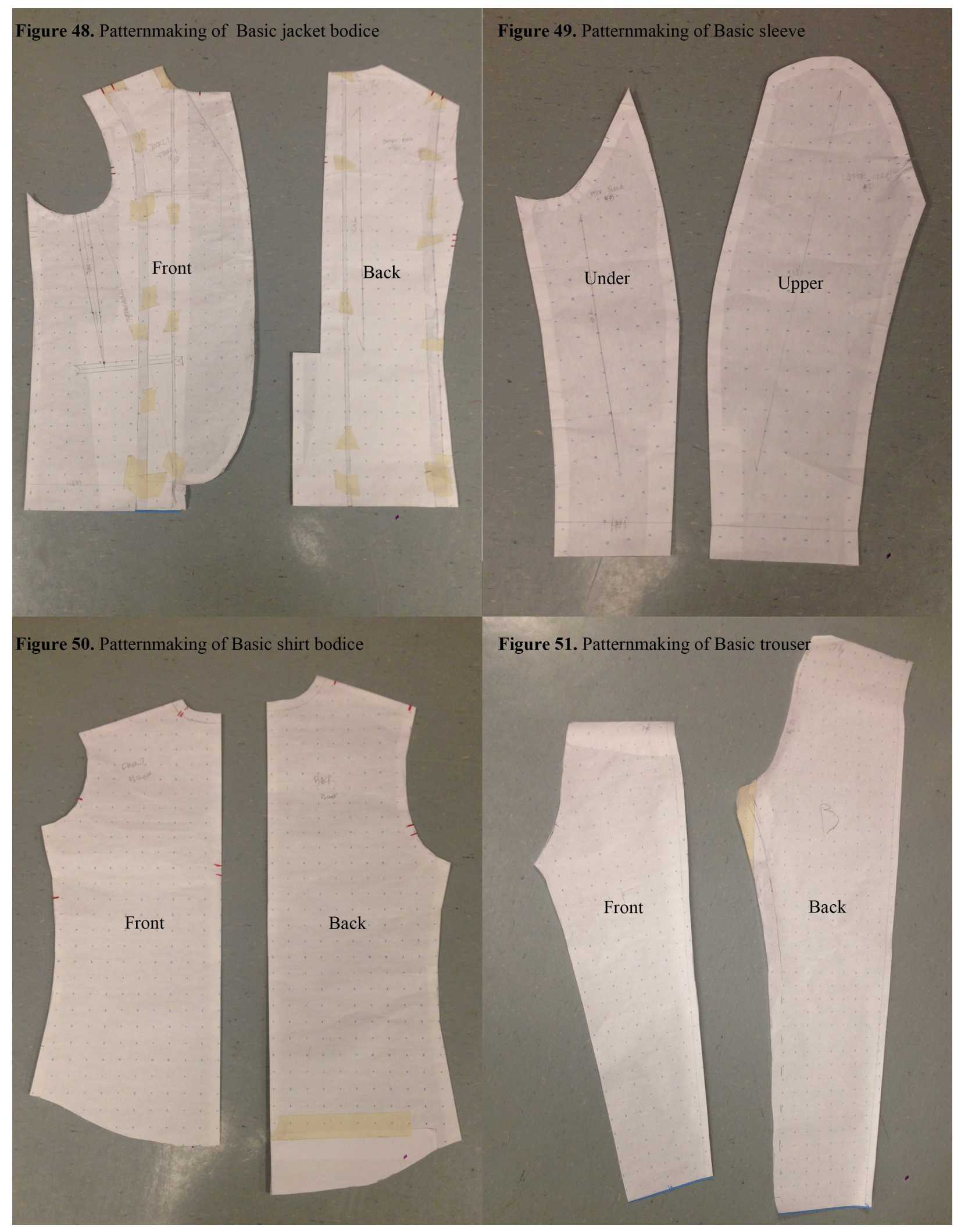




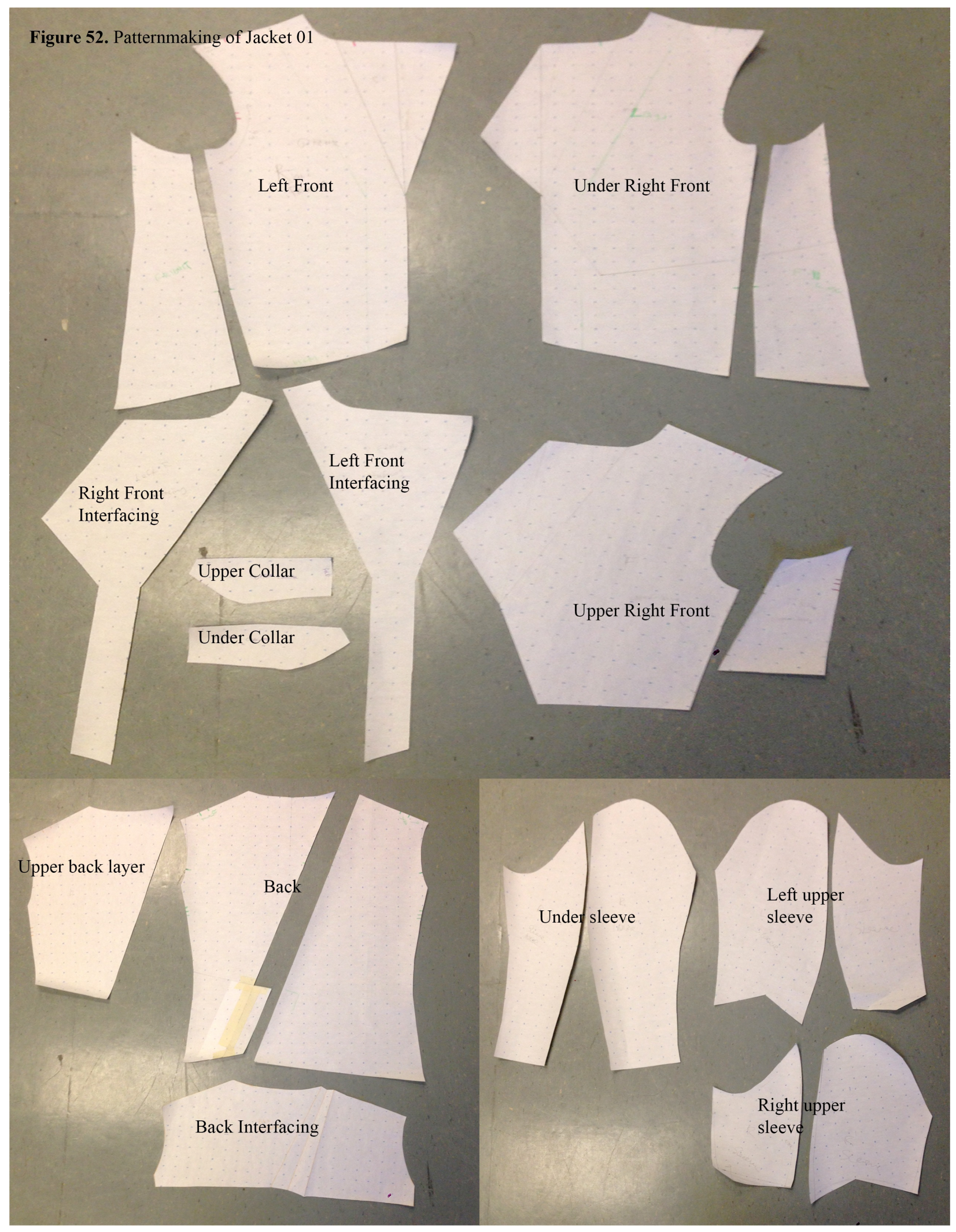




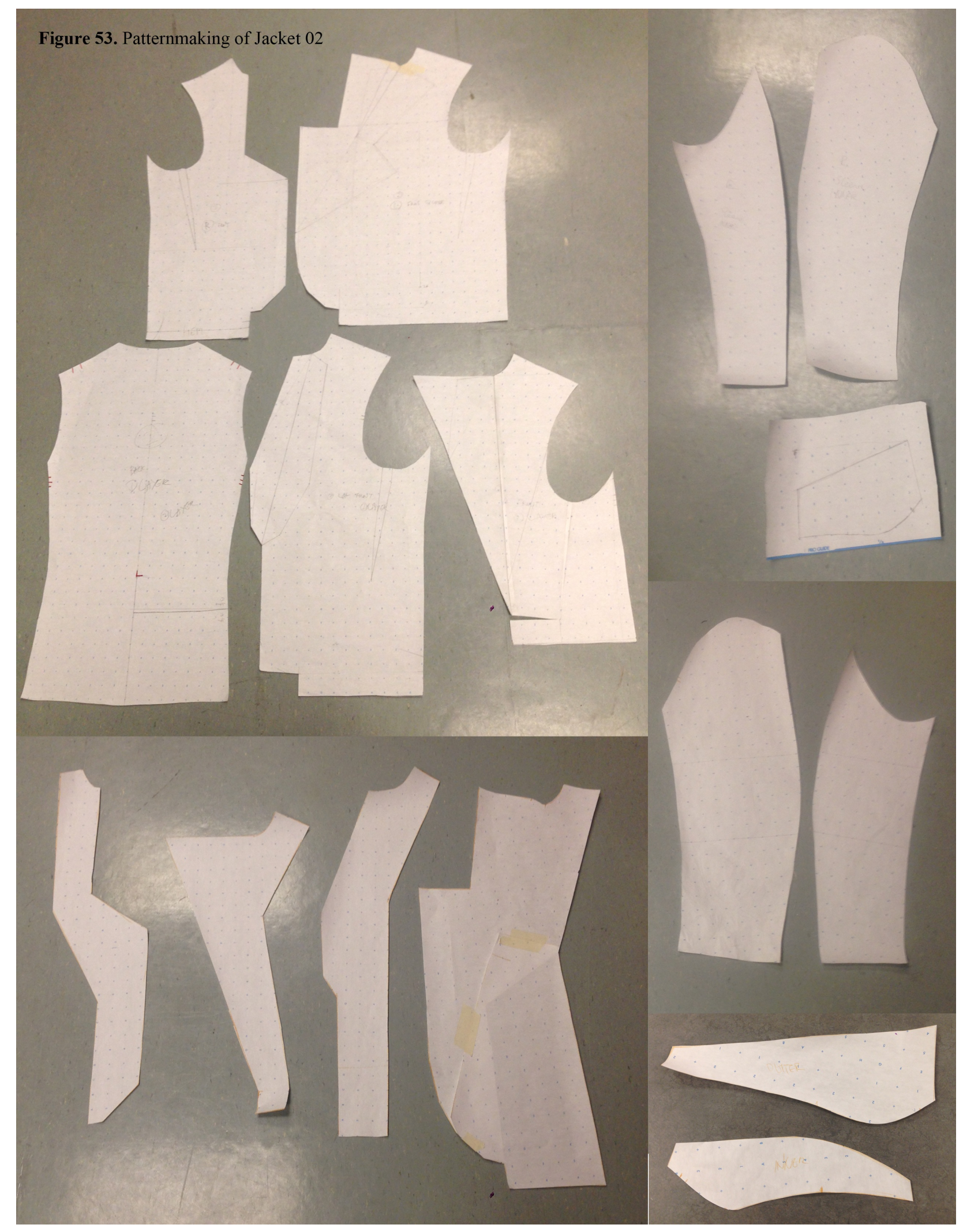


Figure 54. Patternmaking of Jacket 03

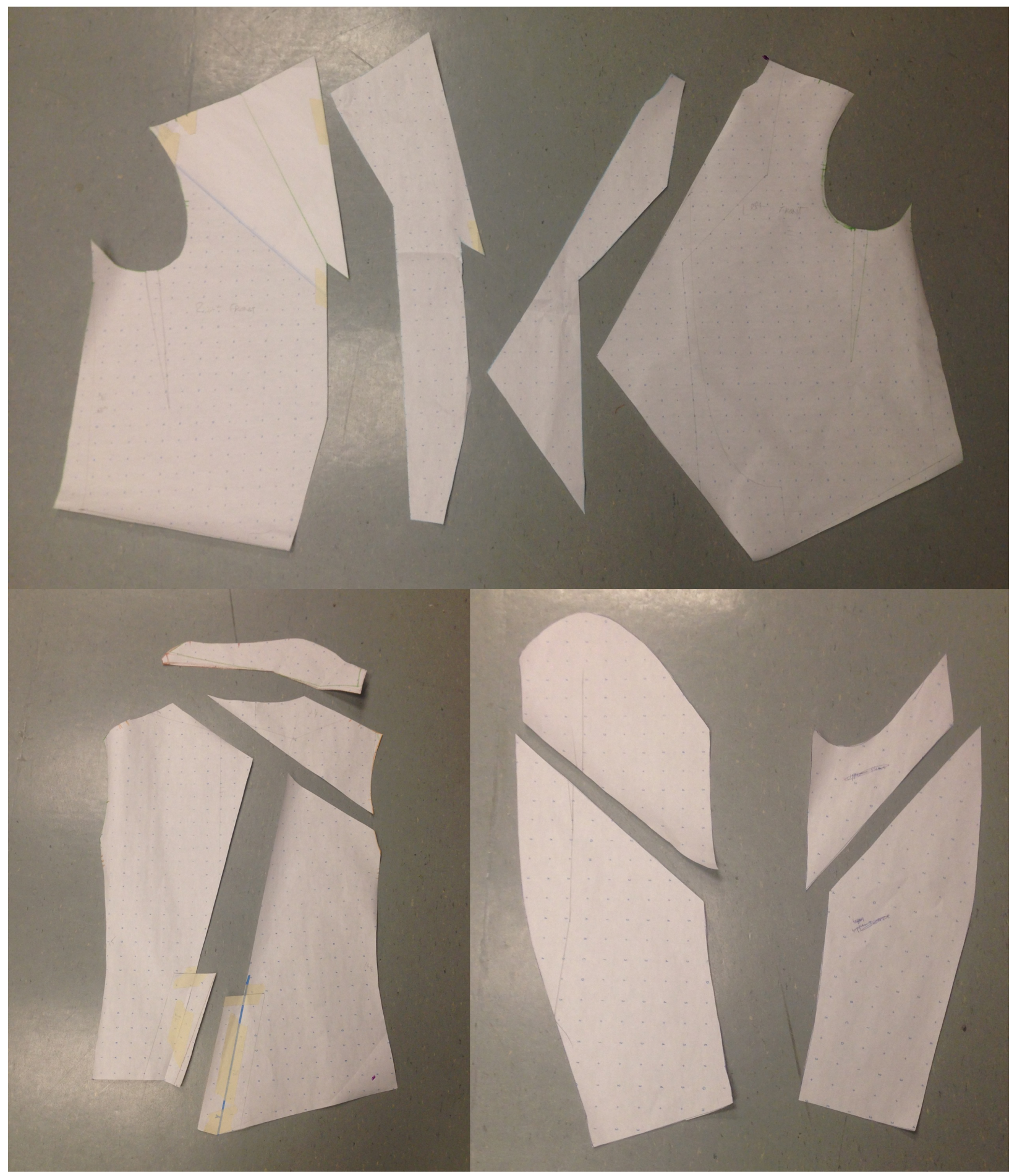


Figure 55. Patternmaking of Jacket 04

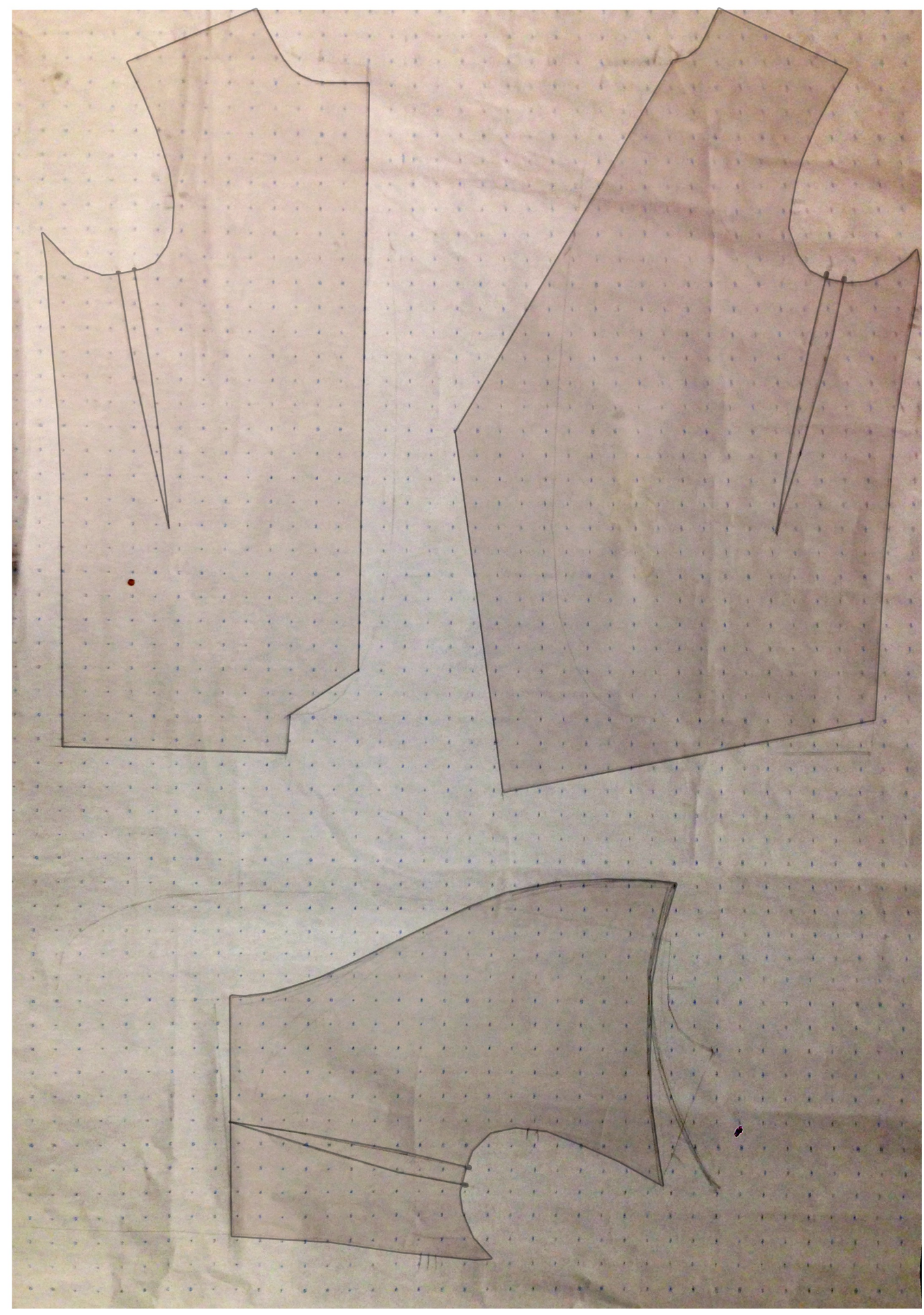


Figure 56. Patternmaking of Jumpsuit

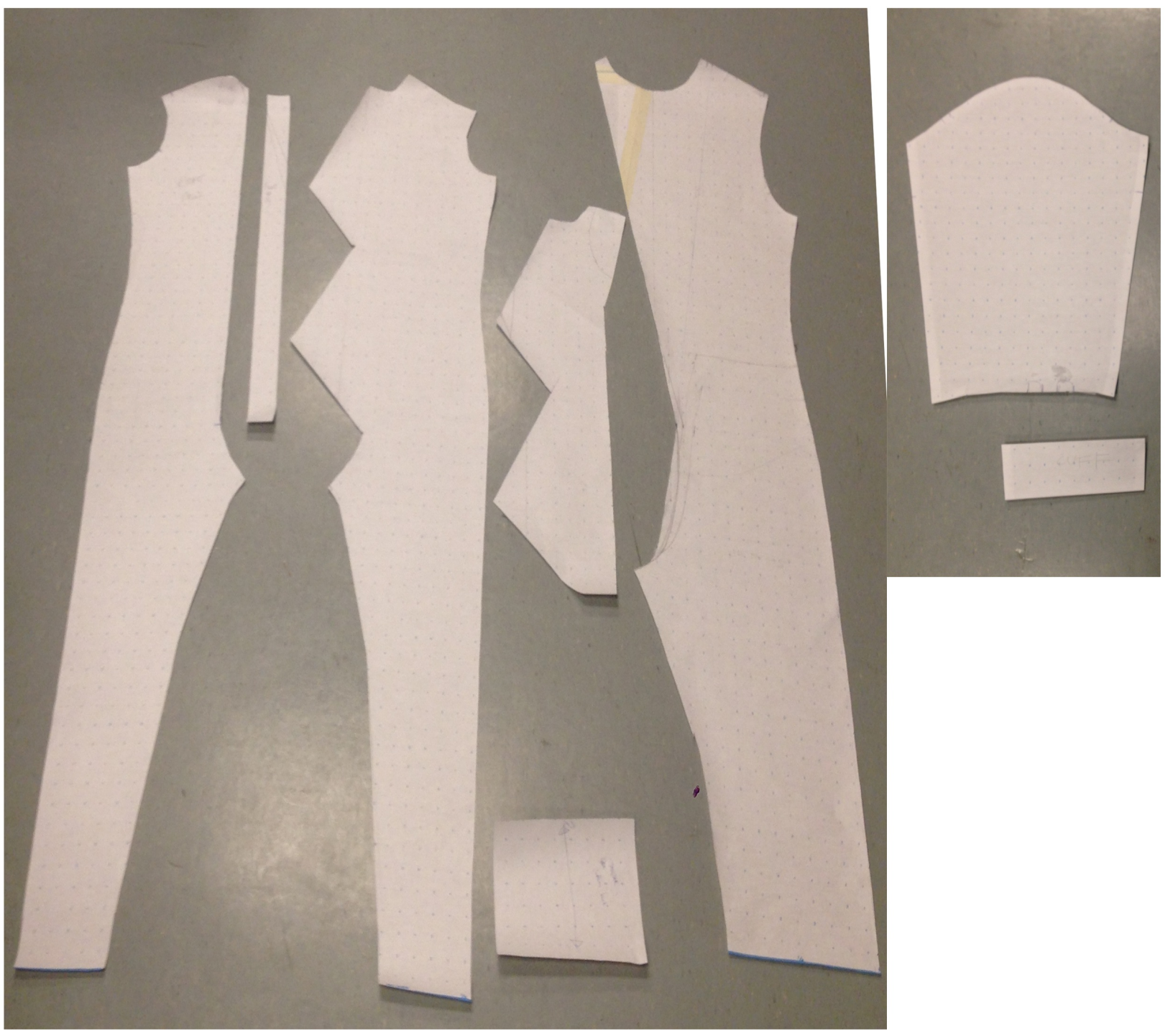


Figure 57. Patternmaking of Jumpsuit

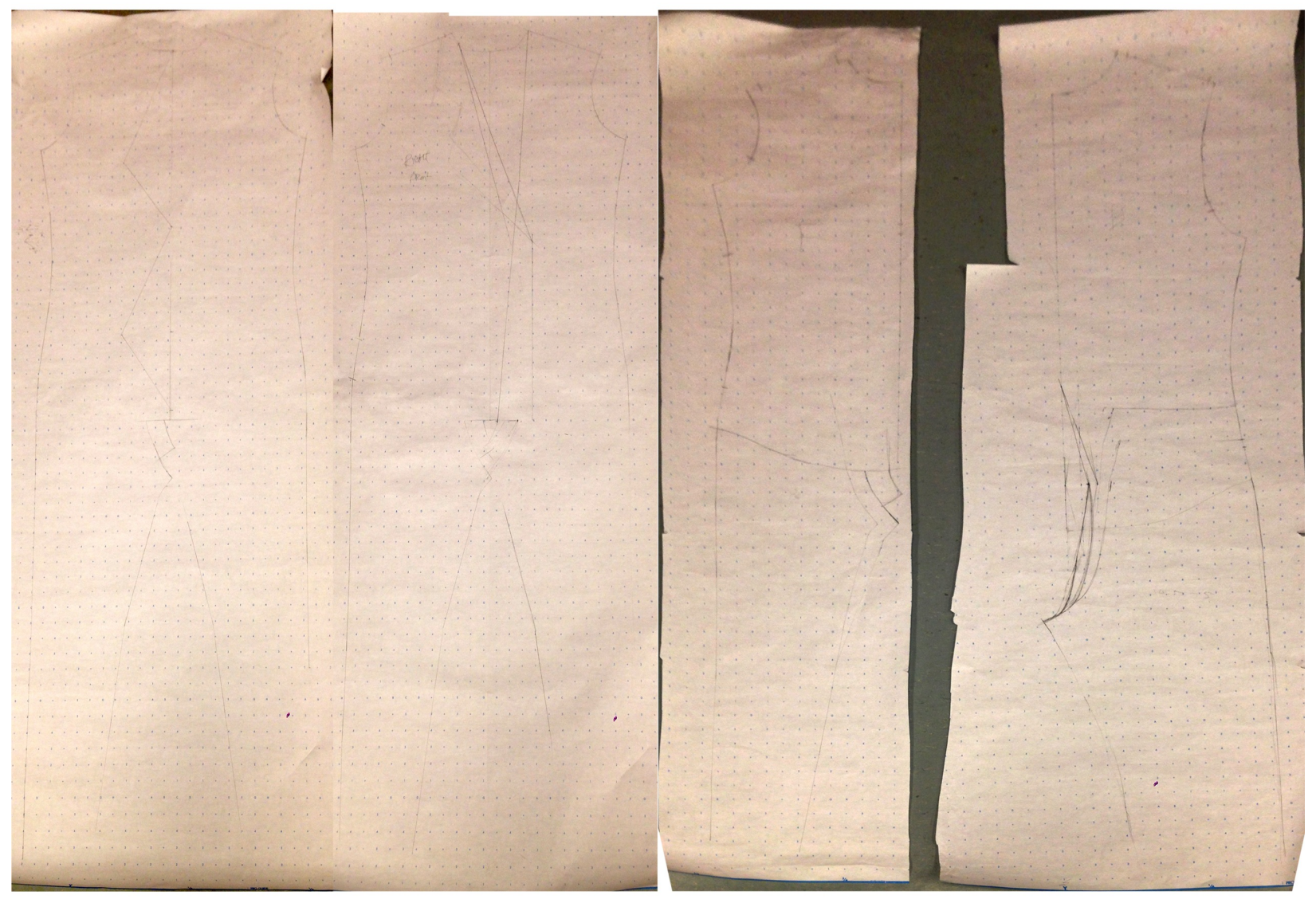


Figure 58. Patternmaking of Upper garments (01\&02)

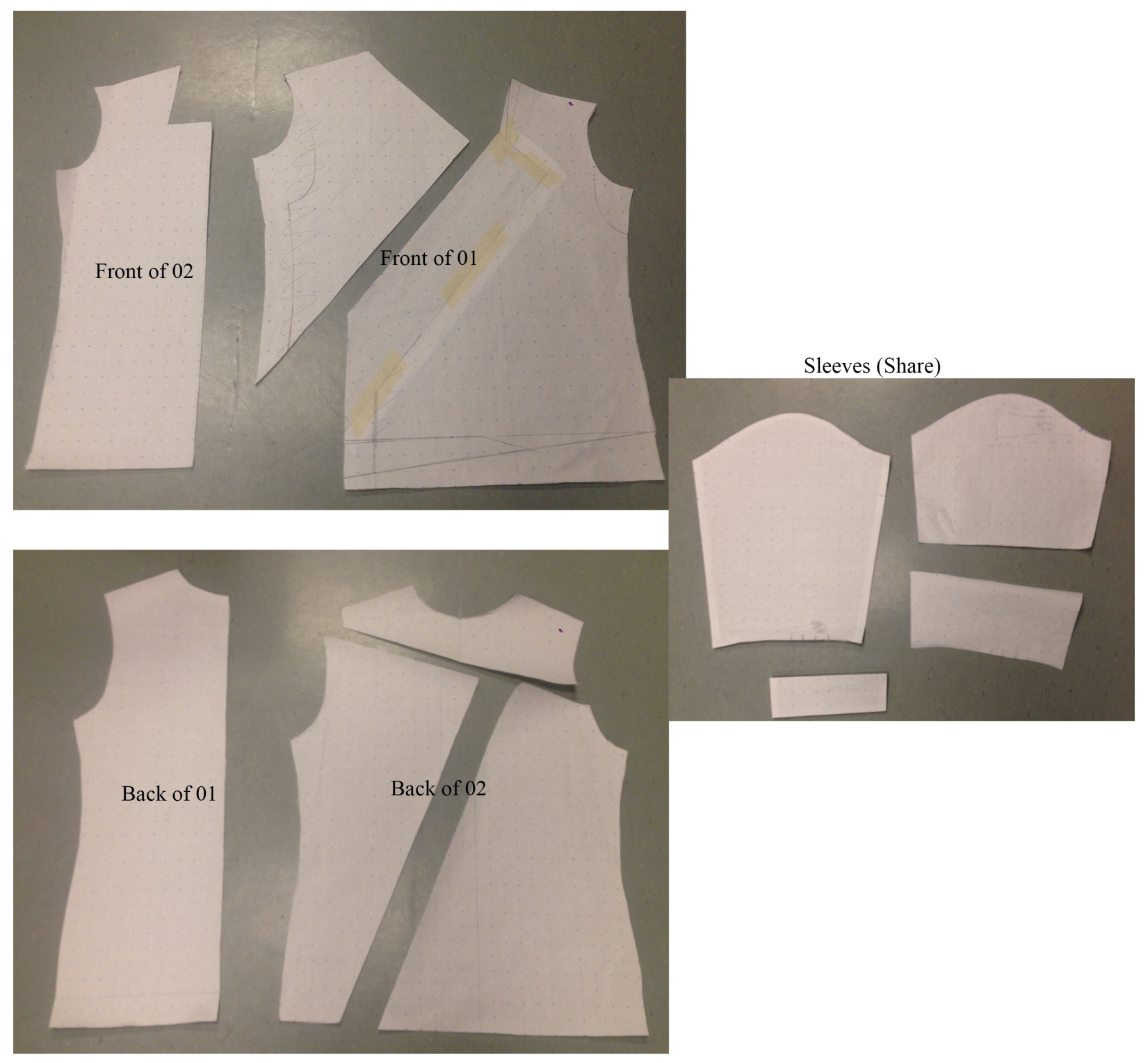


Figure 59. Patternmaking of Trouser

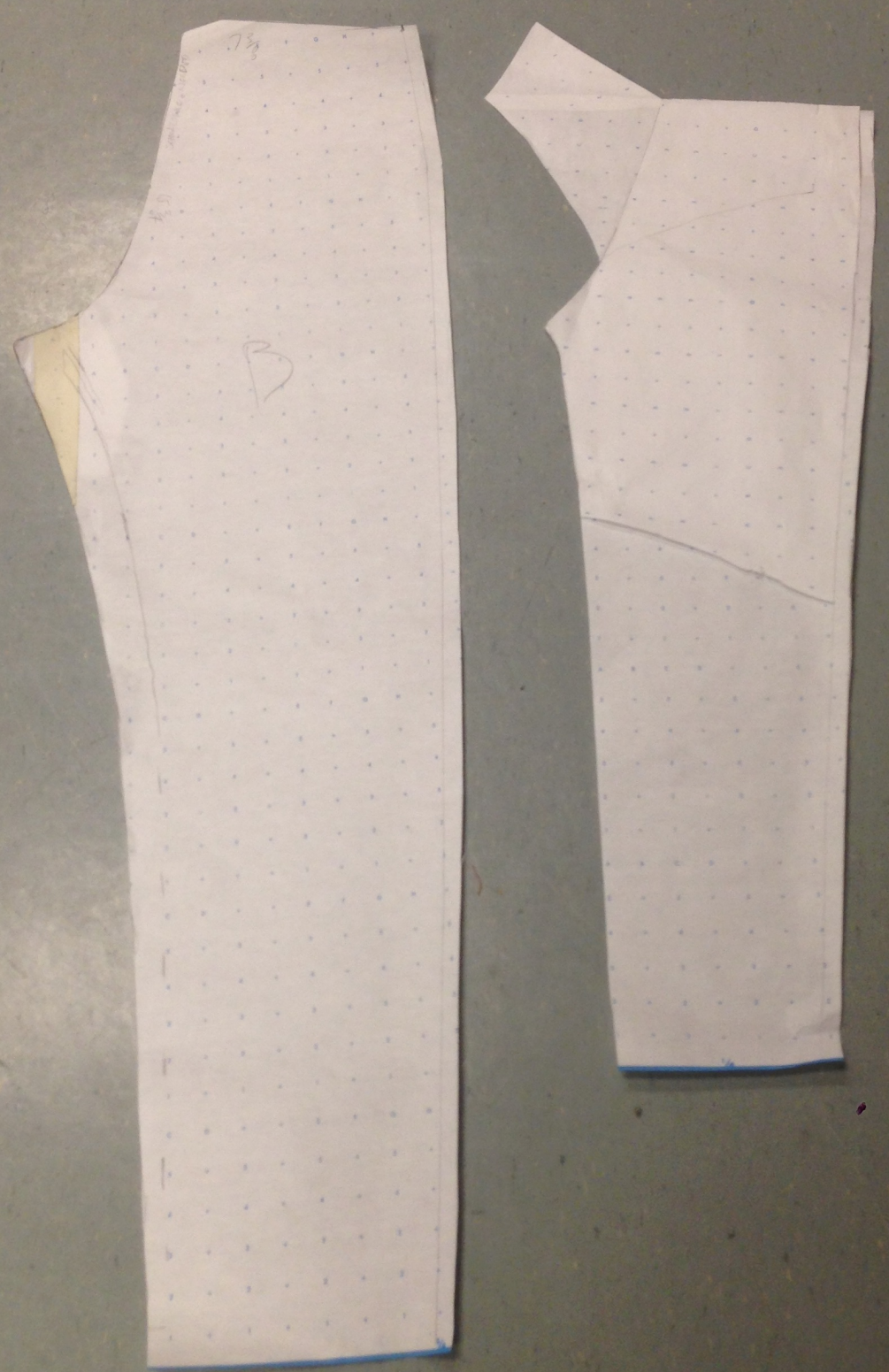


Figure 60. Fabric Swatches of Main Matertial: Cotton Canvas with rubber coated on the back

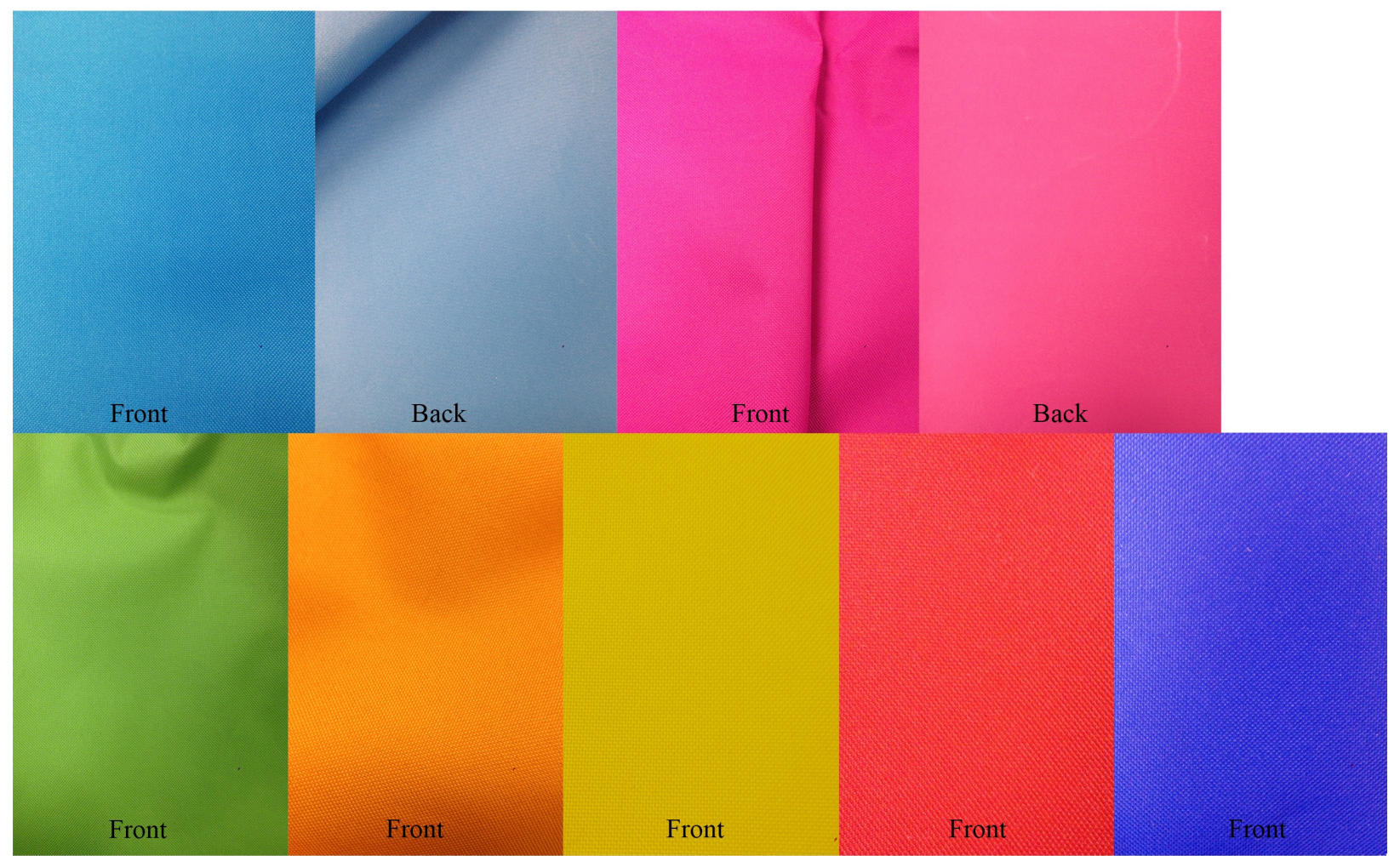

Figure 61. Fabric Swatches of Substitutional Materials

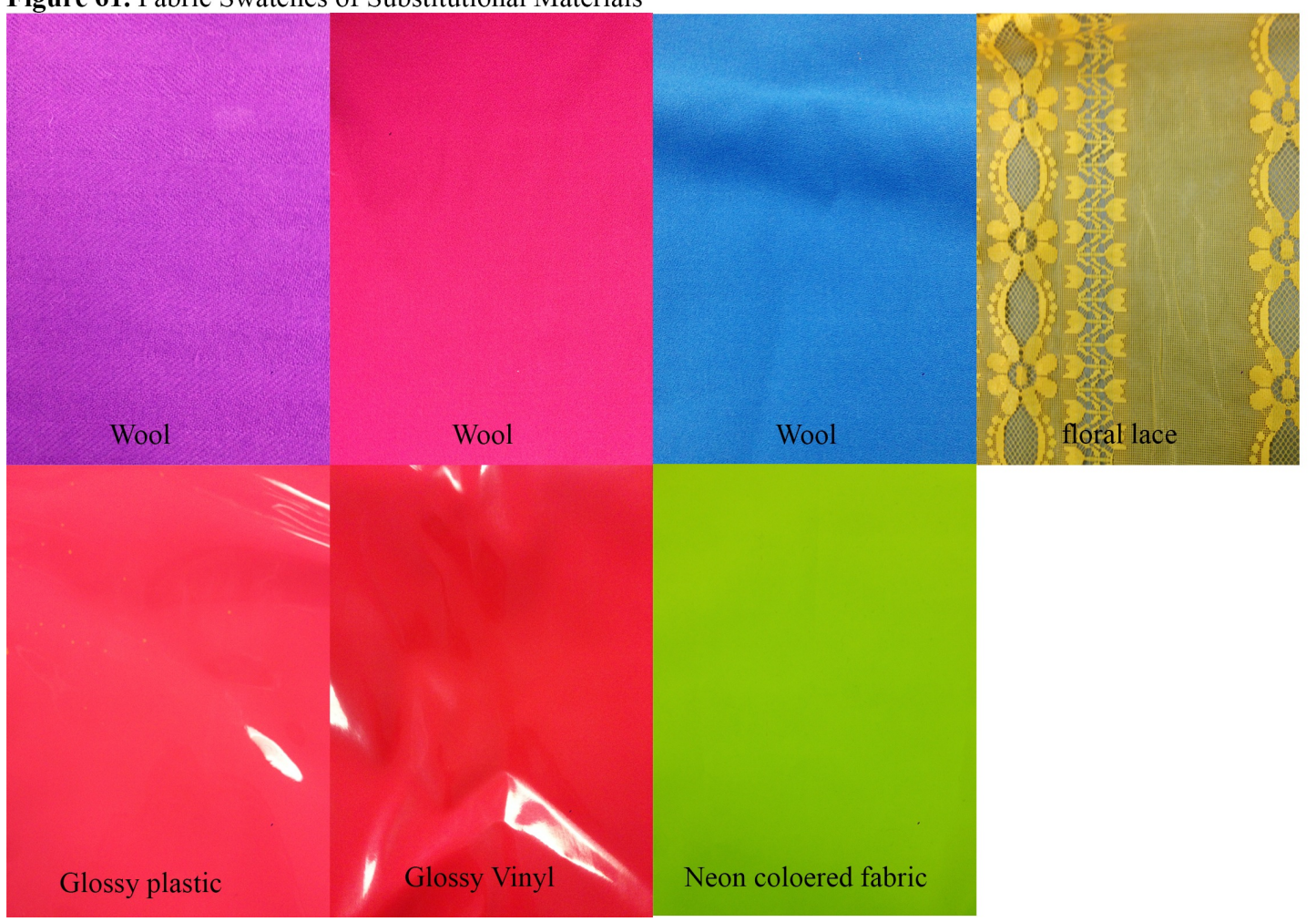


Figure 63. Fortunato Depero, Waistcoat, 1924. Private collection, Milan.

(Battista)
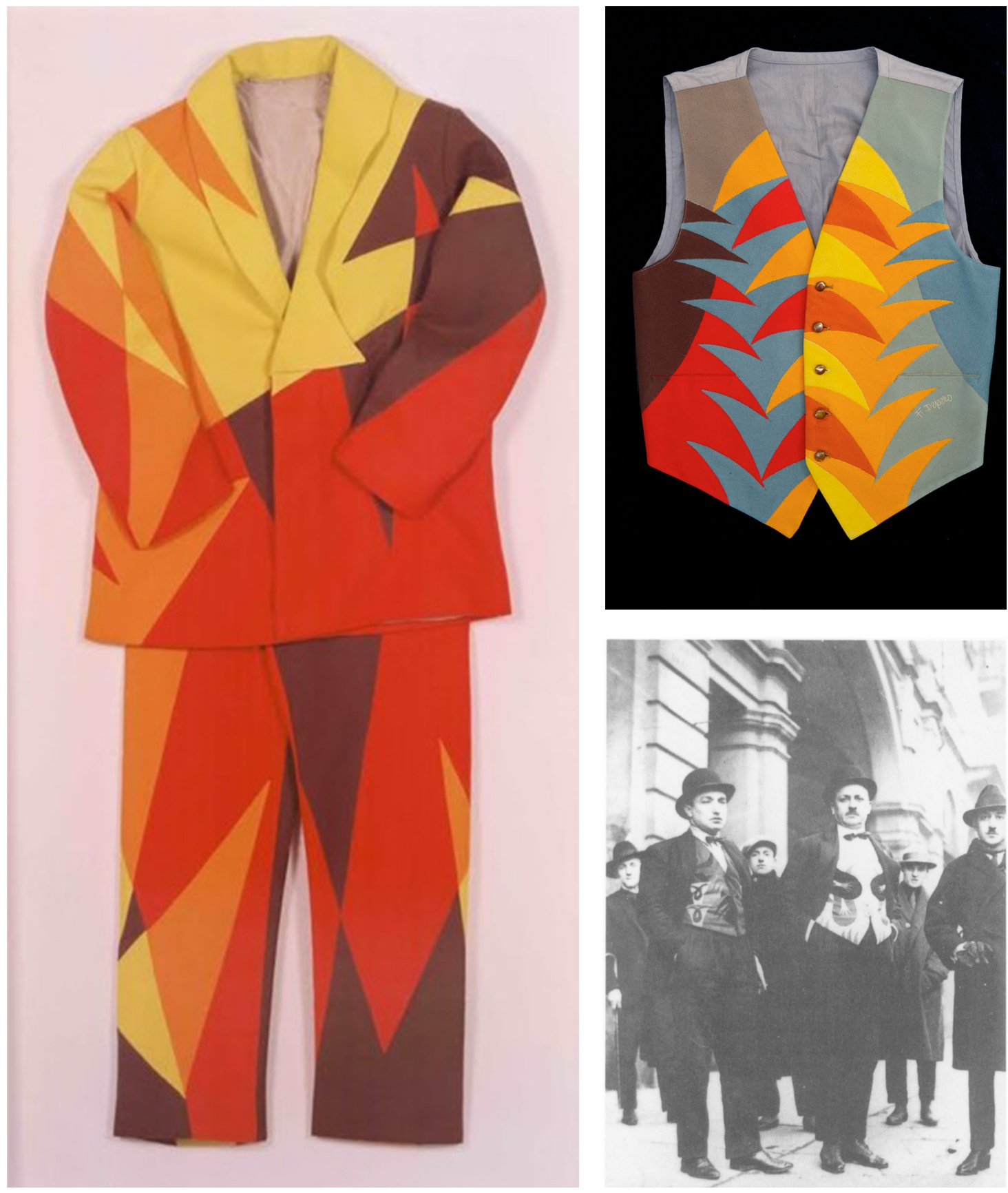

Figure 62. Giacomo Balla, 'Futurist Suit',1918

Figure 64. Fortunato Depero and F.T. Marinetti wearing Futurist vests designed by Depero. 1924 (Braun 34) 
Figure 65. The overall looks for Futurismo Now
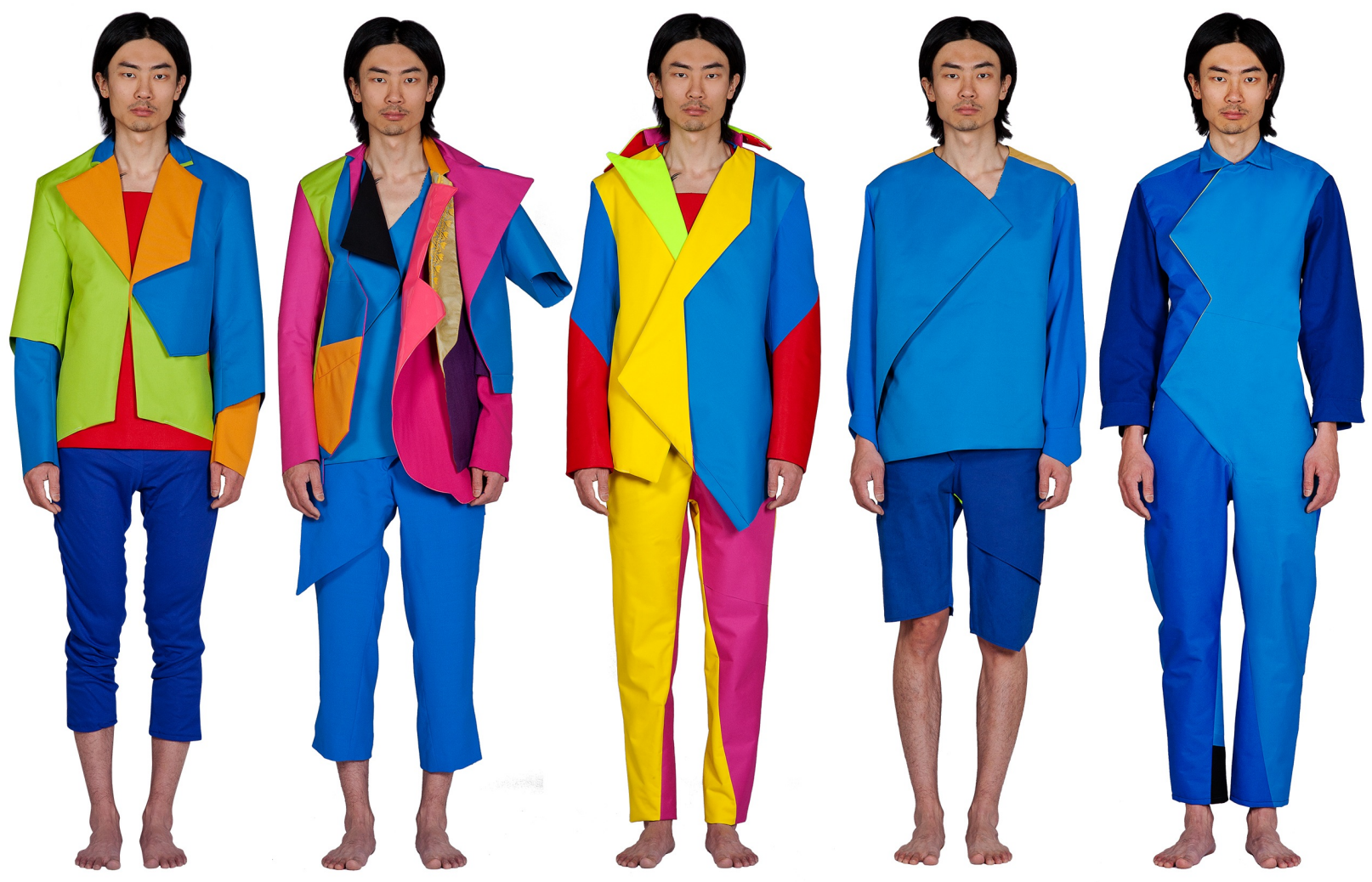

Futurism Now, Yeon Jang, 2014 
Figure 66. Full front and back views of first outfit for Futurismo Now
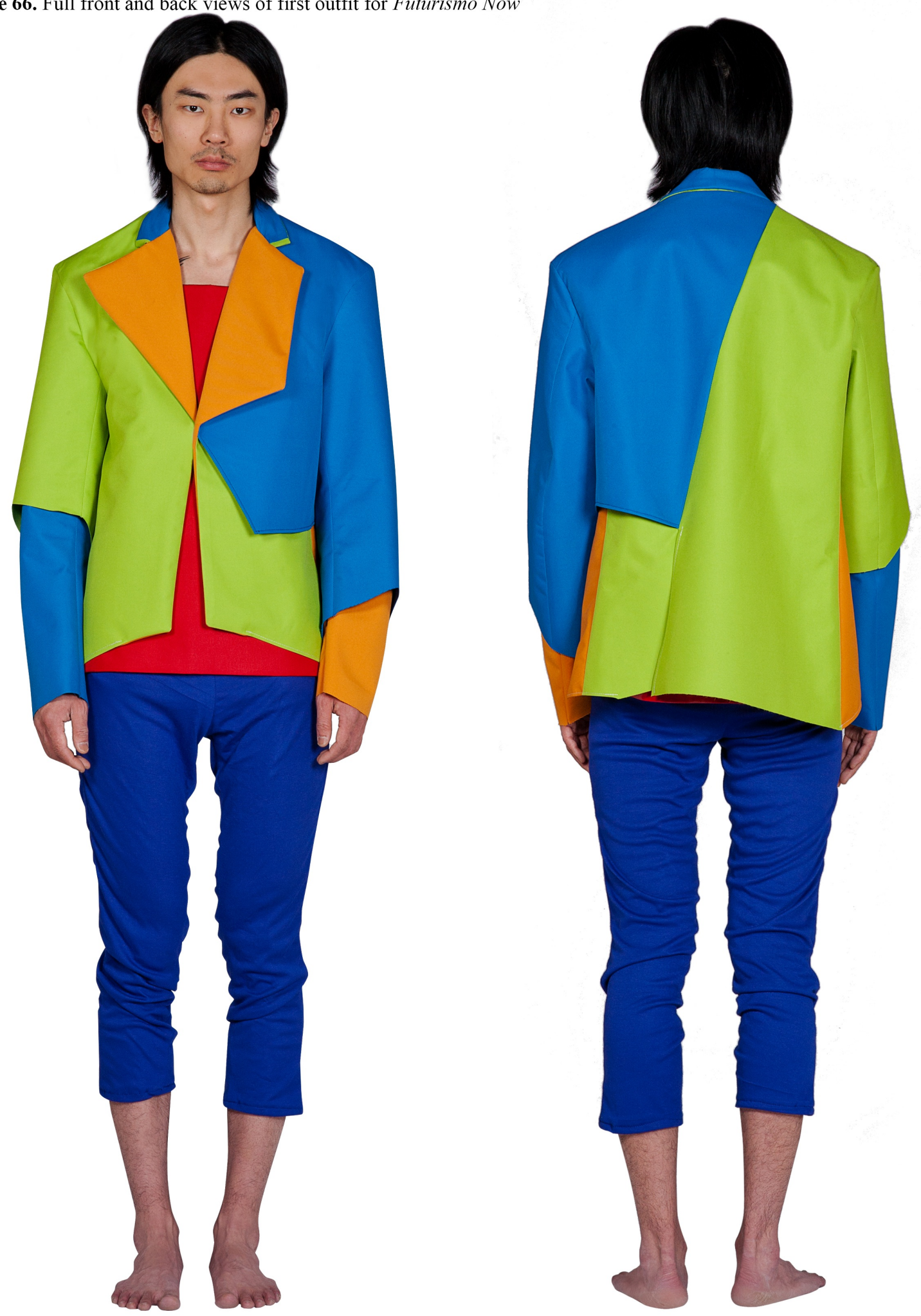
Figure 67. Two detail views of first outfit for Futurismo Now

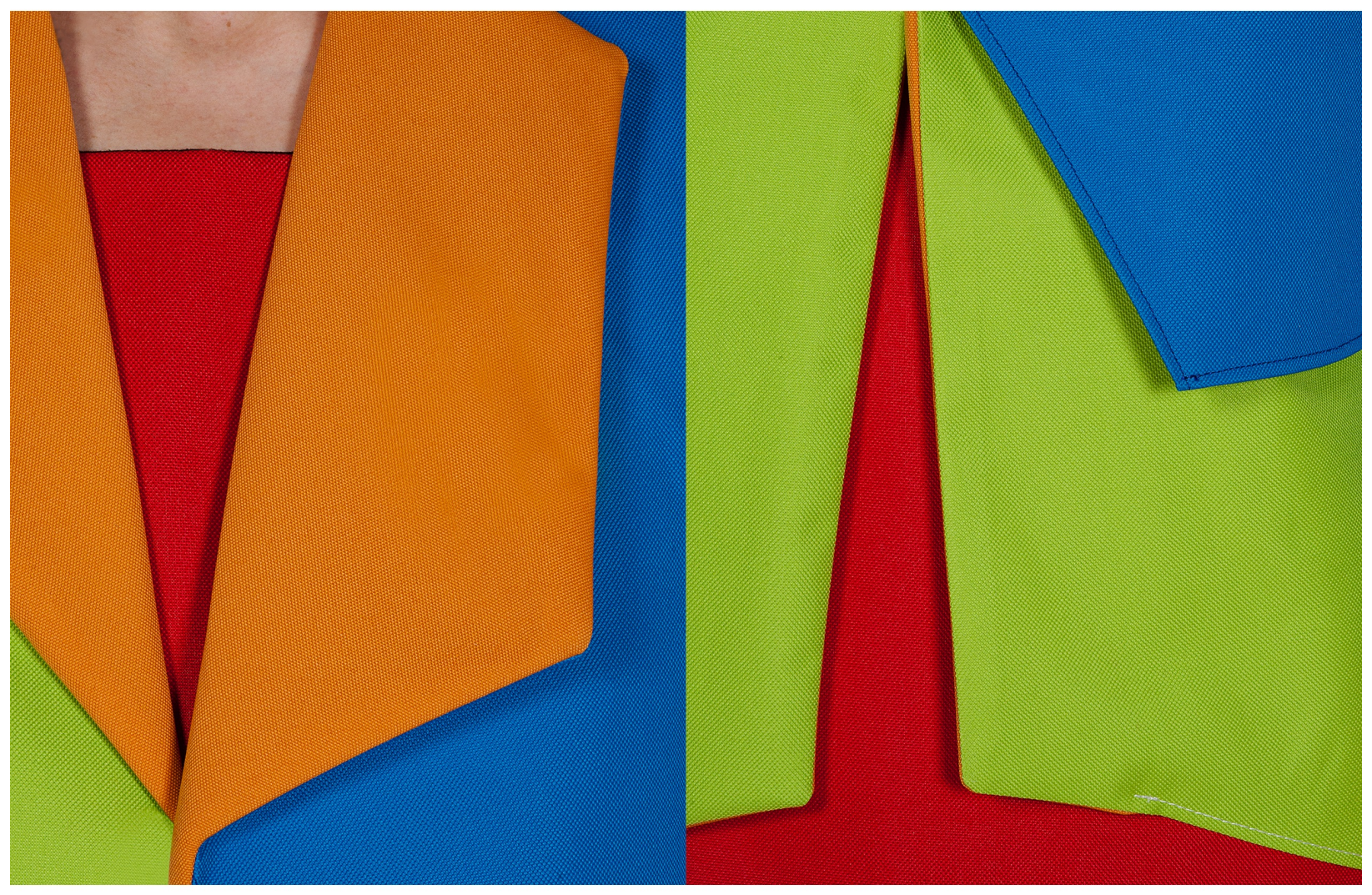


Figure 68. Full front and back views of second outfit for Futurismo Now

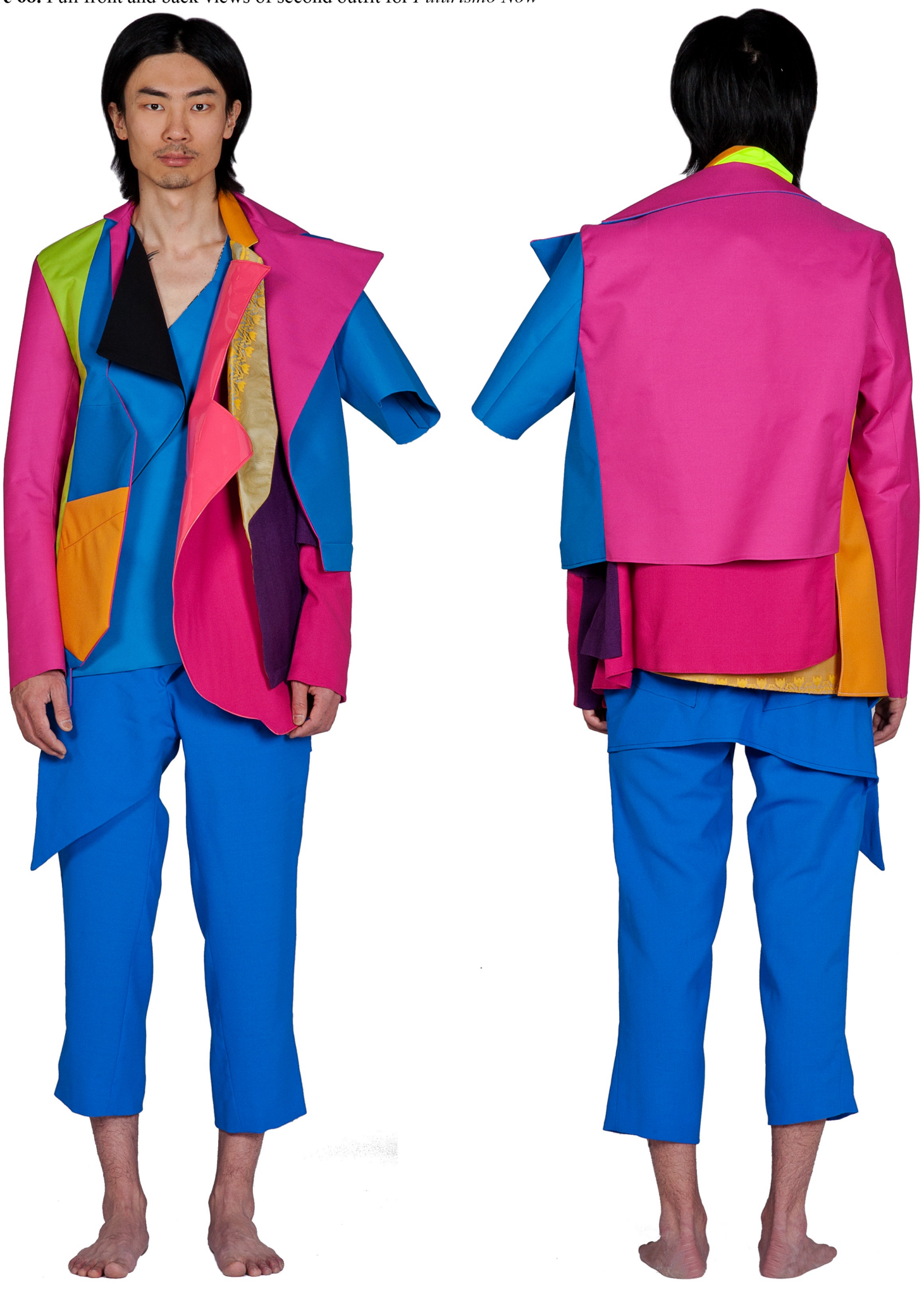


Figure 69. Two detail views of second outfit for Futurismo Now

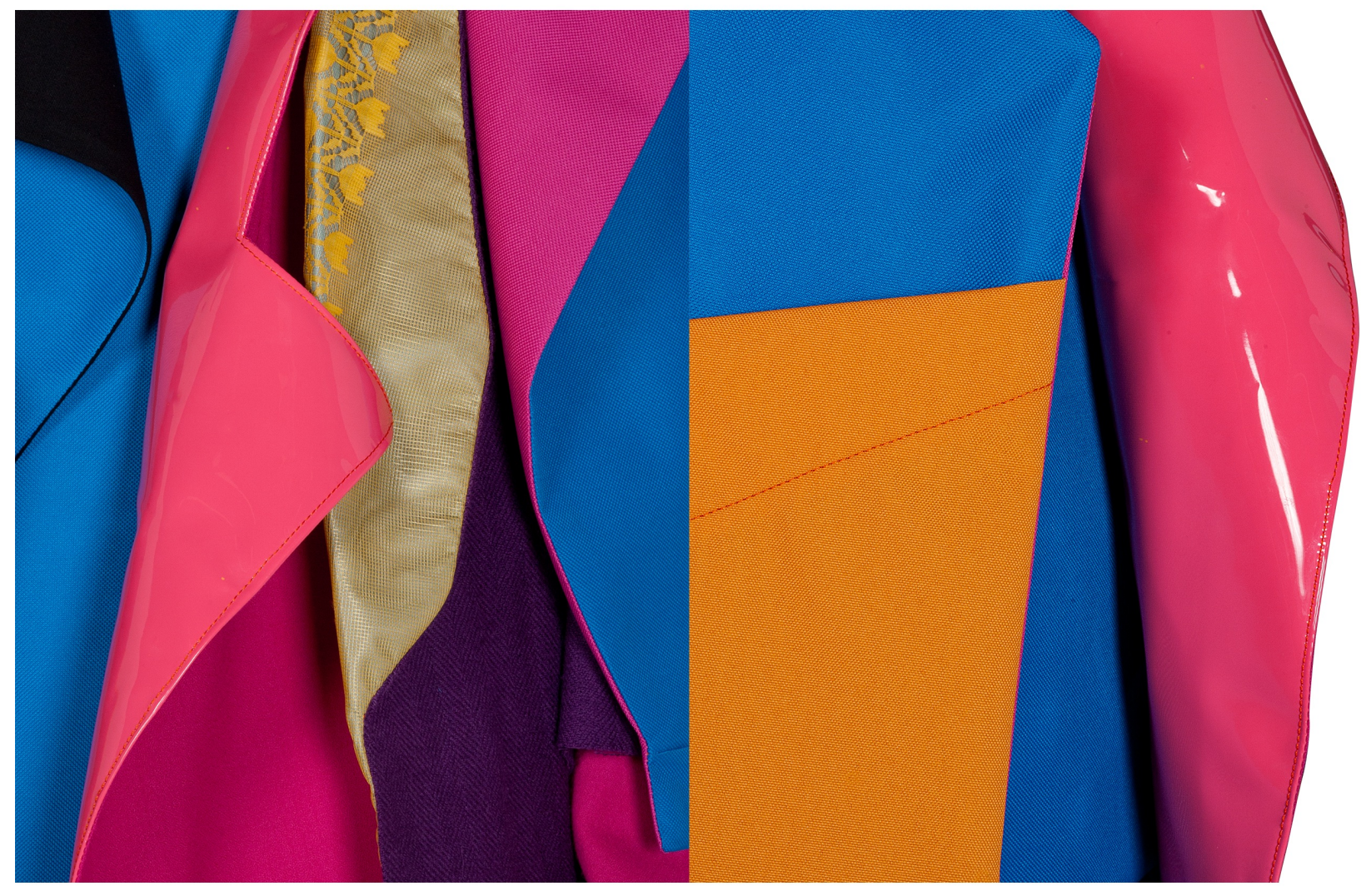


Figure 70. Full front and back views of third outfit for Futurismo Now
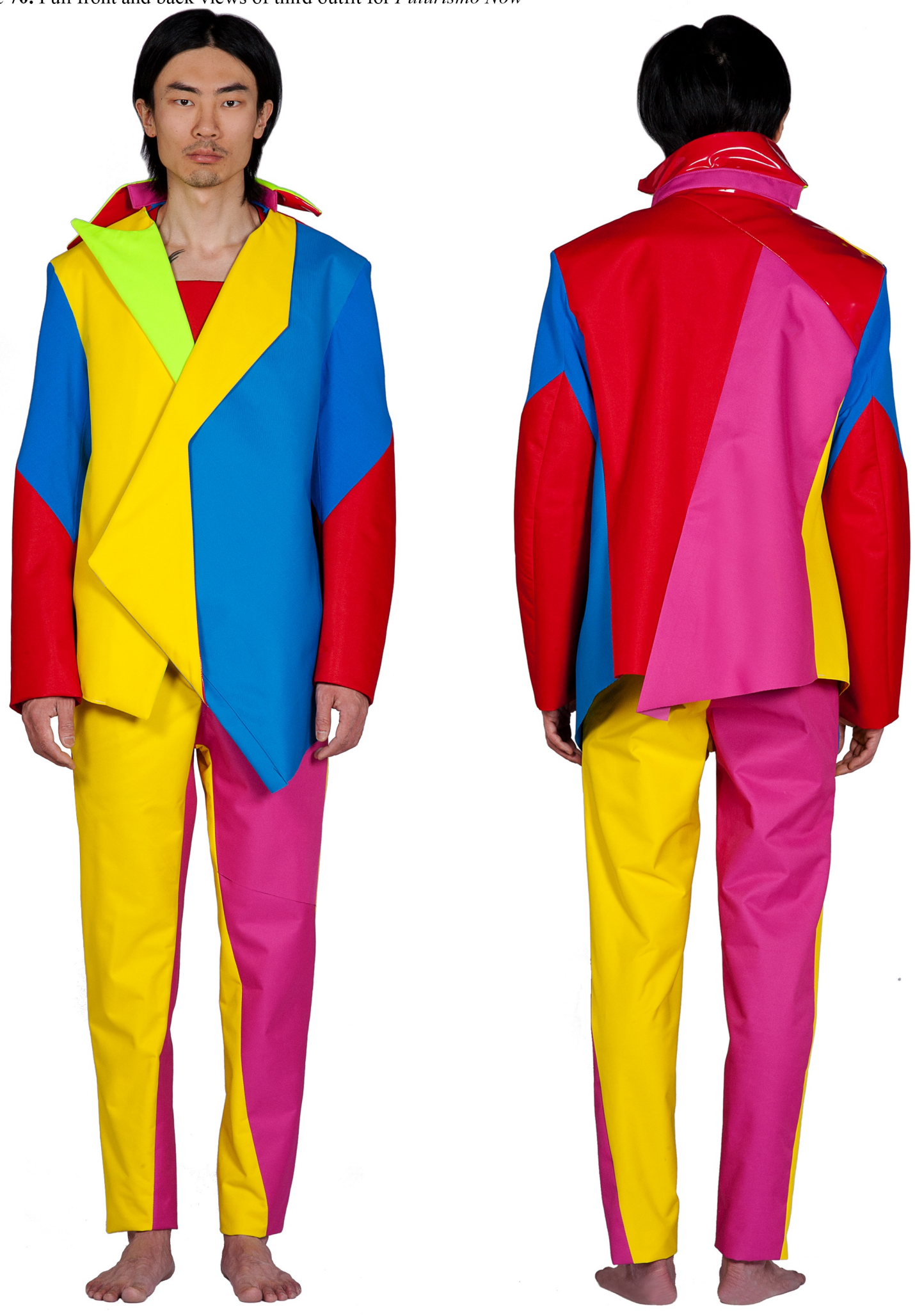
Figure 71. Two detail views of third outfit for Futurismo Now

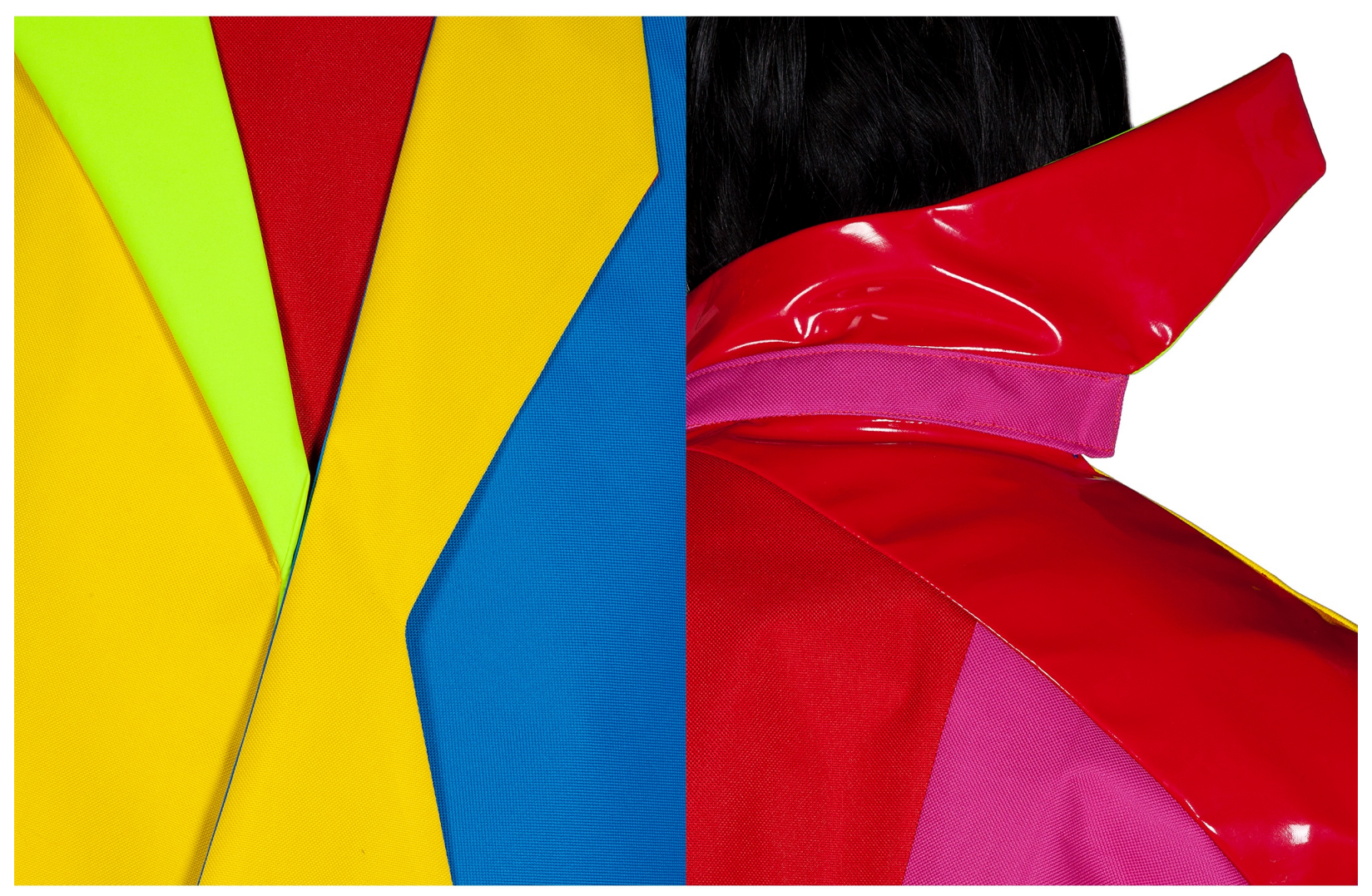


Figure 72. Full front and back views of forth outfit for Futurismo Now
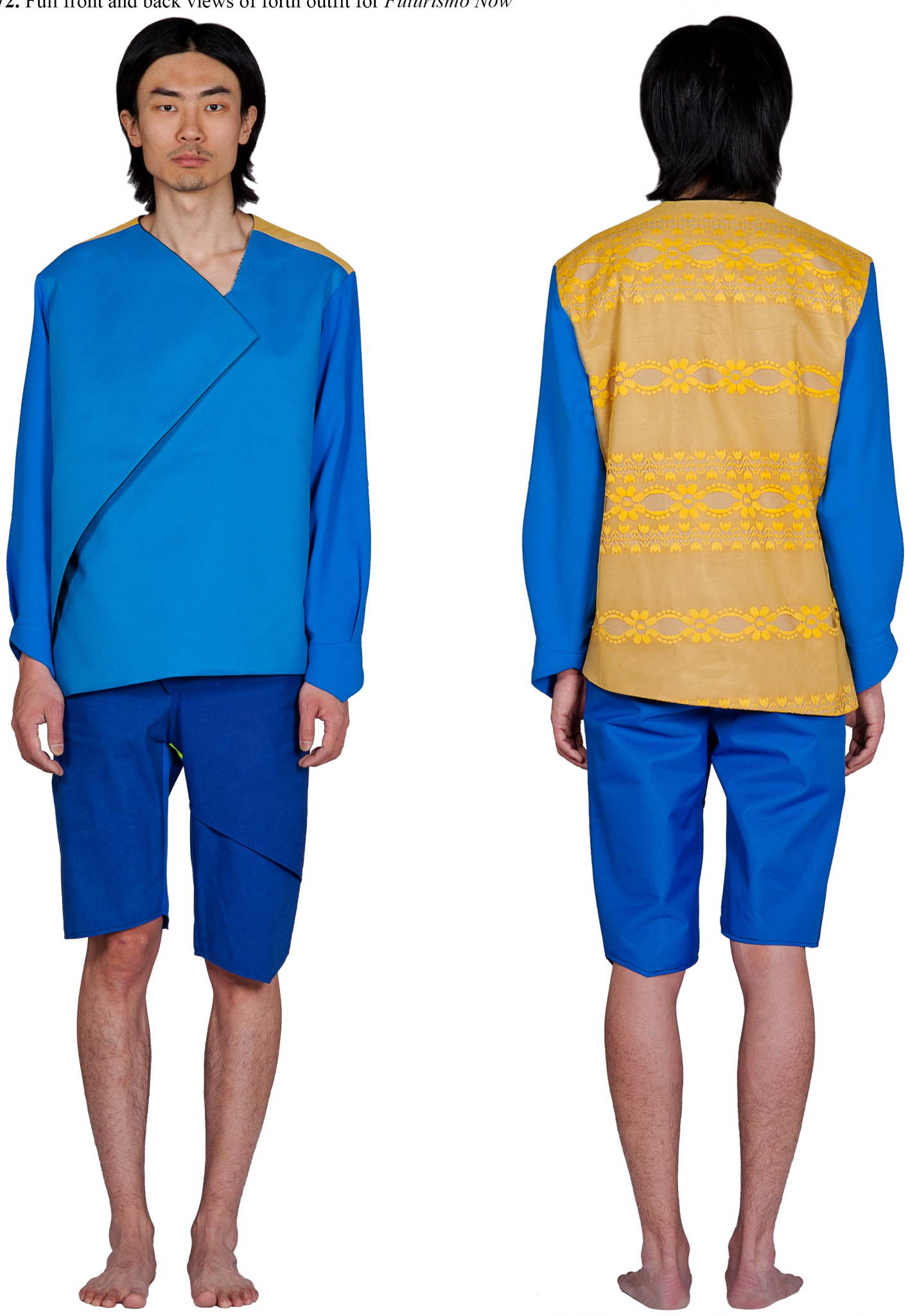
Figure 73. Two detail views of forth outfit for Futurismo Now

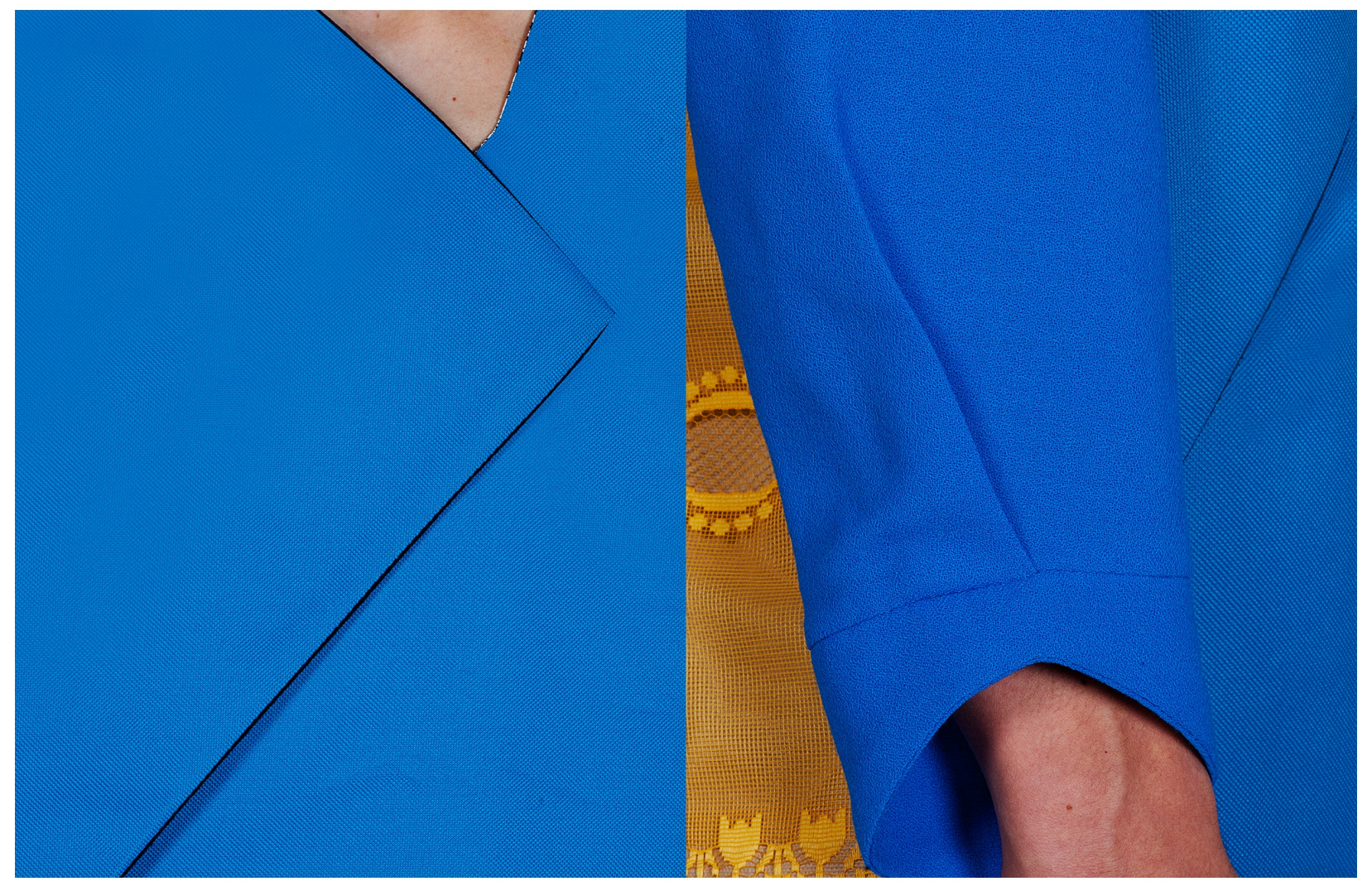


Figure 74. Full front and back views of fifth outfit for Futurismo Now

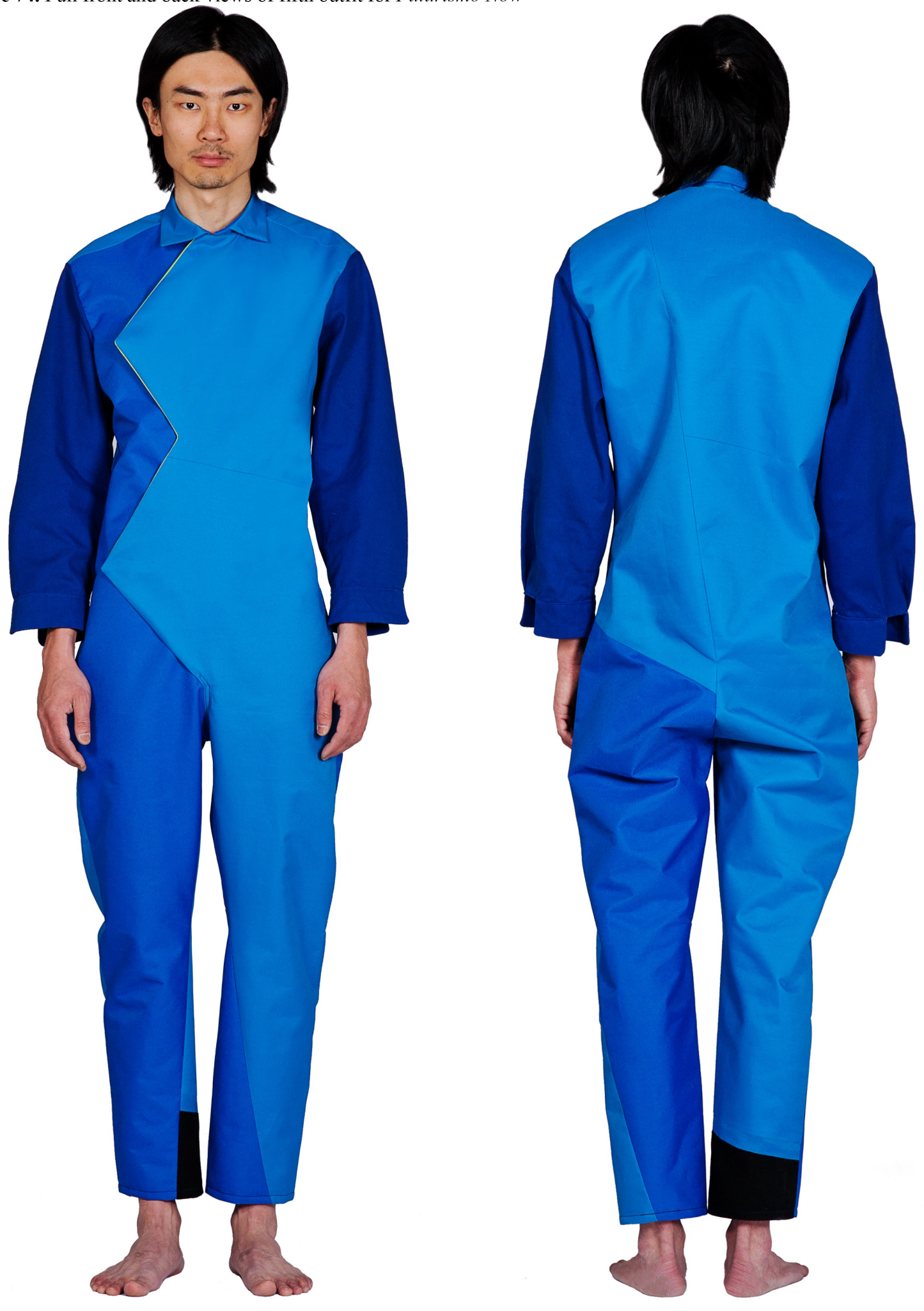


Figure 75. Two detail views of fifth outfit for Futurismo Now

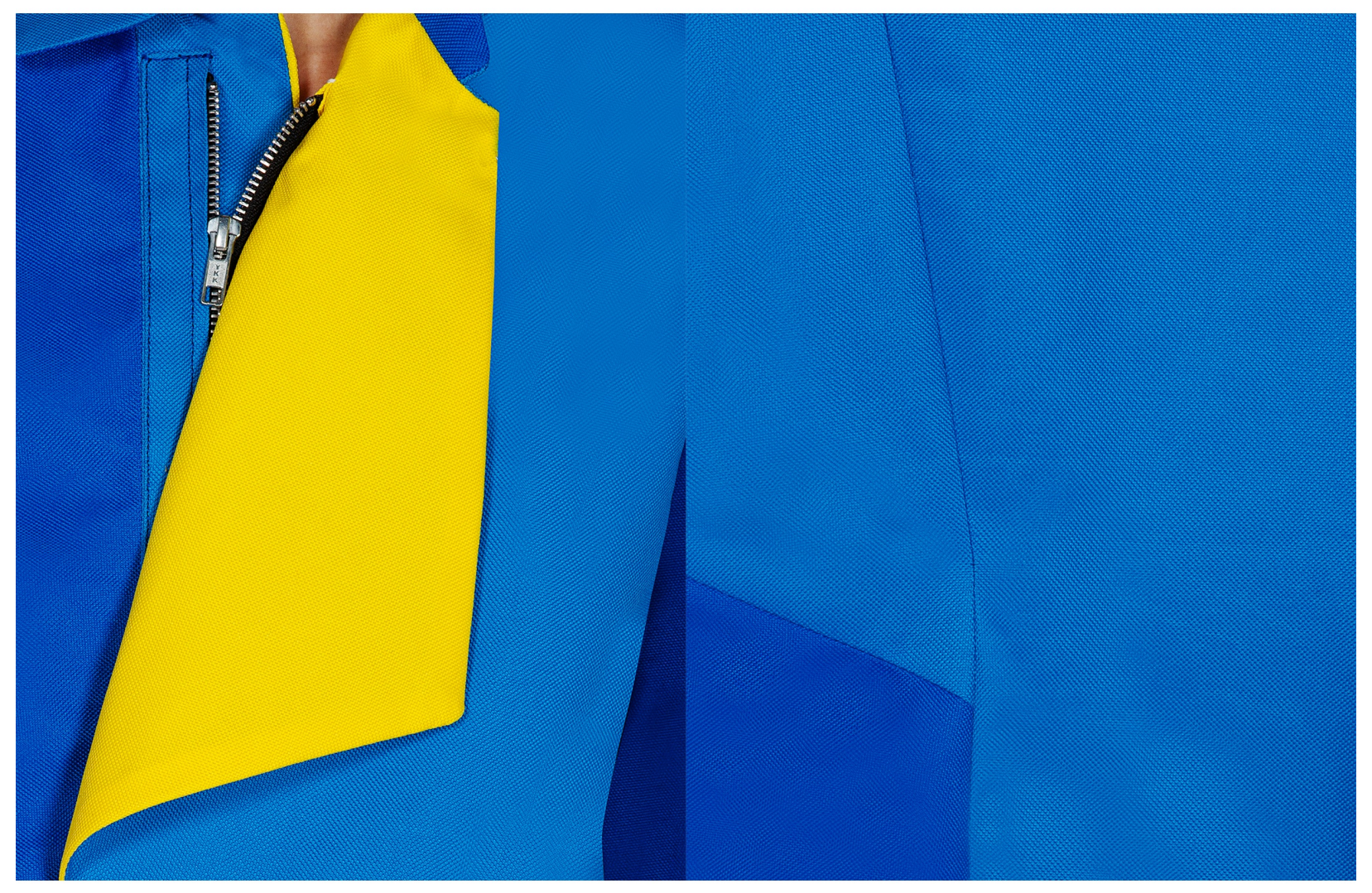

